\title{
Dammarane-Type Saponins from Gynostemma pentaphyllum prevent hypoxia-induced neural injury through activation of ERK, Akt and CREB pathways
}

Jun Wang, ${ }^{\dagger, \natural, \varepsilon}$ Ming Zhao, ${ }^{\star}, \varepsilon$ Xiang Cheng, ${ }^{\star}$ Y Ying Han, ${ }^{*}$ Tong Zhao, ${ }^{\star}$ Ming Fan, ${ }^{\ddagger}, \S$ Lingling Zhu, ${ }^{*}+\S$ Jun-Li Yang, ${ }^{*} \dagger$

${ }^{\dagger}$ CAS Key Laboratory of Chemistry of Northwestern Plant Resources and Key Laboratory for Natural Medicine of Gansu Province, Lanzhou Institute of Chemical Physics (LICP), Chinese Academy of Sciences (CAS), Lanzhou, 730000, China.

$\$$ Department of Cognitive Science, Institute of Cognition and Brain Sciences, Beijing, China

${ }^{\S}$ Co-innovation Center of Neuroregeneration, Nantong University, Nantong, China

" Beijing Institute for Brain Disorders, Capital Medical University, Beijing, China

${ }^{\natural}$ University of Chinese Academy of Sciences, CAS, Beijing 100049, P. R. China) 


\section{Contents:}

Table S1. ${ }^{1} \mathrm{H}(400 \mathrm{MHz})$ and ${ }^{13} \mathrm{C}(100 \mathrm{MHz}) \mathrm{NMR}$ Data for Aglycones a and $\mathbf{b}$ in $\mathrm{CDCl}_{3}$ and DMSO- $d_{4}$

Table S2. ${ }^{13} \mathrm{C}(100 \mathrm{MHz}) \mathrm{NMR}$ Data for Compounds 13, 14, and 4-7 in MeOH- $d_{6}$

Table S3. ${ }^{1} \mathrm{H}(400 \mathrm{MHz})$ and ${ }^{13} \mathrm{C}(100 \mathrm{MHz})$ NMR Data for Compound 3 in DMSO- $d_{6}$

Figure S1. HRESIMS of compound 13

Figure S2. IR spectrum of compound $\mathbf{1 3}$

Figure S3. ${ }^{1} \mathrm{H}$ NMR $\left(400 \mathrm{MHz}, \mathrm{MeOH}-d_{4}\right)$ spectrum of compound 13

Figure S4. ${ }^{13} \mathrm{C}$ NMR NMR $\left(100 \mathrm{MHz}, \mathrm{MeOH}-d_{4}\right)$ spectrum of compound 13

Figure S5. HSQC pectrum of compound 13 in $\mathrm{MeOH}-d_{4}$

Figure S6. HMBC spectrum of compound 13 in $\mathrm{MeOH}-d_{4}$

Figure S7. NOESY spectrum of compound 13 in $\mathrm{MeOH}-d_{4}$

Figure S8. HRESIMS spectrum of compound 14

Figure S9. IR spectrum of compound 14

Figure S10. ${ }^{1} \mathrm{H}$ NMR (400 MHz, MeOH- $d_{4}$ ) spectrum of compound 14

Figure S11. ${ }^{13} \mathrm{C}$ NMR (100 MHz, MeOH- $\left.d_{4}\right)$ spectrum of compound 14

Figure S12. HSQC spectrum of compound 14 in $\mathrm{MeOH}-d_{4}$

Figure S13. HMBC spectrum of compound 14 in $\mathrm{MeOH}-d_{4}$

Figure S14. NOESY spectrum of compound 14 in $\mathrm{MeOH}-d_{4}$

Figure S15. HRESIMS of compound 15

Figure S16. IR spectrum of compound 15

Figure S17. ${ }^{1} \mathrm{H}\left(400 \mathrm{MHz}, \mathrm{MeOH}-d_{4}\right)$ spectrum of compound 15

Figure S18. ${ }^{13} \mathrm{C}$ NMR $\left(100 \mathrm{MHz}, \mathrm{MeOH}-d_{4}\right)$ spectrum of compound 15

Figure S19. HSQC spectrum of compound $\mathbf{1 5}$ in $\mathrm{MeOH}-d_{4}$ 
Figure S20. HMBC spectrum of compound 15 in $\mathrm{MeOH}-d_{4}$

Figure S21. NOESY spectrum of compound 15 in $\mathrm{MeOH}-d_{4}$

Figure S22. HRESIMS spectrum of compound $\mathbf{1 6}$

Figure S23. IR spectrum of compound 16

Figure S24. ${ }^{1} \mathrm{H}$ NMR (400 MHz, MeOH- $\left.d_{4}\right)$ spectrum of compound 16

Figure S25. ${ }^{13} \mathrm{C}$ NMR $\left(100 \mathrm{MHz}, \mathrm{MeOH}-d_{4}\right)$ spectrum of compound 16

Figure S26. HSQC spectrum of compound 16 in $\mathrm{MeOH}-d_{4}$

Figure S27. HMBC spectrum of compound 16 in $\mathrm{MeOH}-d_{4}$

Figure.S28. NOESY spectrum of compound 16 in $\mathrm{MeOH}-d_{4}$

Figure S29. HRESIMS spectrum of compound 17 in $\mathrm{MeOH}-d_{4}$

Figure S30. IR spectrum of compound 17

Figure S31. ${ }^{1} \mathrm{H}$ NMR (400 MHz, MeOH- $\left.d_{4}\right)$ spectrum of compound 17

Figure S32. ${ }^{13} \mathrm{C}$ NMR $\left(100 \mathrm{MHz}, \mathrm{MeOH}-d_{4}\right)$ spectrum of compound 17

Figure S33. HSQC spectrum of compound 17 in $\mathrm{MeOH}-d_{4}$

Figure S34. HMBC spectrum of compound 17 in $\mathrm{MeOH}-d_{4}$

Figuer S35. NOESY spectrum of compound 17 in $\mathrm{MeOH}-d_{4}$

Figure S36. HRESIMS spectrum of compound 18

Figure S37. IR spectrum of compound 18

Figure S38. ${ }^{1} \mathrm{H}$ NMR (400 MHz, MeOH- $\left.d_{4}\right)$ spectrum of compound 18

Figure S39. ${ }^{13} \mathrm{C}$ NMR $\left(100 \mathrm{MHz}, \mathrm{MeOH}-d_{4}\right)$ spectrum of compound 18

Figure S40. HSQC spectrum of compound 18 in $\mathrm{MeOH}-d_{4}$

Figure S41. HMBC spectrum of compound 18 in $\mathrm{MeOH}-d_{4}$

Figure S42. NOESY spectrum of compound 18 in $\mathrm{MeOH}-d_{4}$

Figure S43. ${ }^{1} \mathrm{H}$ NMR (400 MHz, DMSO-d6) spectrum of compound 3 in DMSO-d6

Figure S44. ${ }^{13} \mathrm{C}$ NMR (100 MHz, DMSO-d6) spectrum of compound 3 
Figure S45. HSQC spectrum of compound 3 in DMSO- $d 6$

Figure S46. HMBC spectrum of compound 3 in DMSO- $d 6$

Figure S47. NOESY spectrum of compound 3 in DMSO-d6

Figure S48. ${ }^{1} \mathrm{H}$ NMR $\left(400 \mathrm{MHz}, \mathrm{CDCl}_{3}\right)$ spectrum of a

Figure S49. ${ }^{13} \mathrm{C} \mathrm{NMR}\left(100 \mathrm{MHz}, \mathrm{CDCl}_{3}\right)$ spectrum of a

Figure S50. ${ }^{1} \mathrm{H}$ NMR $\left(400 \mathrm{MHz}, \mathrm{DMSO}-d_{6}\right)$ spectrum of a in DMSO- $d_{6}$

Figure S51. ${ }^{13} \mathrm{C}$ NMR (100 MHz, DMSO- $\left.d_{6}\right)$ spectrum of a in DMSO- $d_{6}$

Figure S52. HSQC spectrum of a in DMSO- $d_{6}$

Figure S53. NOESY spectrum of a in DMSO- $d_{6}$

Figure S54. ${ }^{1} \mathrm{H}$ NMR(400 MHz, $\left.\mathrm{CDCl}_{3}\right)$ spectrum of $\mathbf{b}$

Figure S55. ${ }^{13} \mathrm{C}$ NMR $\left(100 \mathrm{MHz}, \mathrm{CDCI}_{3}\right)$ spectrum of $\mathbf{b}$

Figure S56. ${ }^{1} \mathrm{H}$ NMR $\left(400 \mathrm{MHz}, \mathrm{DMSO}-d_{6}\right)$ spectrum of $\mathbf{b}$

Figure S57. ${ }^{13} \mathrm{C}$ NMR $\left(100 \mathrm{MHz}, \mathrm{DMSO}-d_{6}\right)$ spectrum of $\mathbf{b}$

Figure S58. HSQC spectrum of $\mathbf{b}$ in DMSO- $d_{6}$

Figure S59. NOESY spectrum of $\mathbf{b}$ in DMSO- $d_{6}$ 
Table S1. ${ }^{1} \mathrm{H}(400 \mathrm{MHz})$ and ${ }^{13} \mathrm{C}(100 \mathrm{MHz}) \mathrm{NMR}$ Data for Aglycones a and $\mathbf{b}$ in $\mathrm{CDCl}_{3}$ and DMSO- $d_{4}$

\begin{tabular}{|c|c|c|c|c|c|c|}
\hline \multirow[t]{2}{*}{ no. } & \multicolumn{3}{|l|}{$\mathbf{a}$} & \multicolumn{3}{|l|}{ b } \\
\hline & $\begin{array}{l}{ }^{1} \mathrm{H}(J \text { in } \mathrm{Hz}) \\
\left(\mathrm{DMSO}-d_{6}\right)\end{array}$ & $\begin{array}{l}{ }^{13} \mathrm{C} \\
\left(\mathrm{DMSO}-d_{6}\right) \\
\end{array}$ & $\begin{array}{l}{ }^{13} \mathrm{C} \\
\left(\mathrm{CDCl}_{3}\right) \\
\end{array}$ & $\begin{array}{l}{ }^{1} \mathrm{H}(J \text { in } \mathrm{Hz}) \\
\left(\mathrm{DMSO}-d_{6}\right)\end{array}$ & $\begin{array}{l}{ }^{13} \mathrm{C} \\
\left(\mathrm{DMSO}-d_{6}\right) \\
\end{array}$ & $\begin{array}{l}{ }^{13} \mathrm{C} \\
\left(\mathrm{CDCl}_{3}\right) \\
\end{array}$ \\
\hline 1 & $1.58 \mathrm{~m}, 0.89 \mathrm{~m}$ & 38.7 & 39.1 & $1.58 \mathrm{~m}, 0.89 \mathrm{~m}$ & 38.7 & 39.1 \\
\hline 2 & $1.45 \mathrm{~m}, 0.96 \mathrm{~m}$ & 27.2 & 27.4 & $1.46 \mathrm{~m}, 0.97 \mathrm{~m}$ & 27.2 & 27.4 \\
\hline 3 & $2.99 \mathrm{~m}$ & 76.7 & 78.9 & $2.99 \mathrm{~m}$ & 76.7 & 78.9 \\
\hline 4 & & 38.6 & 39.0 & & 38.6 & 39.6 \\
\hline 5 & $0.68 \mathrm{~m}$ & 55.4 & 55.9 & $0.68 \mathrm{~m}$ & 55.4 & 55.8 \\
\hline 6 & $1.45 \mathrm{~m}, 1.39 \mathrm{~m}$ & 17.9 & 18.3 & $1.45 \mathrm{~m}, 1.39 \mathrm{~m}$ & 17.9 & 18.2 \\
\hline 7 & $1.46 \mathrm{~m}, 1.20 \mathrm{~m}$ & 35.0 & 35.3 & $1.48 \mathrm{~m}, 1.19 \mathrm{~m}$ & 35.0 & 35.3 \\
\hline 8 & & 40.0 & 40.5 & & 40.0 & 40.4 \\
\hline 9 & $1.27 \mathrm{~m}$ & 50.3 & 50.8 & $1.27 \mathrm{~m}$ & 50.2 & 50.7 \\
\hline 10 & & 36.7 & 37.2 & & 36.7 & 37.2 \\
\hline 11 & $1.41 \mathrm{~m}, 1.13 \mathrm{~m}$ & 20.9 & 21.4 & $1.43 \mathrm{~m}, 1.17 \mathrm{~m}$ & 20.9 & 21.4 \\
\hline 12 & $1.93 \mathrm{~m}, 0.89 \mathrm{~m}$ & 26.9 & 26.4 & $1.93 \mathrm{~m}, 1.18 \mathrm{~m}$ & 26.9 & 27.4 \\
\hline 13 & $1.72 \mathrm{~m}$ & 41.7 & 42.2 & $1.48 \mathrm{~m}$ & 43.8 & 44.3 \\
\hline 14 & & 50.3 & 50.6 & & 49.4 & 50.0 \\
\hline 15 & $1.42 \mathrm{~m}, 1.00 \mathrm{~m}$ & 30.8 & 31.4 & $1.43 \mathrm{~m}, 1.00 \mathrm{~m}$ & 30.9 & 31.3 \\
\hline 16 & $1.66 \mathrm{~m}, 0.94 \mathrm{~m}$ & 25.0 & 25.2 & $1.66 \mathrm{~m}, 0.94 \mathrm{~m}$ & 25.0 & 25.6 \\
\hline 17 & $2.00 \mathrm{~m}$ & 44.2 & 45.7 & $2.07 \mathrm{~m}$ & 43.9 & 45.9 \\
\hline 18 & $0.67 \mathrm{~s}$ & 15.8 & 15.5 & $0.67 \mathrm{~s}$ & 15.8 & 15.5 \\
\hline 19 & $0.79 \mathrm{~s}$ & 16.1 & 16.4 & $0.79 \mathrm{~s}$ & 16.1 & 16.3 \\
\hline 20 & & 77.3 & 78.2 & & 79.7 & 81.3 \\
\hline 21 & & 178.0 & 178.8 & & 176.7 & 177.3 \\
\hline \multirow[t]{2}{*}{22} & $2.38 \mathrm{dd}(13.2,6.5)$ & 39.9 & 40.7 & $2.14 \mathrm{dd}(13.4,4.9)$ & 37.8 & 37.7 \\
\hline & $1.82 \mathrm{dd}(13.2,6.9)$ & & & $1.76 \mathrm{~m}$ & & \\
\hline 23 & $5.17 \mathrm{~m}$ & 72.8 & 74.1 & $5.27 \mathrm{~m}$ & 74.1 & 75.2 \\
\hline 24 & $5.25 \mathrm{~d}(9.3)$ & 124.3 & 123.2 & $5.25 \mathrm{~m}$ & 123.2 & 122.4 \\
\hline 25 & & 138.0 & 140.2 & & 138.7 & 140.6 \\
\hline 26 & $1.71 \mathrm{~s}$ & 25.4 & 25.8 & $1.74 \mathrm{~s}$ & 25.4 & 25.8 \\
\hline 27 & $1.70 \mathrm{~s}$ & 18.5 & 18.4 & $1.71 \mathrm{~s}$ & 18.1 & 18.5 \\
\hline 28 & $0.88 \mathrm{~s}$ & 28.1 & 28.0 & $0.88 \mathrm{~s}$ & 28.1 & 28.0 \\
\hline 29 & $0.92 \mathrm{~s}$ & 15.3 & 15.3 & $0.91 \mathrm{~s}$ & 15.2 & 15.4 \\
\hline 30 & $0.83 \mathrm{~s}$ & 16.2 & 16.3 & $0.84 \mathrm{~s}$ & 15.9 & 16.1 \\
\hline OH-3 & $4.27 \mathrm{~d}(5.2)$ & & & $4.27 \mathrm{~d}(5.1)$ & & \\
\hline ОН-20 & $5.53 \mathrm{~s}$ & & & $5.73 \mathrm{~s}$ & & \\
\hline
\end{tabular}


Table S2. ${ }^{13} \mathrm{C}(100 \mathrm{MHz}) \mathrm{NMR}$ Data for Compounds 13, 14, and 4-7 in $\mathrm{MeOH}-d_{6}$

\begin{tabular}{|c|c|c|c|c|c|c|}
\hline no. & 13 & 14 & 4 & 5 & 6 & 7 \\
\hline 1 & 40.5 & 40.5 & 40.6 & 40.6 & 40.6 & 40.6 \\
\hline 2 & 26.2 & 26.8 & 26.2 & 26.2 & 26.8 & 26.8 \\
\hline 3 & 90.9 & 90.9 & 90.2 & 90.6 & 90.6 & 90.2 \\
\hline 4 & 40.6 & 40.5 & 40.9 & 41.0 & 41.0 & 40.9 \\
\hline 5 & 57.8 & 57.8 & 58.2 & 58.2 & 58.2 & 58.1 \\
\hline 6 & 19.4 & 19.4 & 19.4 & 19.4 & 19.4 & 19.4 \\
\hline 7 & 36.7 & 36.7 & 36.7 & 36.7 & 36.7 & 36.7 \\
\hline 8 & 41.9 & 41.8 & 41.9 & 41.9 & 41.9 & 41.8 \\
\hline 9 & 52.4 & 52.4 & 52.5 & 52.5 & 52.5 & 52.4 \\
\hline 10 & 38.2 & 38.2 & 38.2 & 38.3 & 38.3 & 38.2 \\
\hline 11 & 22.7 & 22.7 & 22.7 & 22.7 & 22.7 & 22.7 \\
\hline 12 & 27.9 & 28.6 & 27.9 & 28.5 & 28.5 & 28.6 \\
\hline 13 & 43.8 & 45.9 & 43.8 & 46.6 & 46.0 & 45.9 \\
\hline 14 & 51.7 & 51.2 & 51.7 & 51.7 & 51.2 & 51.2 \\
\hline 15 & 32.5 & 32.5 & 32.5 & 32.5 & 32.5 & 32.5 \\
\hline 16 & 27.4 & 27.4 & 27.6 & 27.4 & 27.4 & 27.6 \\
\hline 17 & 46.6 & 45.8 & 46.6 & 43.8 & 45.8 & 45.8 \\
\hline 18 & 16.2 & 16.1 & 16.2 & 16.2 & 16.2 & 16.2 \\
\hline 19 & 17.0 & 17.0 & 17.0 & 17.1 & 17.1 & 17.2 \\
\hline 20 & 79.7 & 82.1 & 79.7 & 79.7 & 82.1 & 82.1 \\
\hline 21 & 180.9 & 179.5 & 180.9 & 180.9 & 179.5 & 179.5 \\
\hline 22 & 41.6 & 39.4 & 41.6 & 41.6 & 39.4 & 39.4 \\
\hline 23 & 75.6 & 76.7 & 75.6 & 75.6 & 76.7 & 76.7 \\
\hline 24 & 125.2 & 124.0 & 125.2 & 125.2 & 124.0 & 124.0 \\
\hline 25 & 140.6 & 141.4 & 140.6 & 140.5 & 141.4 & 141.4 \\
\hline 26 & 26.0 & 26.0 & 26.0 & 26.0 & 26.0 & 26.0 \\
\hline 27 & 18.4 & 18.6 & 18.4 & 18.4 & 18.6 & 18.6 \\
\hline 28 & 28.6 & 28.6 & 28.5 & 28.6 & 28.6 & 28.5 \\
\hline 29 & 17.0 & 17.0 & 17.2 & 17.0 & 16.8 & 17.2 \\
\hline 30 & 17.0 & 16.8 & 17.2 & 17.2 & 17.1 & 16.8 \\
\hline \multicolumn{7}{|c|}{ sugar } \\
\hline $1^{\prime}$ & 106.9 & 106.9 & 105.5 & 105.4 & 105.4 & 105.5 \\
\hline $2^{\prime}$ & 75.8 & 75.8 & 77.6 & 75.2 & 75.2 & 77.6 \\
\hline $3^{\prime}$ & 77.8 & 77.8 & 88.3 & 88.0 & 88.0 & 88.3 \\
\hline $4^{\prime}$ & 71.8 & 71.8 & 71.1 & 71.1 & 71.1 & 71.1 \\
\hline $5^{\prime}$ & 78.5 & 78.4 & 78.1 & 78.1 & 78.1 & 78.1 \\
\hline $6^{\prime}$ & 63.0 & 63.0 & 62.9 & 64.9 & 64.9 & 62.9 \\
\hline $\mathrm{AC}$ & & & & 172.7 & 172.7 & \\
\hline $\mathbf{A C}$ & & & & 20.9 & 20.9 & \\
\hline \multicolumn{7}{|c|}{ Sugar } \\
\hline $1^{\prime \prime}$ & & & 102.0 & 102.0 & 102.0 & 102.0 \\
\hline $2^{\prime \prime}$ & & & 72.2 & 72.3 & 72.3 & 72.2 \\
\hline $3^{\prime \prime}$ & & & 72.3 & 72.2 & 72.2 & 72.3 \\
\hline $4^{\prime \prime}$ & & & 73.9 & 73.9 & 74.0 & 73.9 \\
\hline $5^{\prime \prime}$ & & & 70.3 & 70.3 & 70.3 & 70.3 \\
\hline $6^{\prime \prime}$ & & & 18.2 & 18.2 & 18.2 & 18.2 \\
\hline \multicolumn{7}{|c|}{ Sugar } \\
\hline $1^{\prime \prime \prime}$ & & & 105.1 & 105.1 & 105.1 & 105.1 \\
\hline $2^{\prime \prime \prime}$ & & & 75.2 & 74.9 & 74.9 & 75.2 \\
\hline $3^{\prime \prime \prime}$ & & & 78.2 & 78.1 & 78.1 & 78.2 \\
\hline $4^{\prime \prime \prime}$ & & & 70.3 & 70.7 & 70.7 & 70.3 \\
\hline $5^{\prime \prime \prime}$ & & & 67.3 & 67.31 & 67.3 & 67.2 \\
\hline
\end{tabular}


Table S3. ${ }^{1} \mathrm{H}(400 \mathrm{MHz})$ and ${ }^{13} \mathrm{C}(100 \mathrm{MHz})$ NMR Data for Compound 3 in DMSO- $d_{6}$

\begin{tabular}{|c|c|c|c|c|c|}
\hline \multirow[t]{2}{*}{ no. } & \multicolumn{2}{|l|}{3} & \multirow[t]{2}{*}{ no. } & \multicolumn{2}{|l|}{3} \\
\hline & ${ }^{1} \mathrm{H}(J$ in $\mathrm{Hz})$ & ${ }^{13} \mathrm{C}$ & & ${ }^{1} \mathrm{H}(J$ in $\mathrm{Hz})$ & ${ }^{13} \mathrm{C}$ \\
\hline 1 & $2.35 \mathrm{~d}(12.5), 0.79 \mathrm{~m}$ & 32.7 & & xyl $(1 \rightarrow 3)$ & \\
\hline 2 & $1.63 \mathrm{~m}, 1.12 \mathrm{~m}$ & 26.6 & $1^{\prime \prime \prime}$ & $4.34 \mathrm{~m}$ & 103.4 \\
\hline 3 & $3.05 \mathrm{~m}$ & 86.1 & $2^{\prime \prime \prime}$ & $3.07 \mathrm{~m}$ & 73.0 \\
\hline 4 & & 39.2 & $3^{\prime \prime \prime}$ & $3.11 \mathrm{~m}$ & 76.1 \\
\hline 5 & $1.20 \mathrm{~m}$ & 53.8 & $4^{\prime \prime \prime}$ & $3.29 \mathrm{~m}$ & 69.4 \\
\hline 6 & $0.66 \mathrm{~m}$ & 15.3 & $5^{\prime \prime \prime}$ & $3.70 \mathrm{~m}, 3.08 \mathrm{~m}$ & 65.5 \\
\hline 7 & $1.63 \mathrm{~m}, 1.33 \mathrm{~m}$ & 34.1 & & OH-20 & \\
\hline 8 & & 39.5 & & $4.10 \mathrm{~s}$ & \\
\hline 9 & $1.61 \mathrm{~m}$ & 52.0 & & OH-21 & \\
\hline 10 & & 51.9 & & $5.75 \mathrm{~d}(3.8)$ & \\
\hline 11 & $1.49 \mathrm{~m}, 0.81 \mathrm{~m}$ & 21.3 & & & \\
\hline 12 & $1.51 \mathrm{~m}$ & 23.8 & & & \\
\hline 13 & $1.67 \mathrm{~m}$ & 39.8 & & & \\
\hline 14 & & 49.6 & & & \\
\hline 15 & $1.38 \mathrm{~m}, 1.00 \mathrm{~m}$ & 31.2 & & & \\
\hline 16 & $1.53 \mathrm{~m}, 1.05 \mathrm{~m}$ & 25.9 & & & \\
\hline 17 & $1.92 \mathrm{~m}$ & 43.7 & & & \\
\hline 18 & $0.78 \mathrm{~s}$ & 16.9 & & & \\
\hline 19 & $10.10 \mathrm{~s}$ & 206.2 & & & \\
\hline 20 & & 83.2 & & & \\
\hline 21 & $4.89 \mathrm{~d}(3.2)$ & 101.1 & & & \\
\hline 22 & $2.02 \mathrm{dd}(12.5,9.8)$ & 43.5 & & & \\
\hline & $1.35 \mathrm{~m}$ & & & & \\
\hline 23 & $4.70 \mathrm{dd}(9.2,3.4)$ & 71.9 & & & \\
\hline 24 & $5.34 \mathrm{~d}(8.7)$ & 129.0 & & & \\
\hline 25 & & 131.3 & & & \\
\hline 26 & $1.64 \mathrm{~s}$ & 25.4 & & & \\
\hline 27 & $1.58 \mathrm{~s}$ & 17.7 & & & \\
\hline 28 & $0.97 \mathrm{~s}$ & 25.7 & & & \\
\hline 29 & $0.67 \mathrm{~s}$ & 15.3 & & & \\
\hline 30 & $0.81 \mathrm{~s}$ & 16.1 & & & \\
\hline sugar & 3-O-ara & & & & \\
\hline $1^{\prime}$ & $4.34 \mathrm{~m}$ & 103.3 & & & \\
\hline $2^{\prime}$ & $3.69 \mathrm{~m}$ & 72.7 & & & \\
\hline $\mathbf{3}^{\prime}$ & $3.64 \mathrm{~m}$ & 79.9 & & & \\
\hline $4^{\prime}$ & $3.74 \mathrm{~m}$ & 66.6 & & & \\
\hline $5^{\prime}$ & $\begin{array}{l}3.63 \mathrm{~m}, 3.35 \mathrm{~m} \\
\text { rha }(\mathbf{1} \rightarrow \mathbf{2})\end{array}$ & 63.7 & & & \\
\hline 1" & 5.06 brs & 100.4 & & & \\
\hline $2^{\prime \prime}$ & $3.68 \mathrm{~m}$ & 70.5 & & & \\
\hline 3" & $3.42 \mathrm{~m}$ & 70.3 & & & \\
\hline $4^{\prime \prime}$ & $3.18 \mathrm{~m}$ & 71.9 & & & \\
\hline $5^{\prime \prime}$ & $3.67 \mathrm{~m}$ & 68.5 & & & \\
\hline 6" & $1.05 \mathrm{~d}(5.1)$ & 17.8 & & & \\
\hline
\end{tabular}


Figure S1. HRESIMS of compound 13

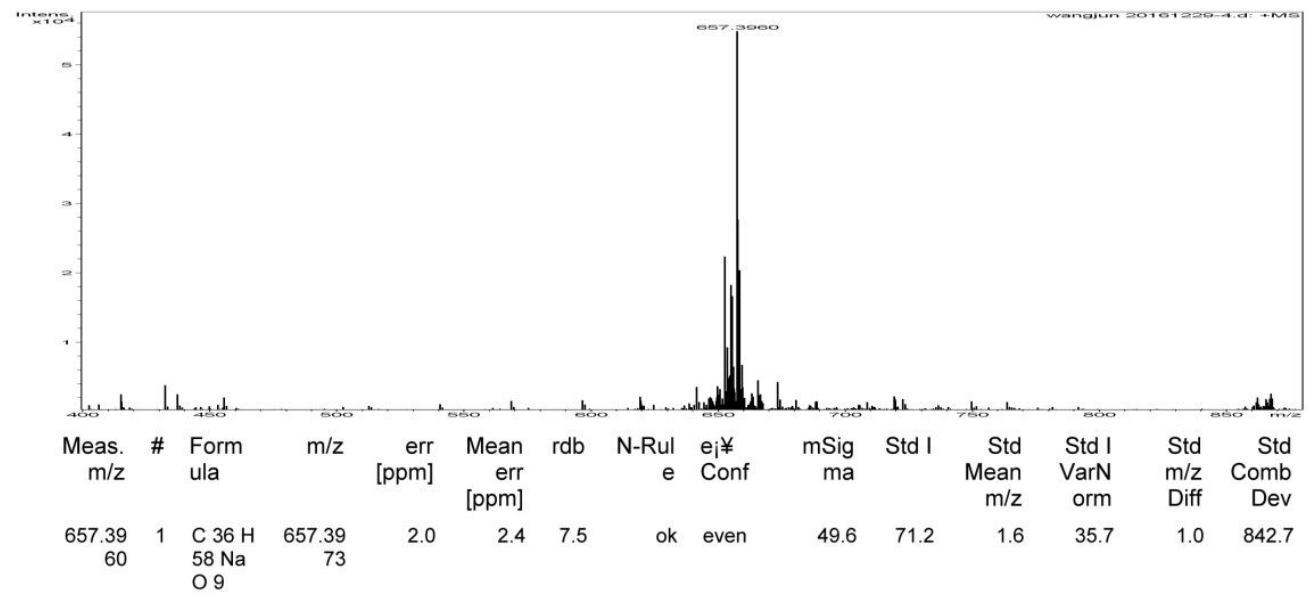

Figure S2. IR spectrum of compound $\mathbf{1 3}$

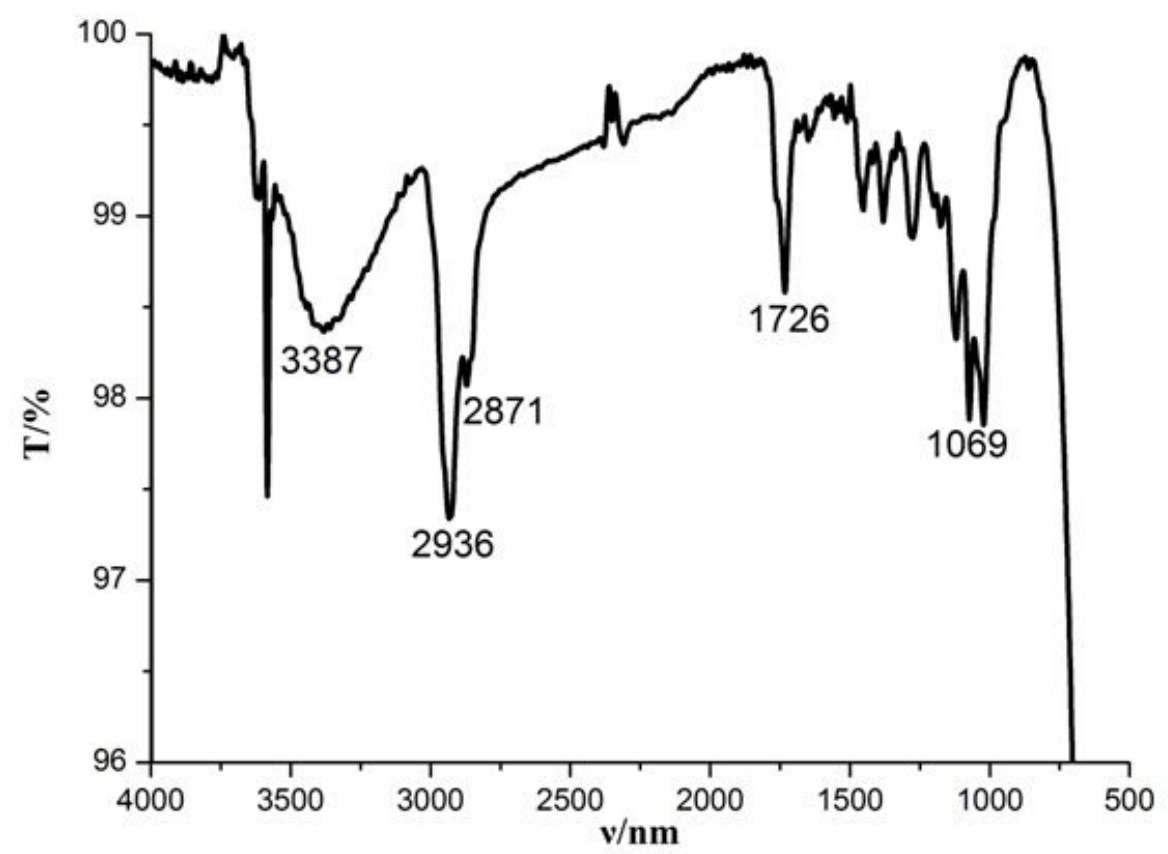


Figure S3. ${ }^{1} \mathrm{H}$ NMR $\left(400 \mathrm{MHz}, \mathrm{MeOH}-d_{4}\right)$ spectrum of compound 13

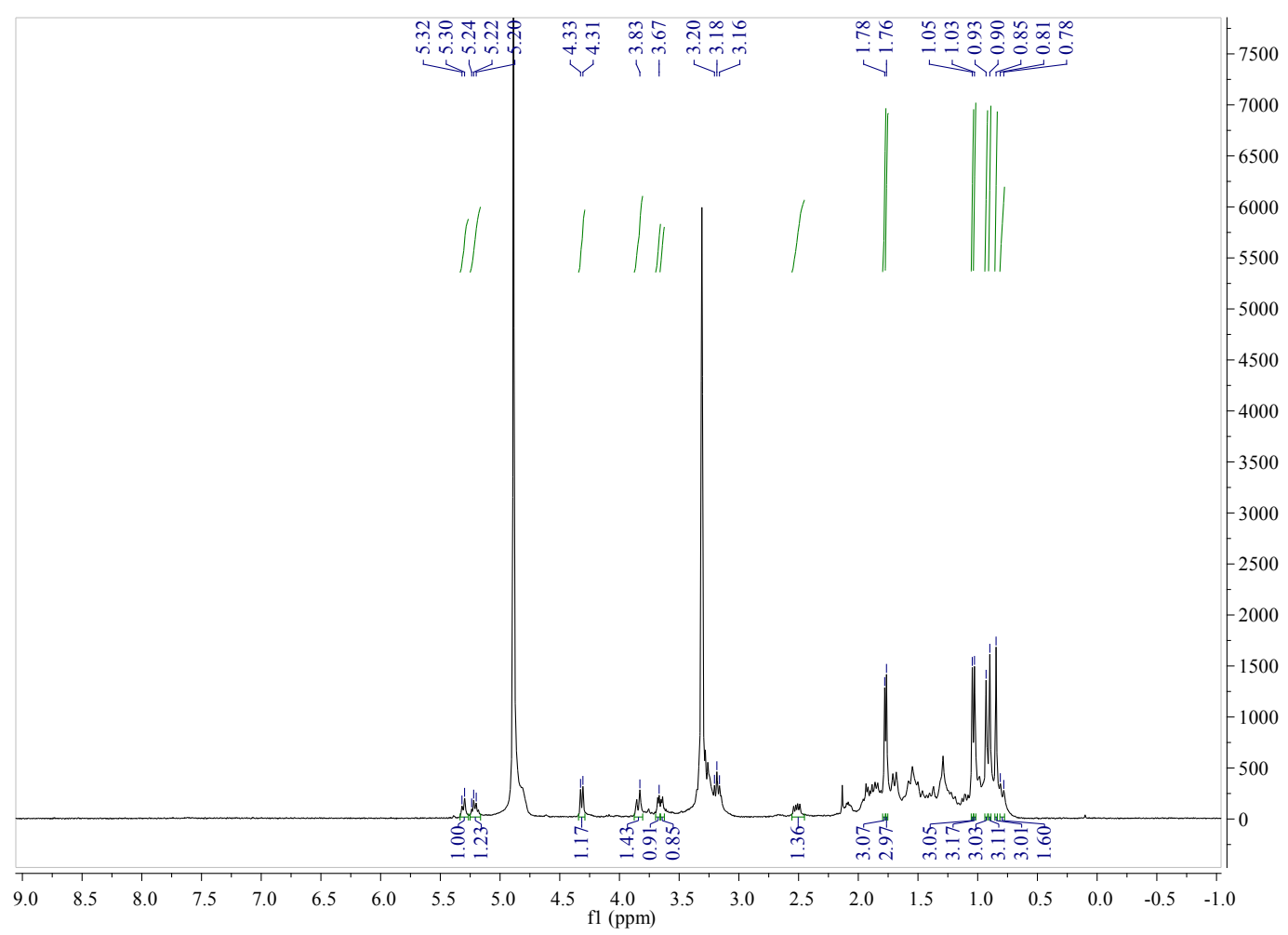

Figure S4. ${ }^{13} \mathrm{C}$ NMR $\left(100 \mathrm{MHz}, \mathrm{MeOH}-d_{4}\right)$ spectrum of compound 13

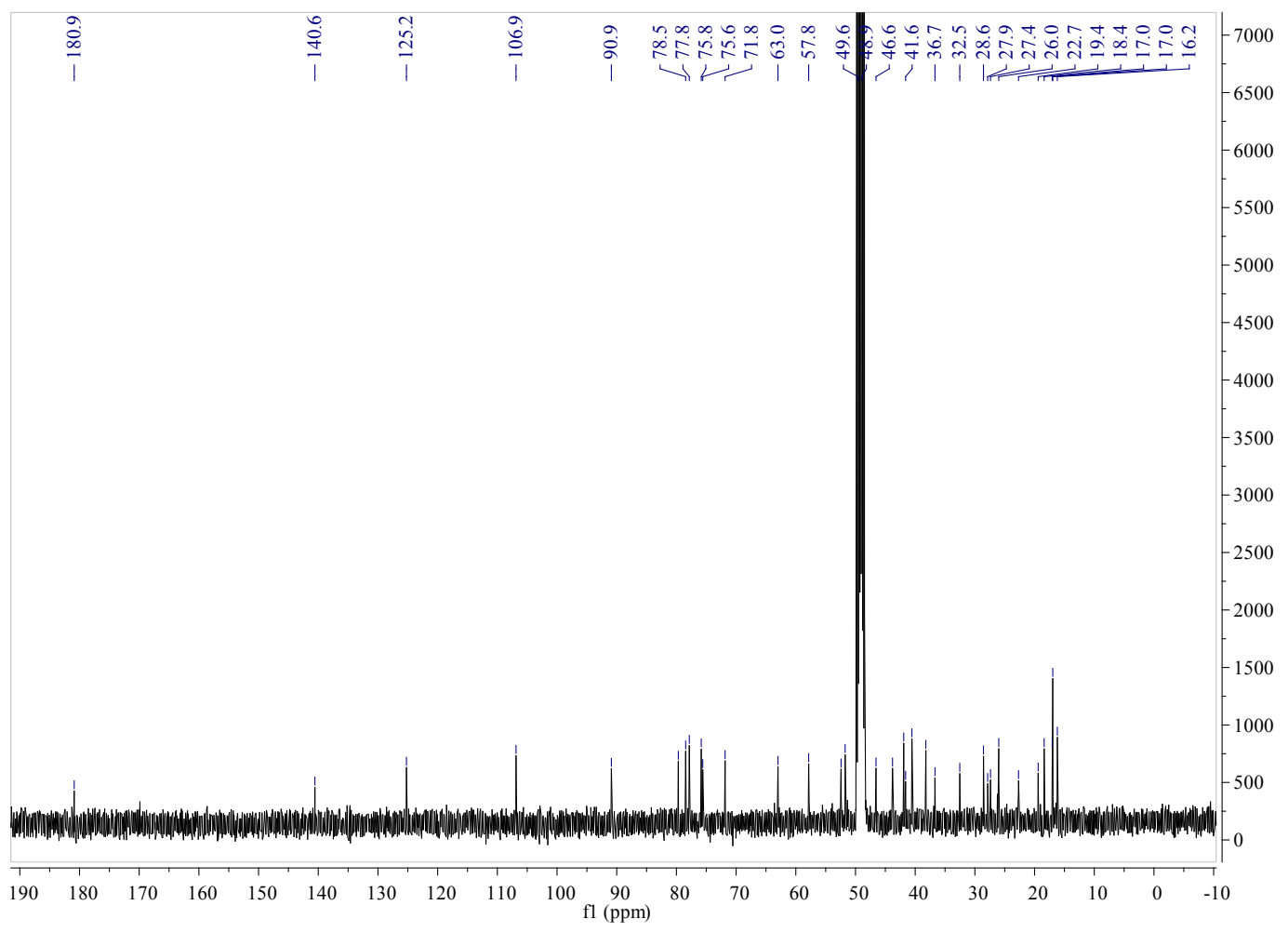


Figure S5. HSQC spectrum of compound $\mathbf{1 3}$ in $\mathrm{MeOH}-d_{4}$

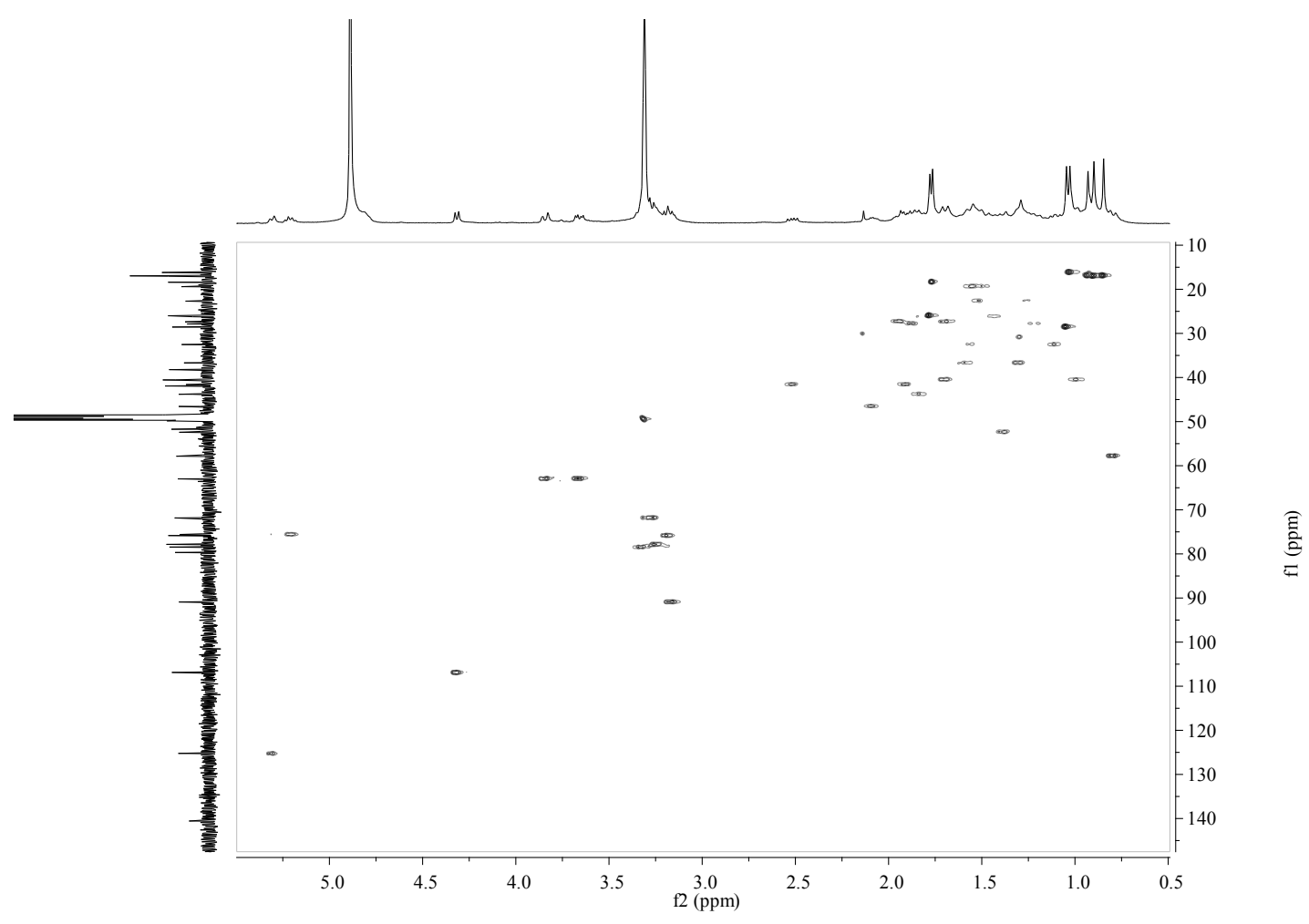

Figure S6. HMBC spectrum of compound 13 in $\mathrm{MeOH}-d 4$

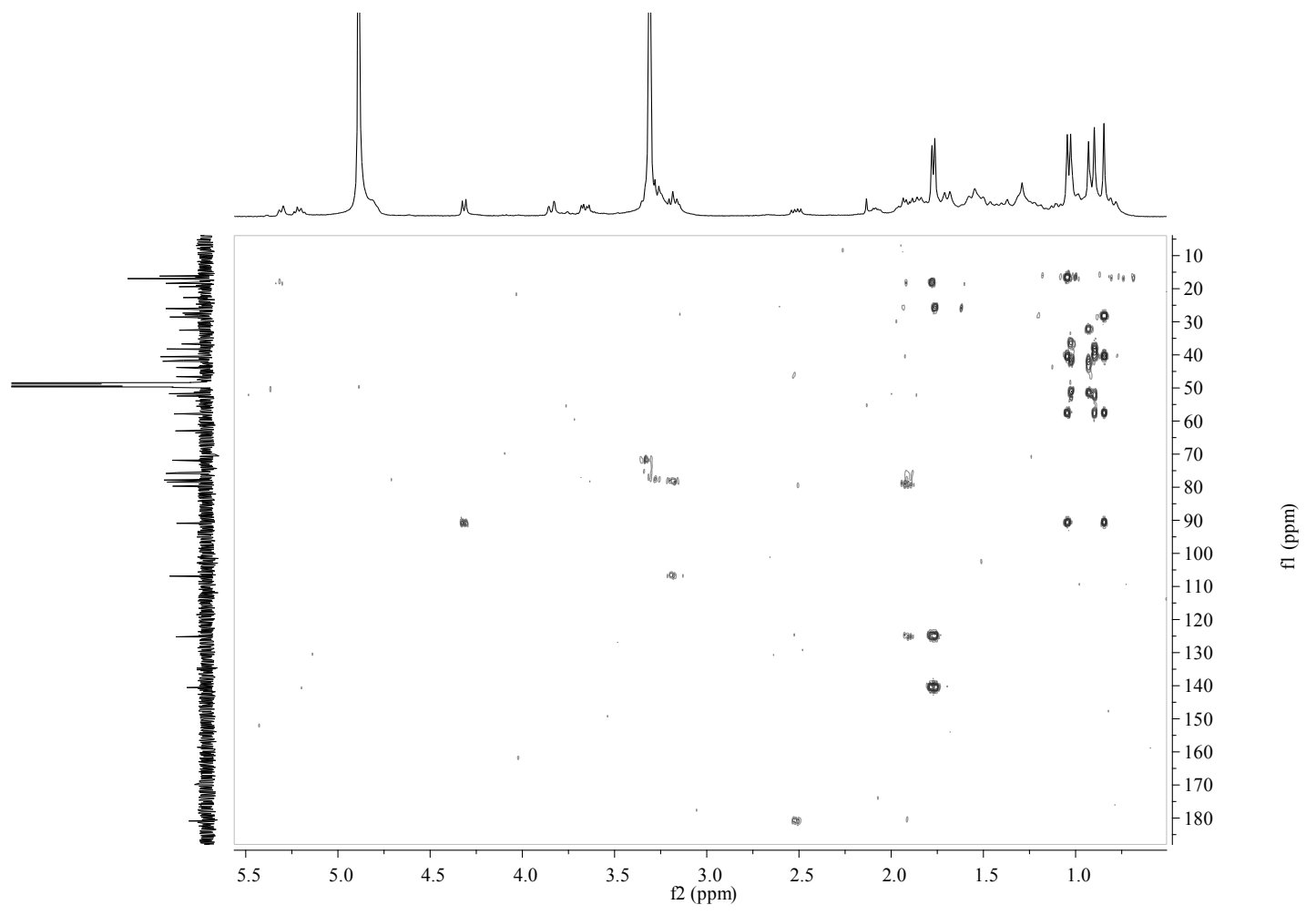


Figure S7. NOESY spectrum of compound 13 in $\mathrm{MeOH}-d_{4}$

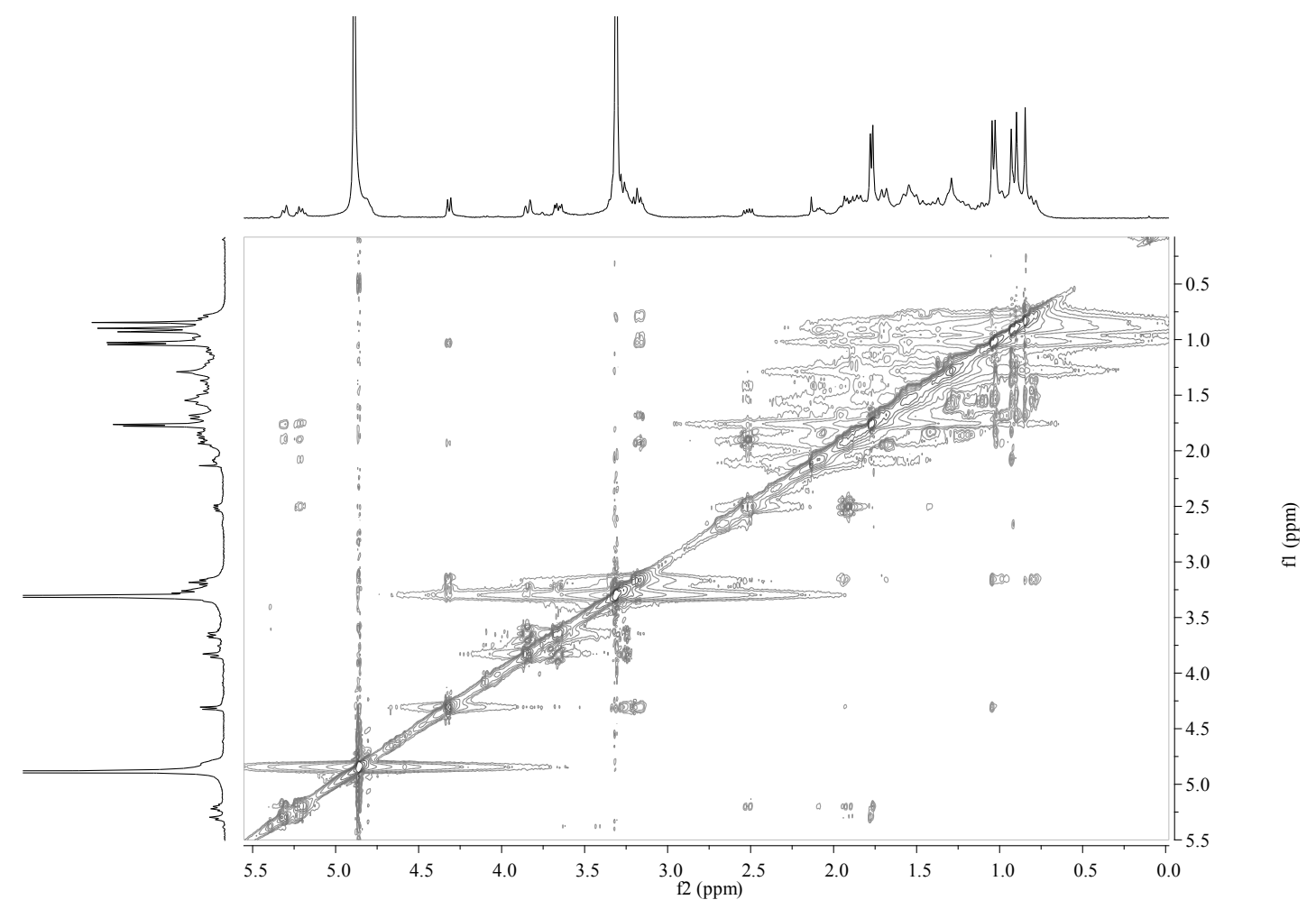

Figure S8. HRESMS of compound 14

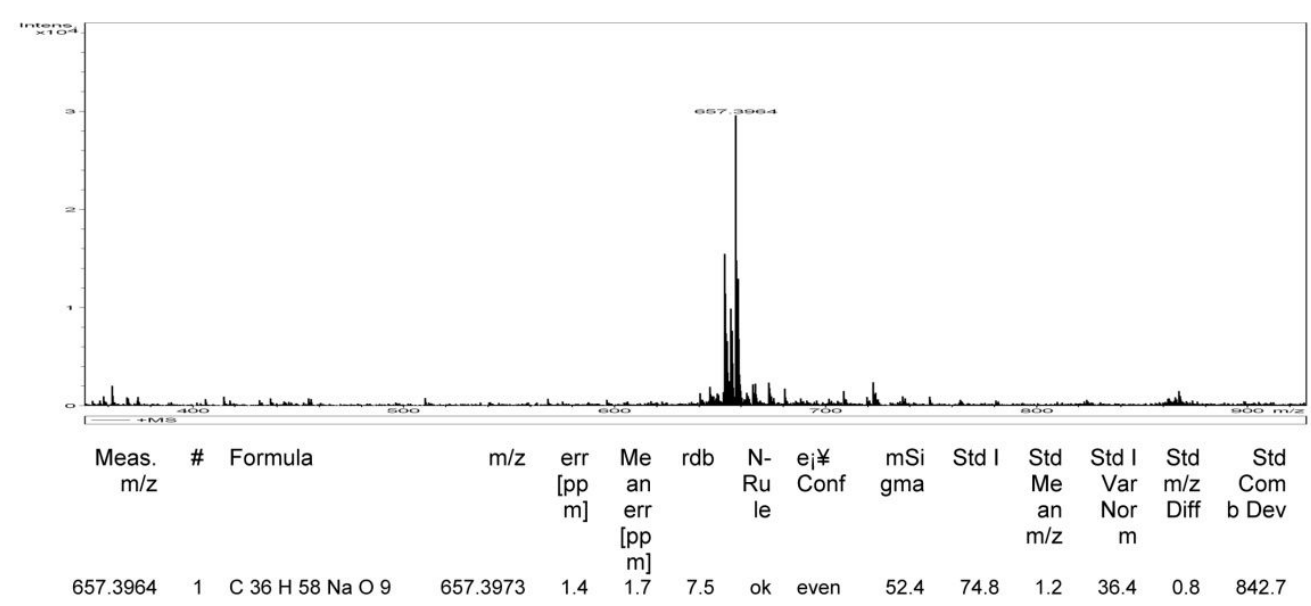


Figure S9. IR spectrum of compound 14

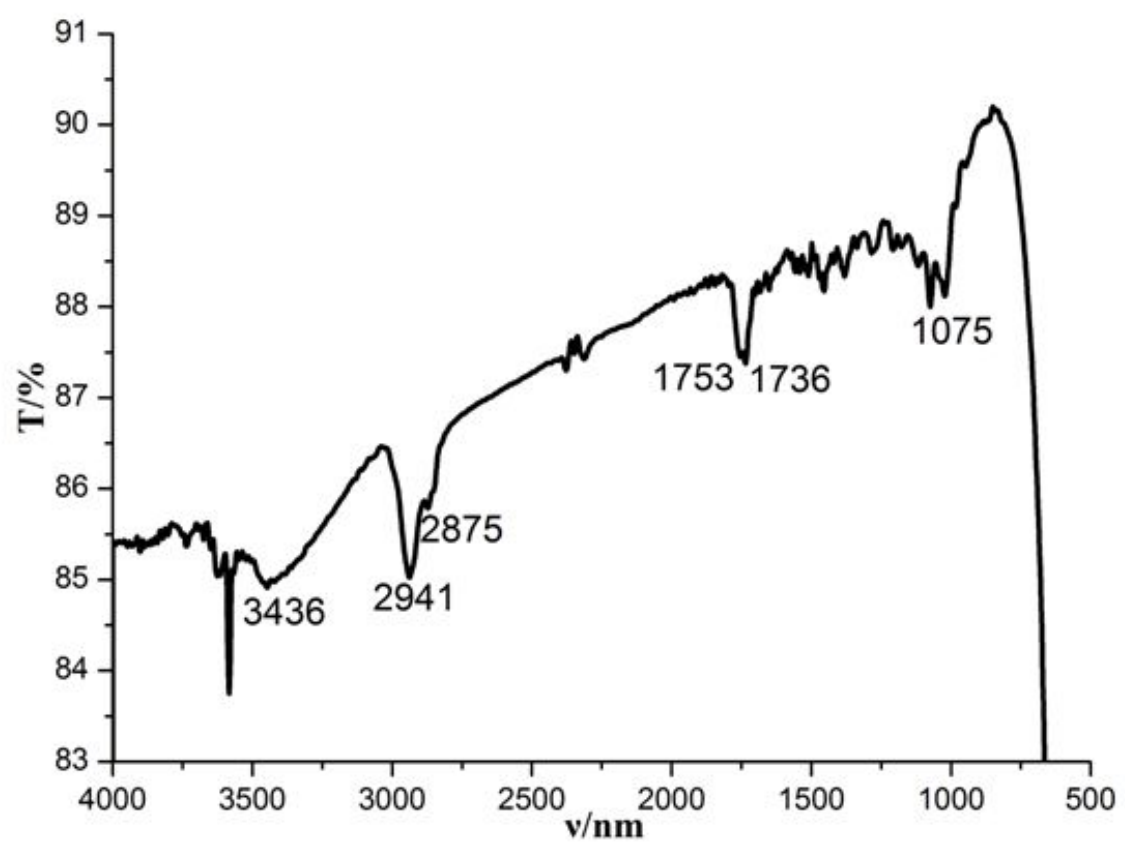

Figure S10. ${ }^{1} \mathrm{H}$ NMR (400 MHz, MeOH- $\left.d_{4}\right)$ spectrum of compound 14

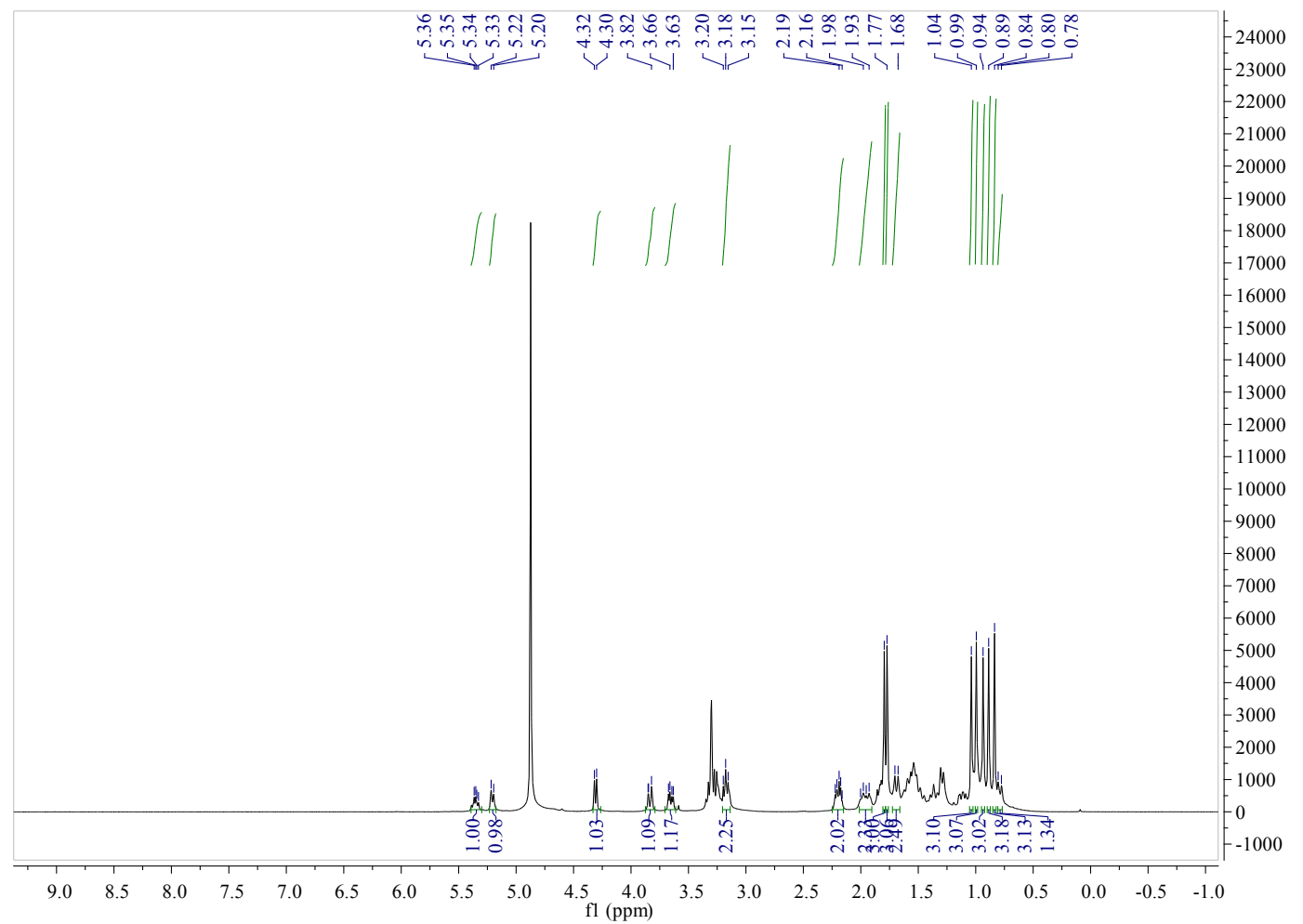


Figure S11. ${ }^{13} \mathrm{C}$ NMR $\left(100 \mathrm{MHz}, \mathrm{MeOH}-d_{4}\right)$ spectrum of compound 14

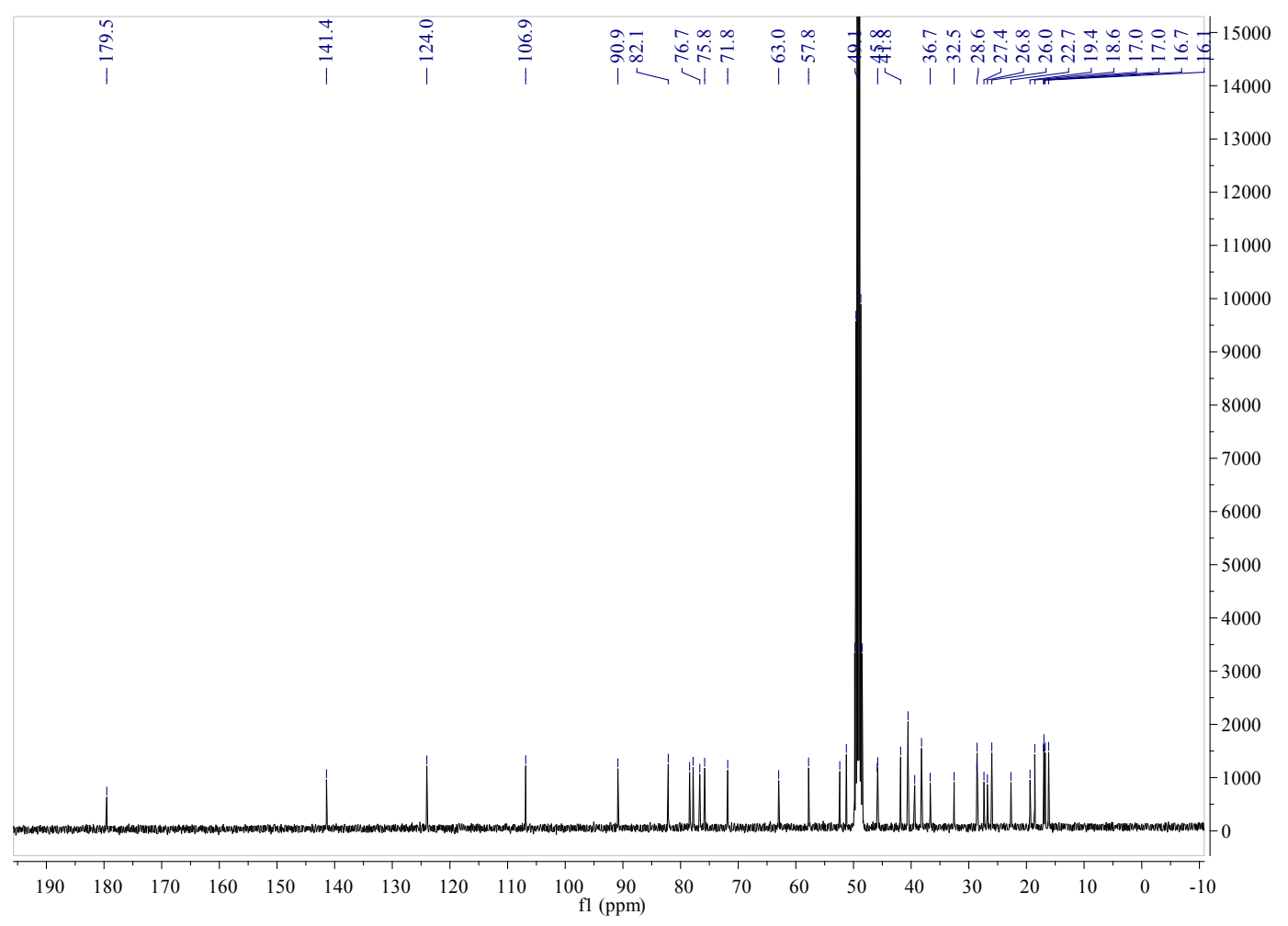

Figure S12. HSQC spectrum of compound 14 in $\mathrm{MeOH}-d 4$

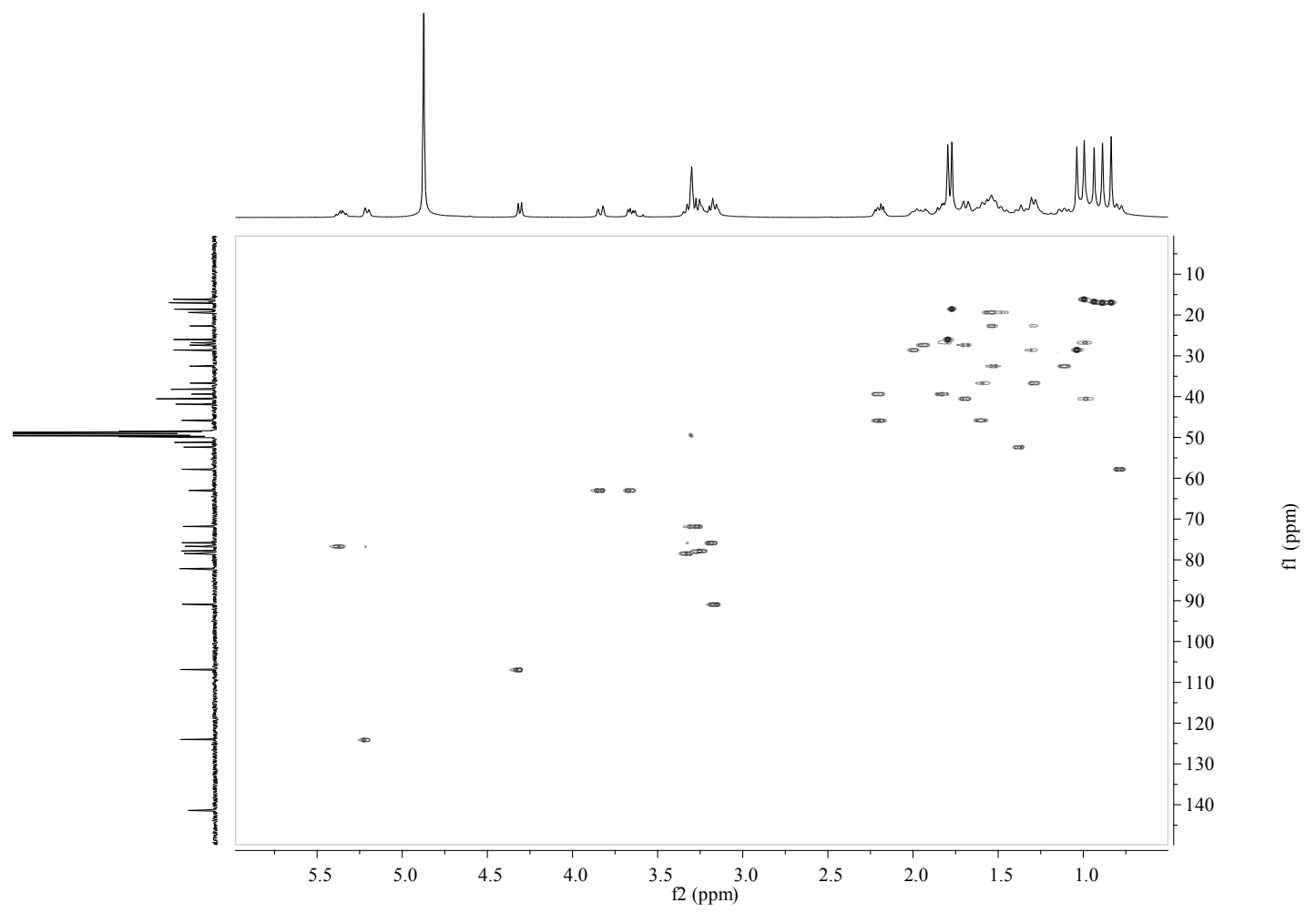


Figure S13. HMBC spectrum of compound 14 in $\mathrm{MeOH}-d_{4}$

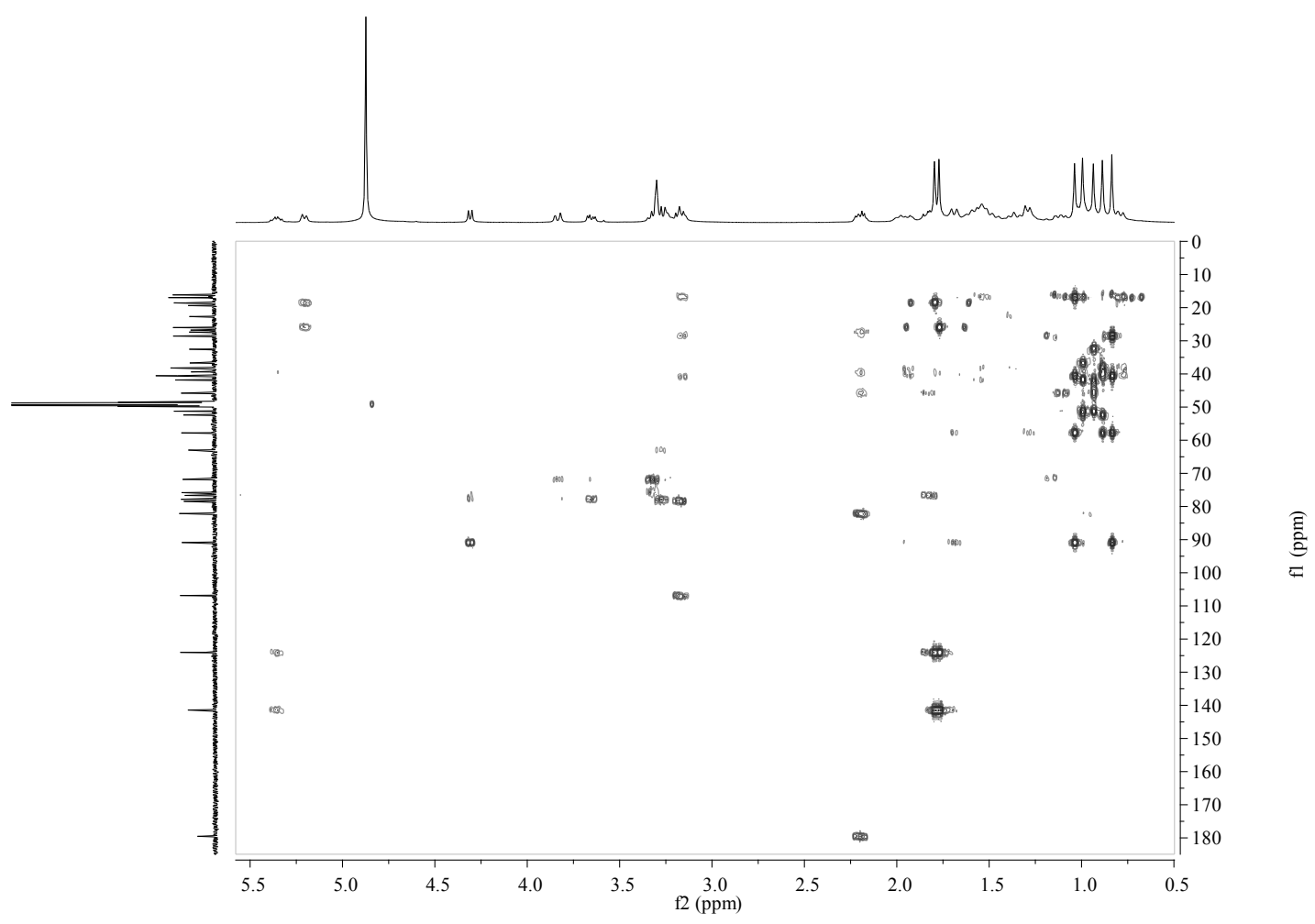

Figure S14. NOESY spectrum of compound 14 in $\mathrm{MeOH}-d_{4}$

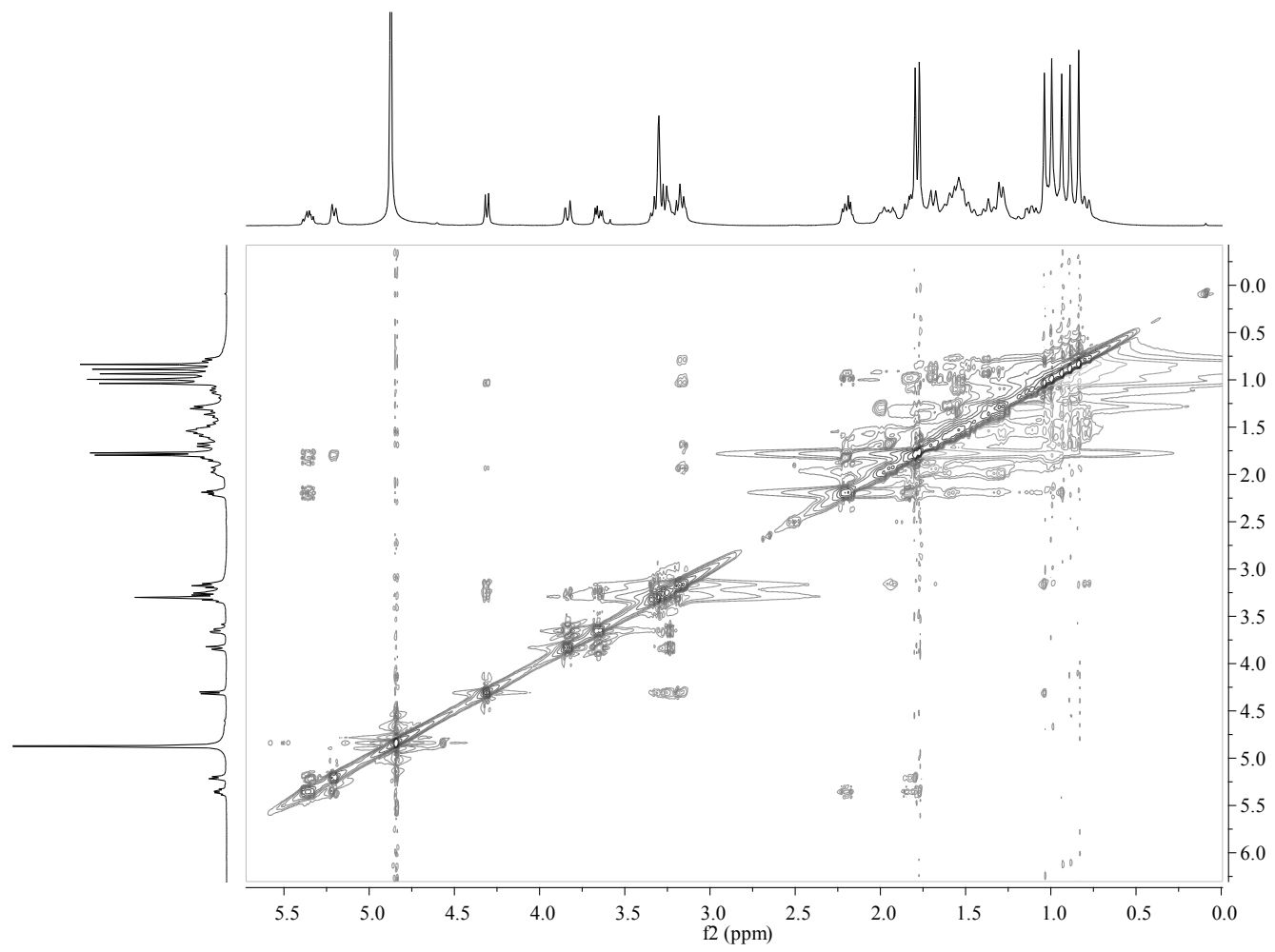


Figure S15. HRESIMS of compound 15

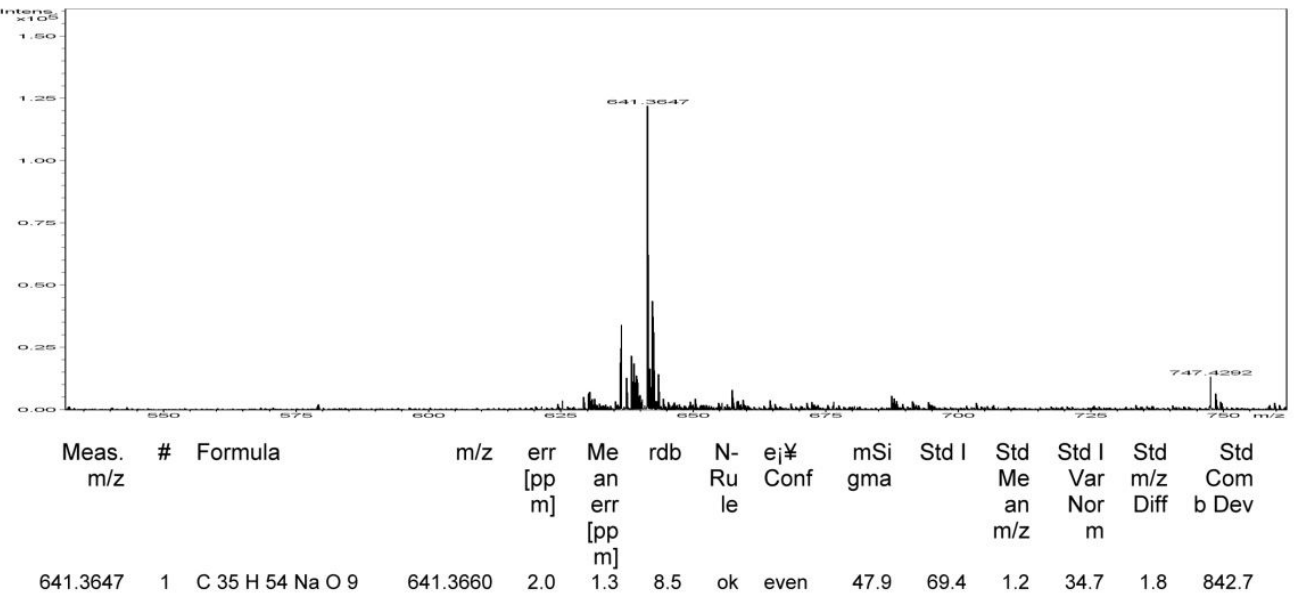

Figure S16. IR spectrum of compound 15

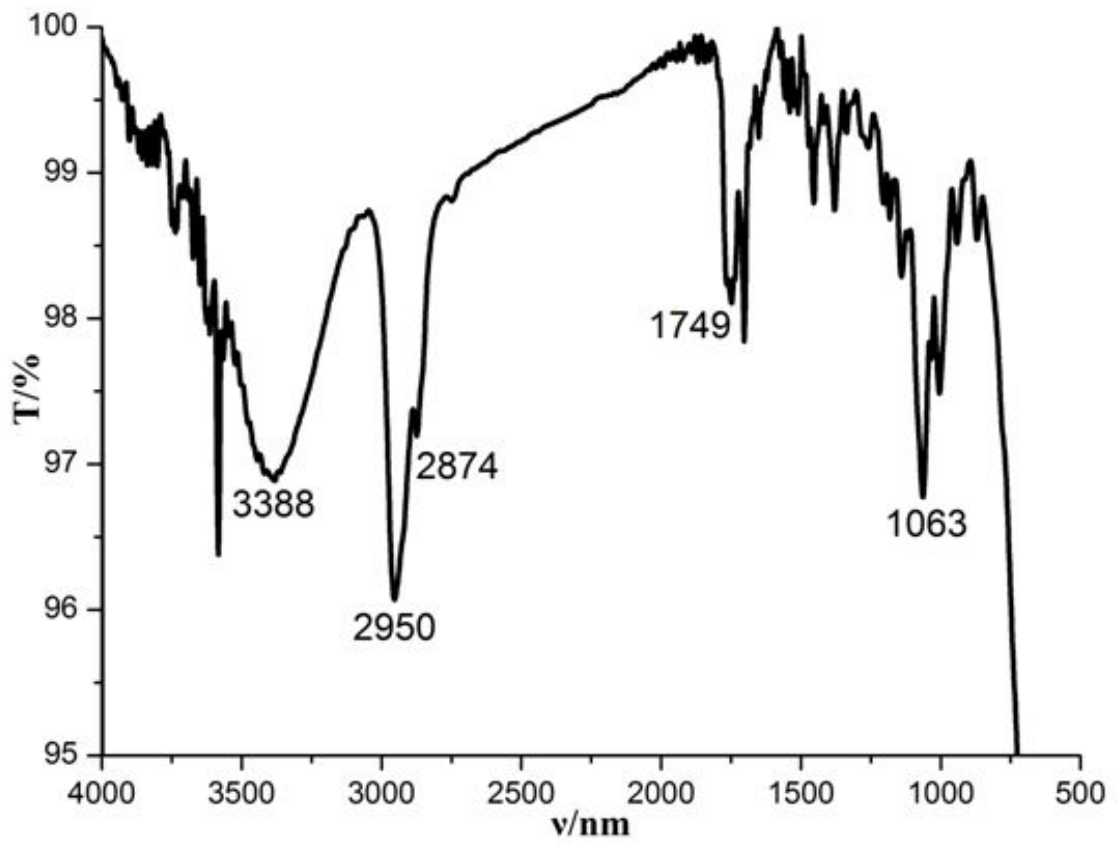


Figure S17. ${ }^{1} \mathrm{H}$ NMR (400 MHz, MeOH- $\left.d_{4}\right)$ spectrum of compound 15

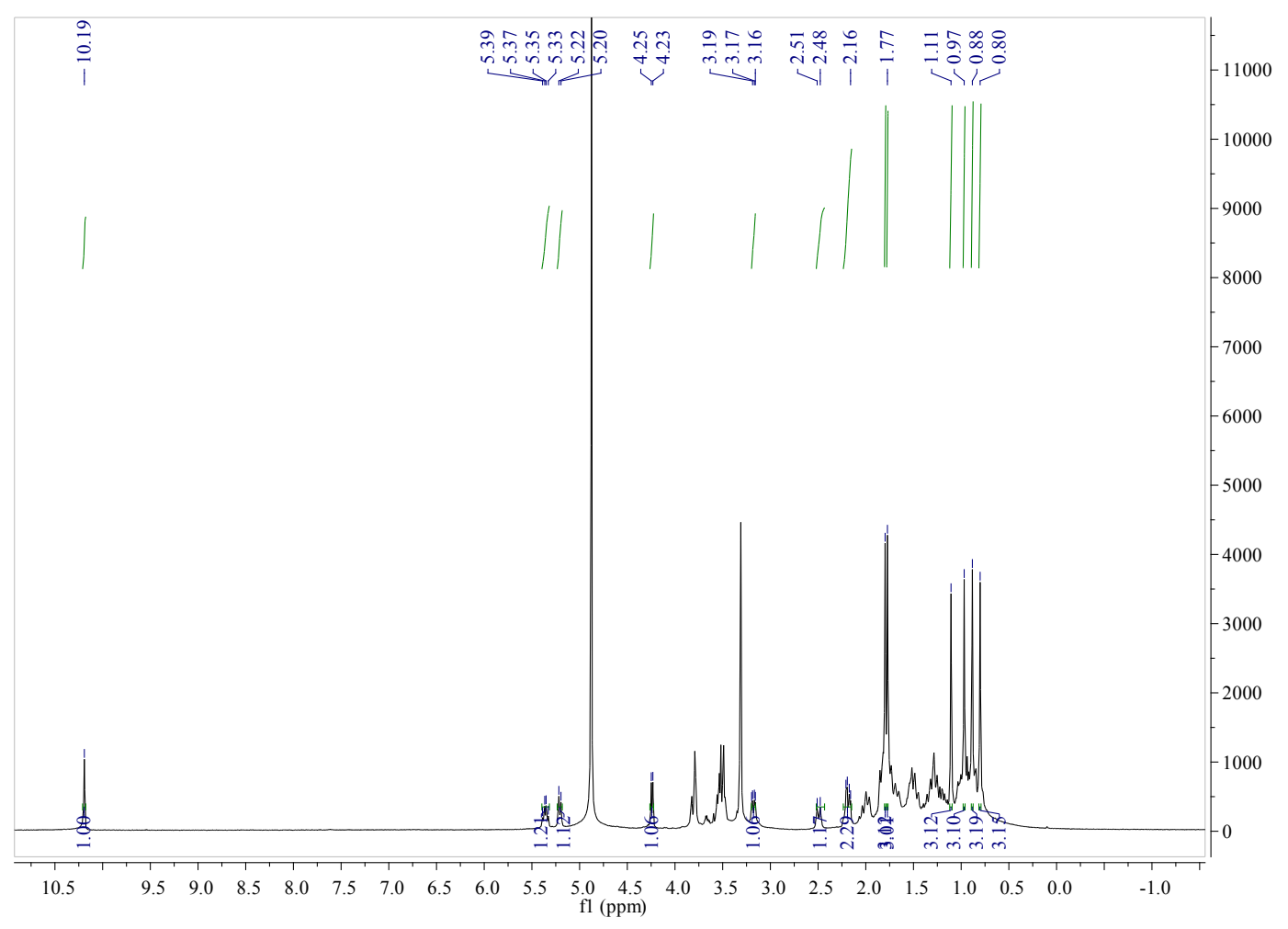

Figure S18. ${ }^{13} \mathrm{C}$ NMR (100 MHz, MeOH- $\left.d_{4}\right)$ spectrum of compound 15

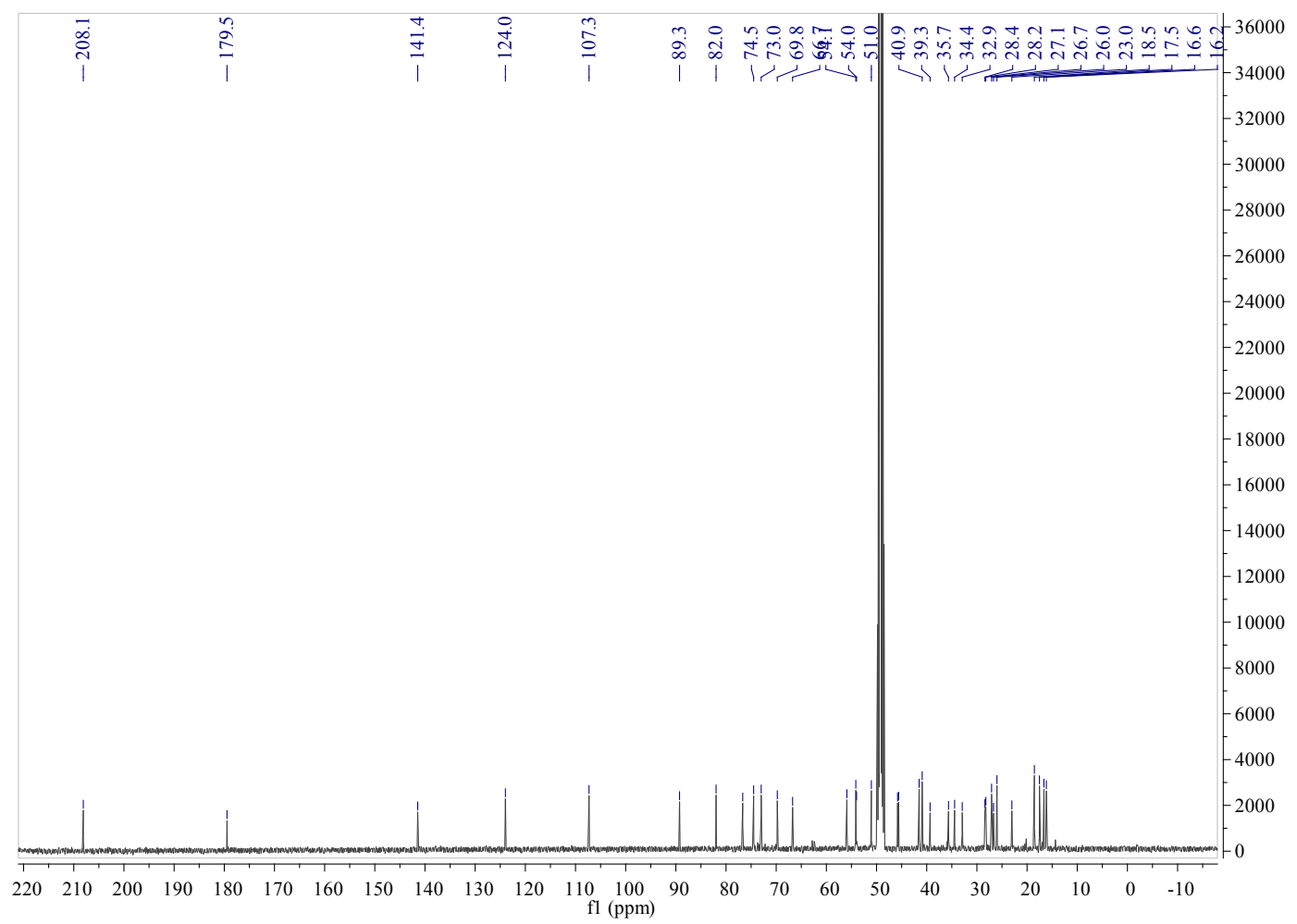


Figure S19. HSQC spectrum of compound 15 in $\mathrm{MeOH}-d_{4}$

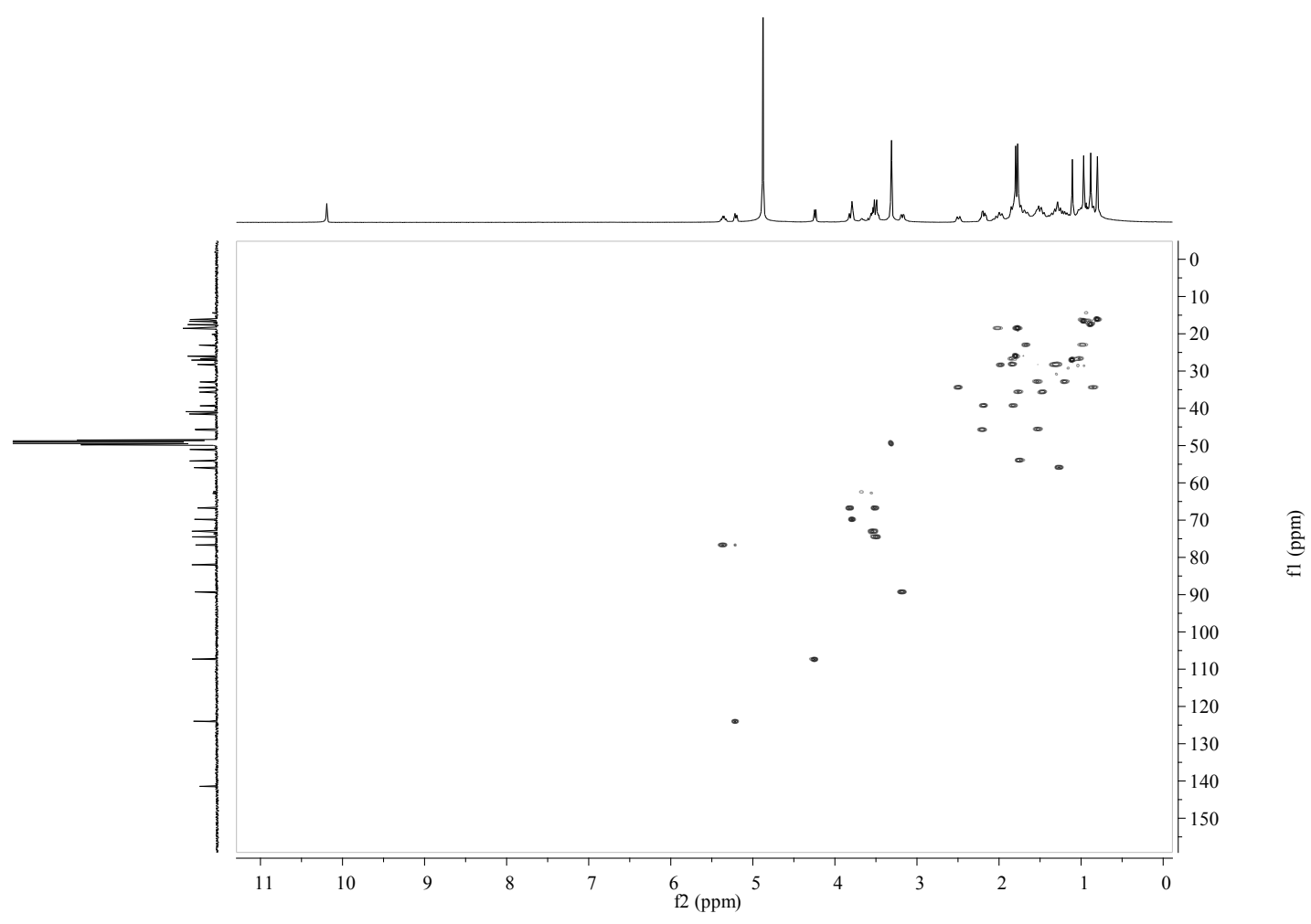

Figure S20. HMBC spectrum of compound 15 in $\mathrm{MeOH}-d_{4}$

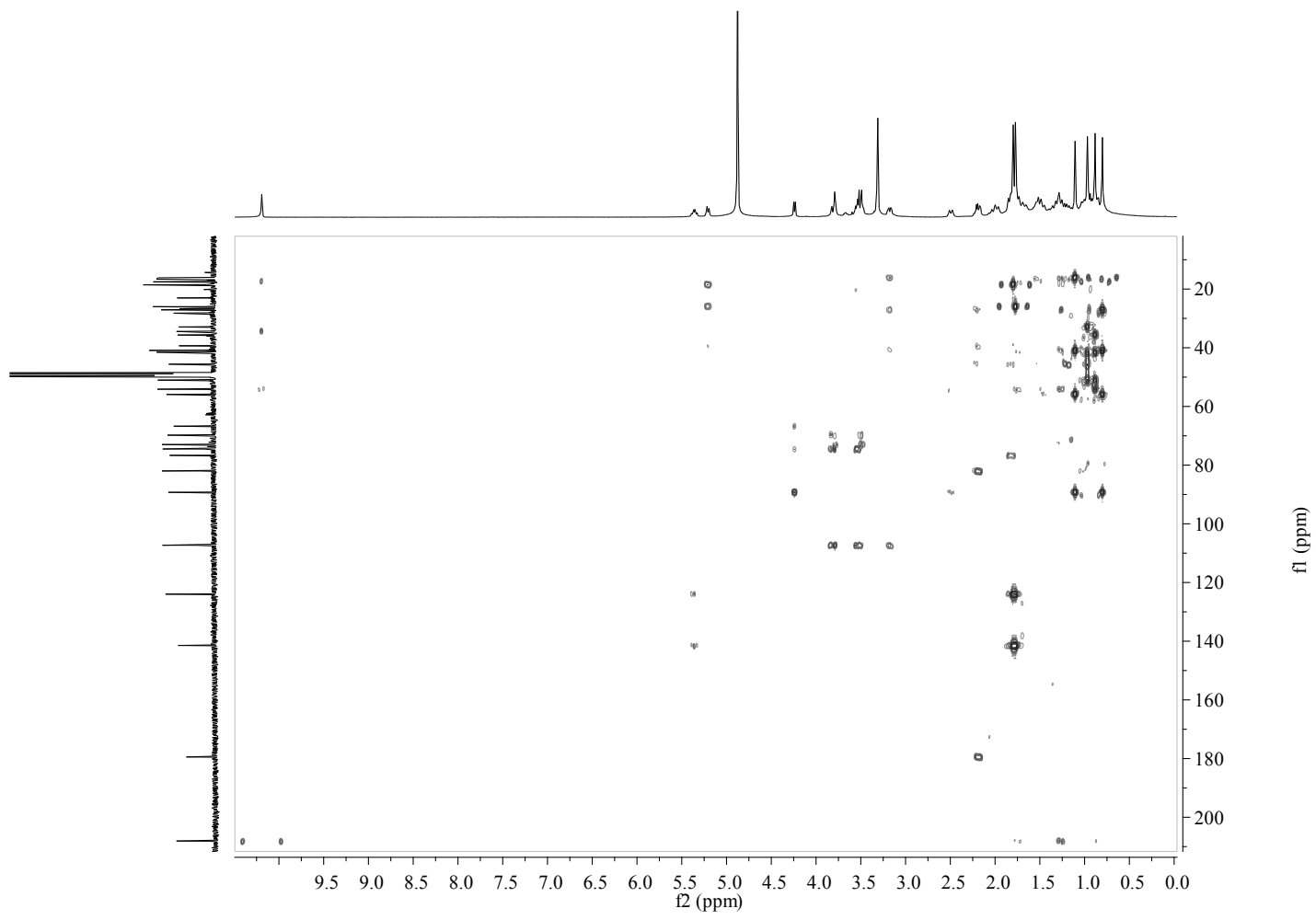


Figure S21. NOESY spectrum of compound 15 in MeOH- $d_{4}$

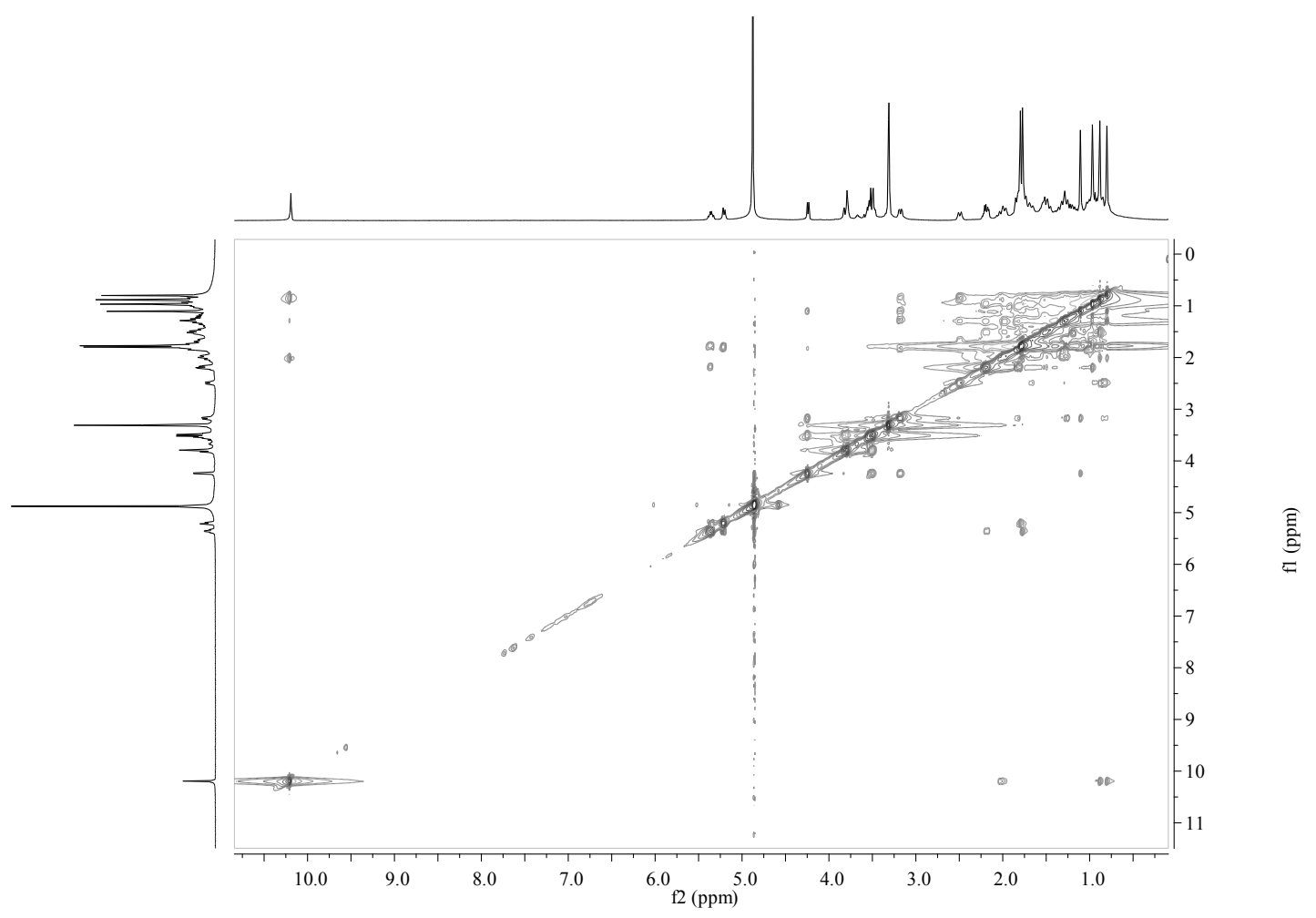

Figure S22. HRESIMS of compound 16

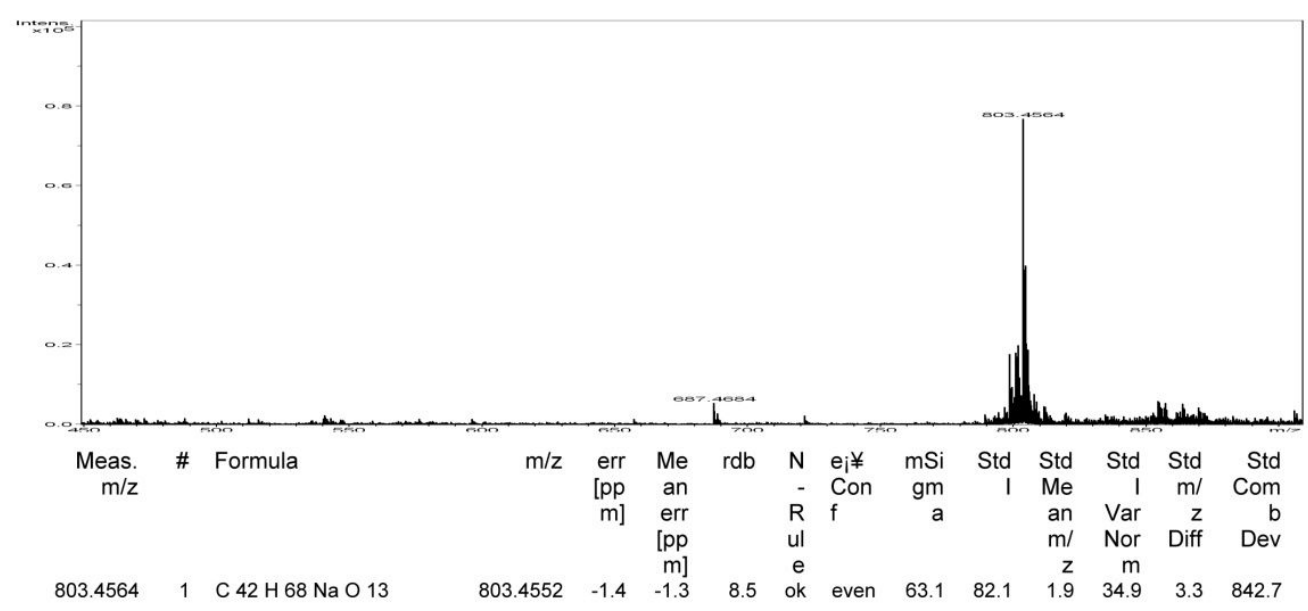


Figure S23. IR spectrum of compound 16

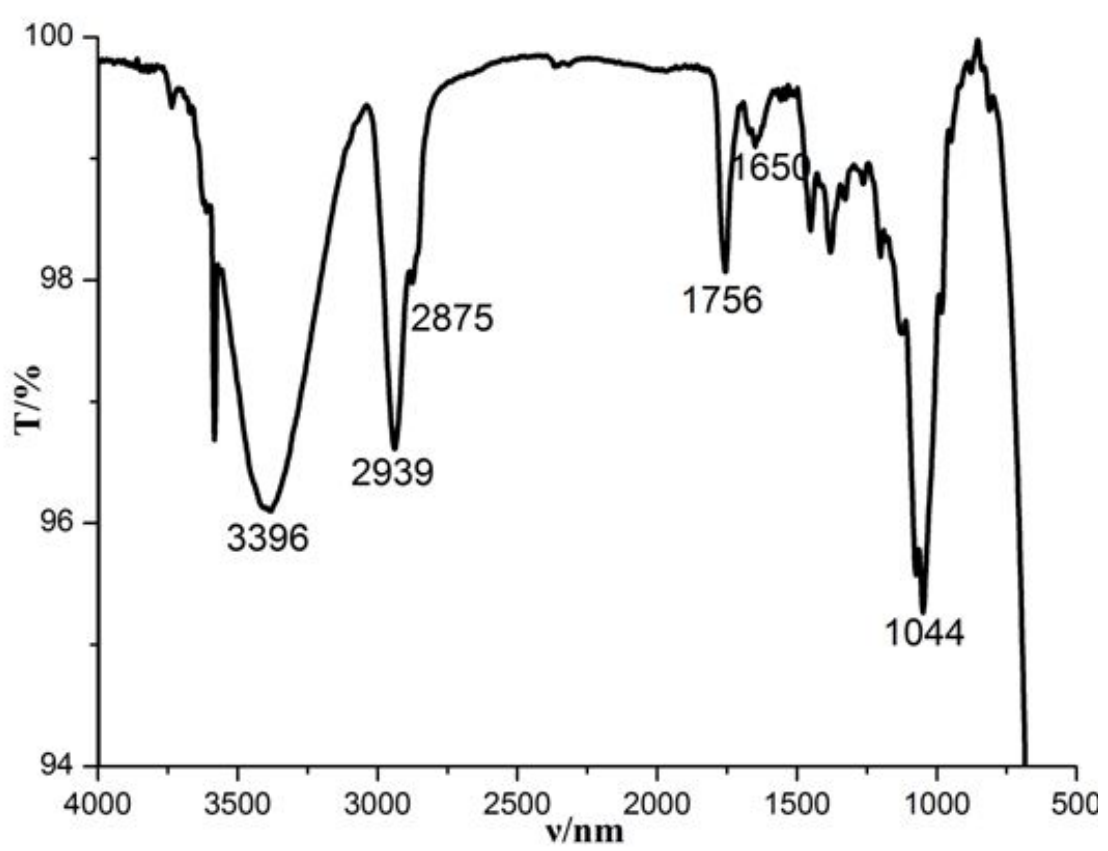

Figure S24. ${ }^{1} \mathrm{H}$ NMR (400 MHz, MeOH- $\left.d_{4}\right)$ spectrum of compound 16

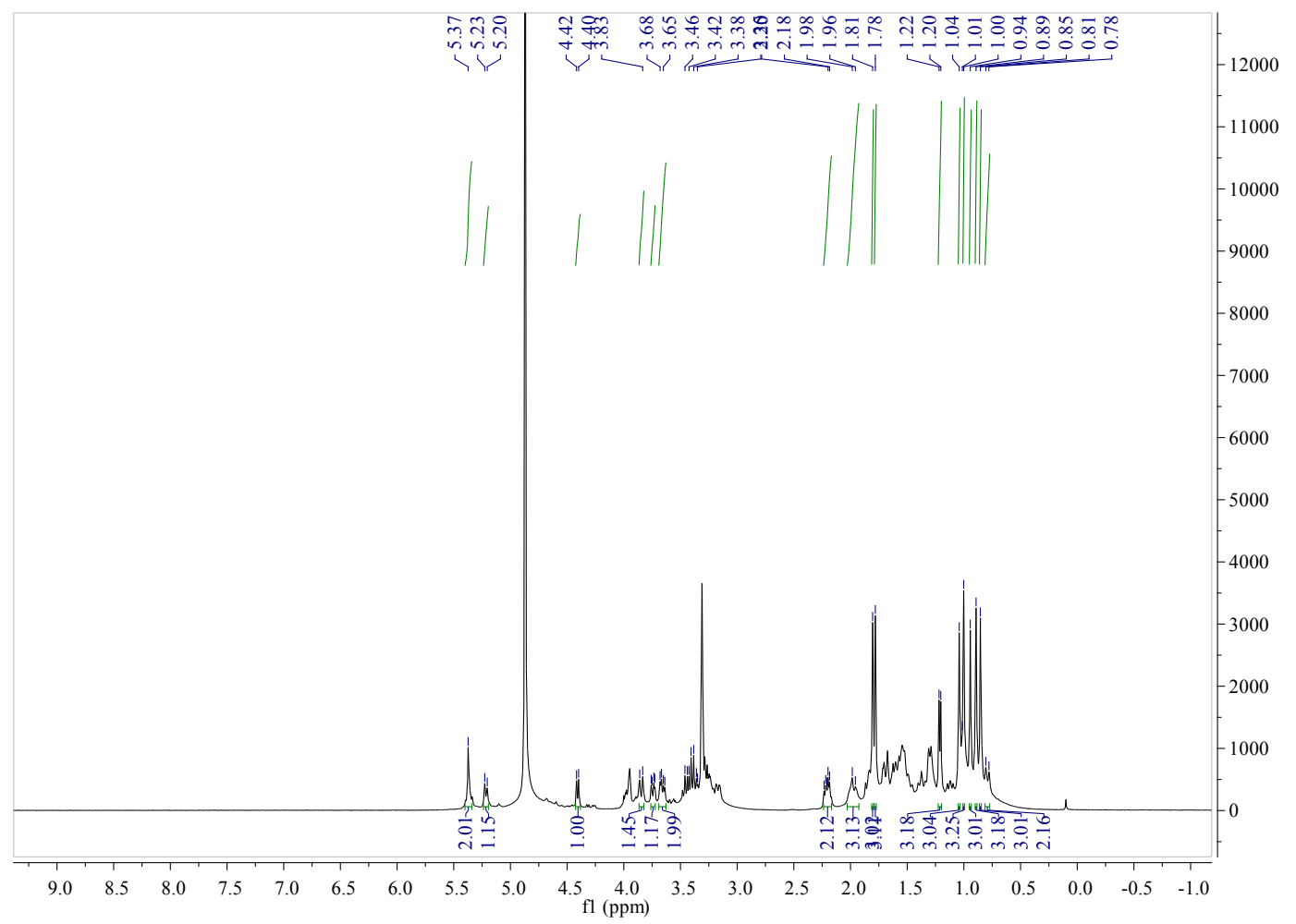


Figure S25. ${ }^{13} \mathrm{C}$ NMR (100 MHz, MeOH- $\left.d_{4}\right)$ spectrum of compound 16

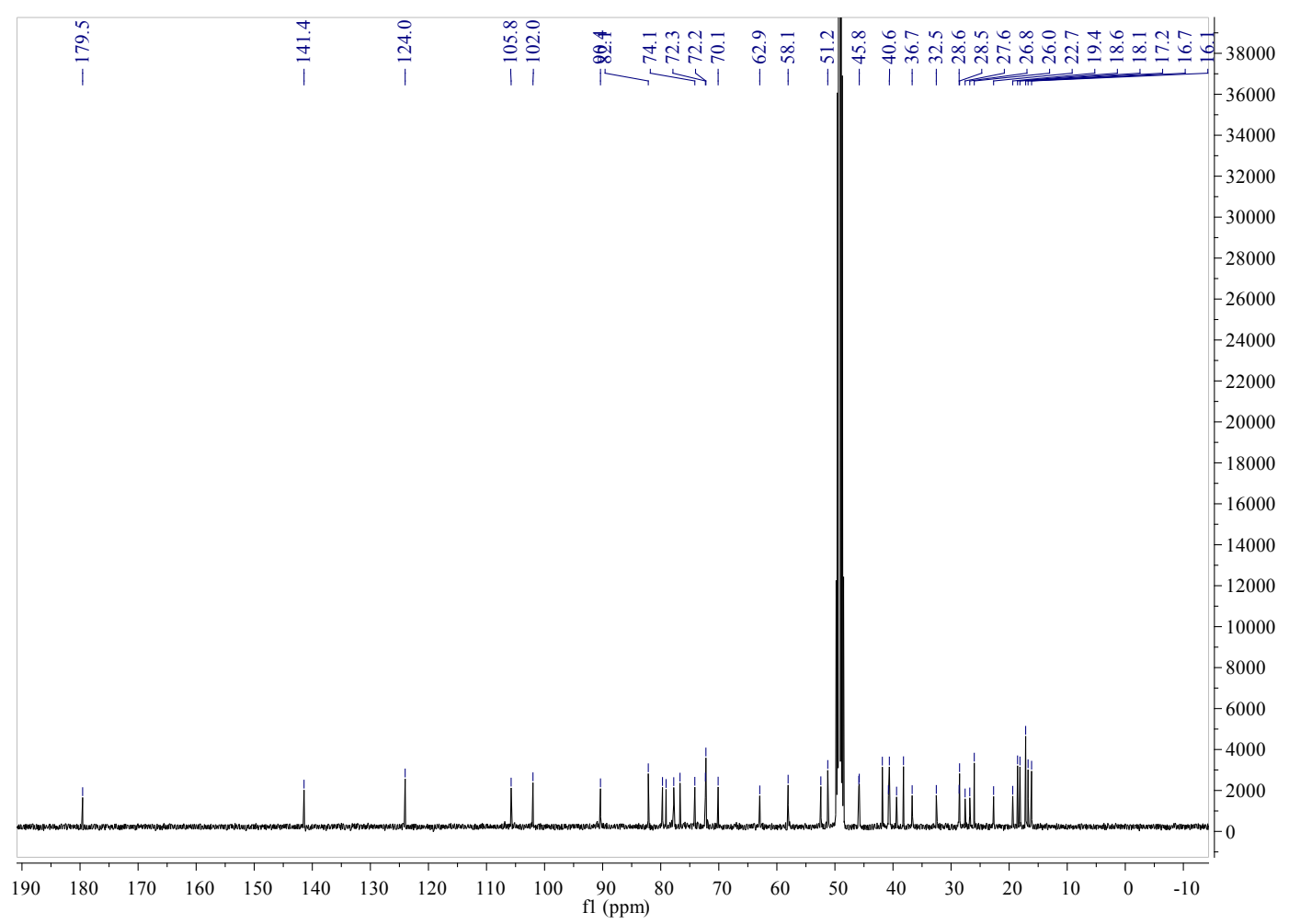

Figure S26. HSQC spectrum of compound 16 in $\mathrm{MeOH}-d_{4}$

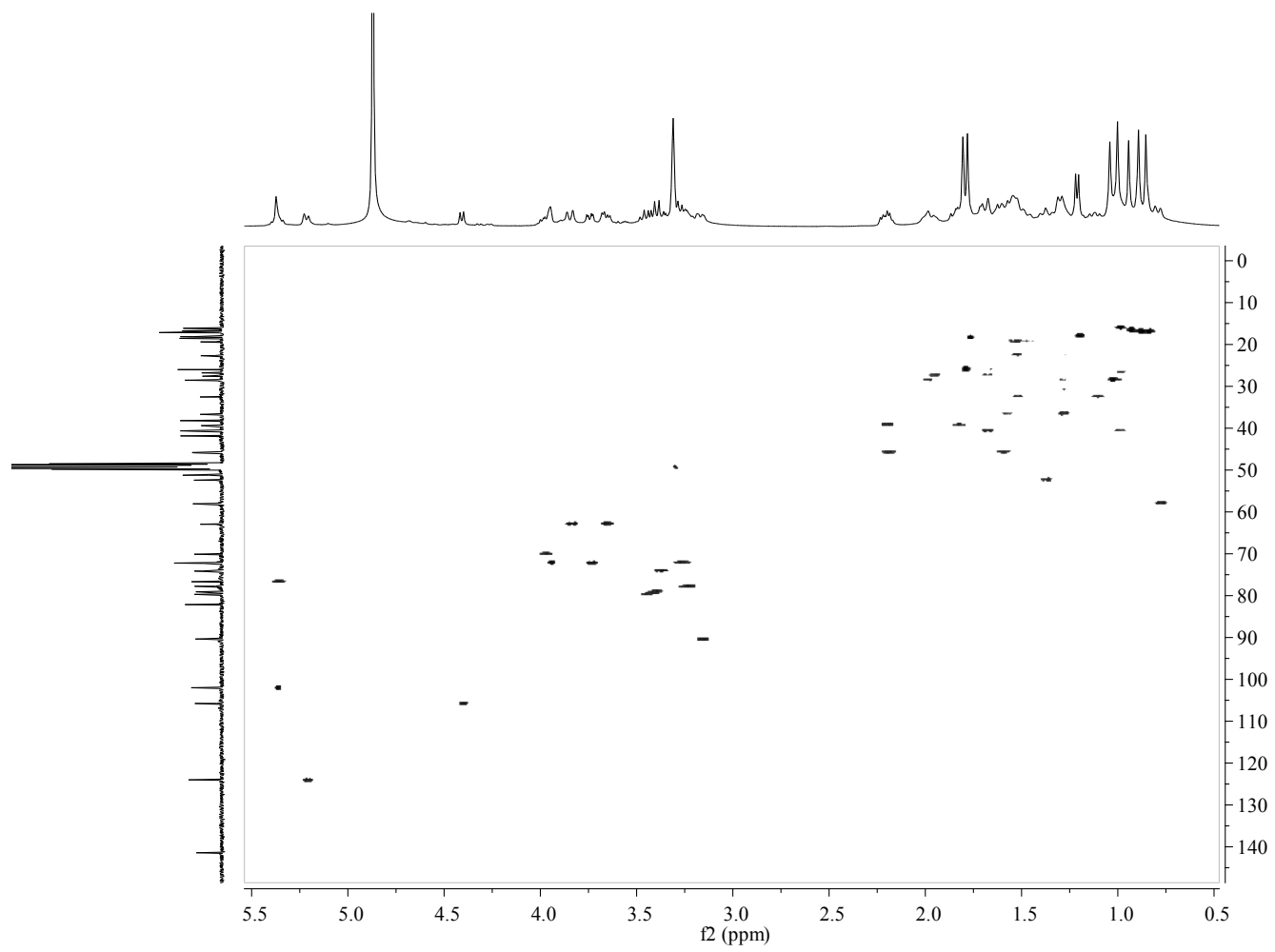


Figure S27. HMBC spectrum of compound 16 in $\mathrm{MeOH}-d_{4}$

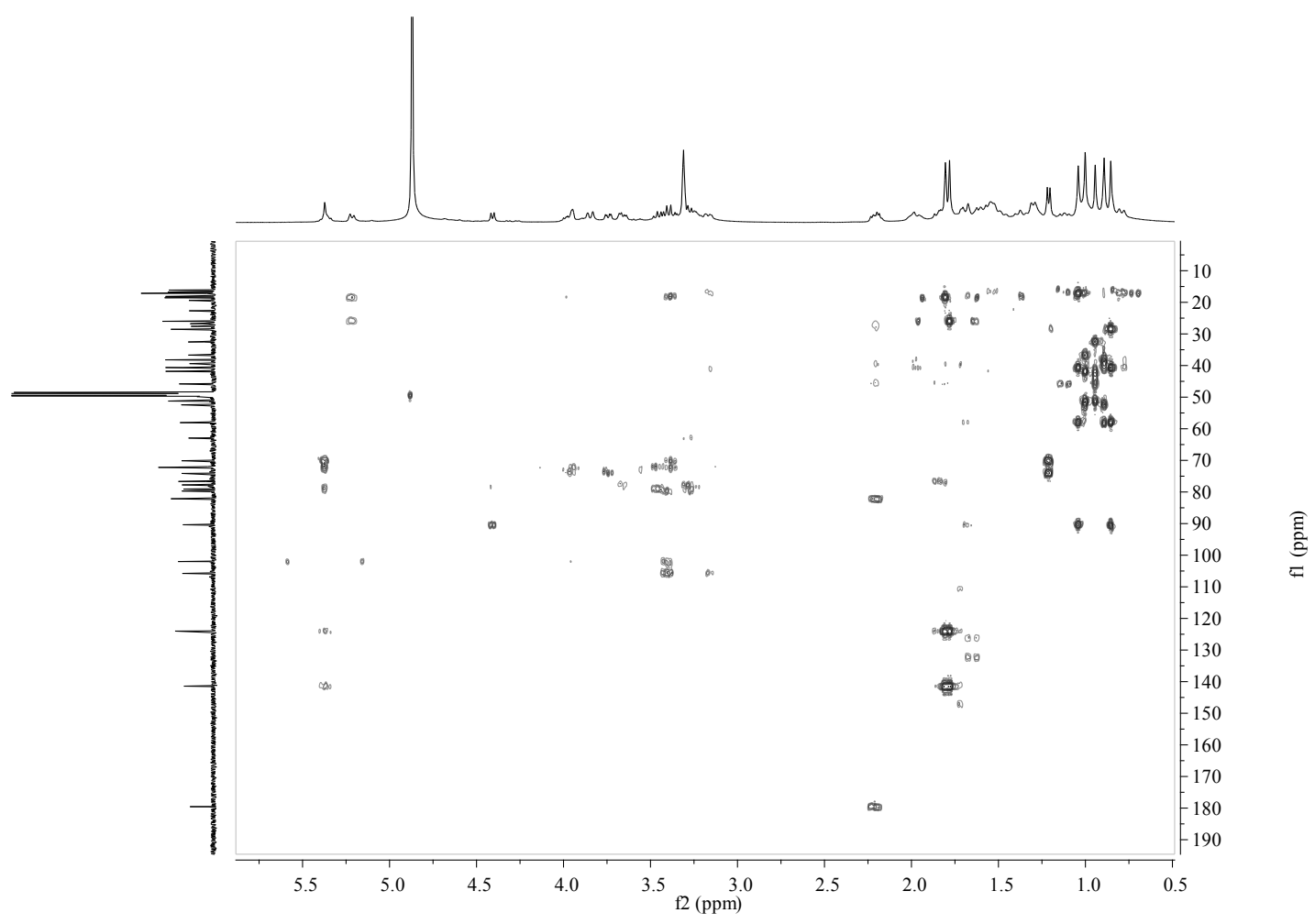

Figure S28. NOESY spectrum of compound 16 in $\mathrm{MeOH}-d_{4}$

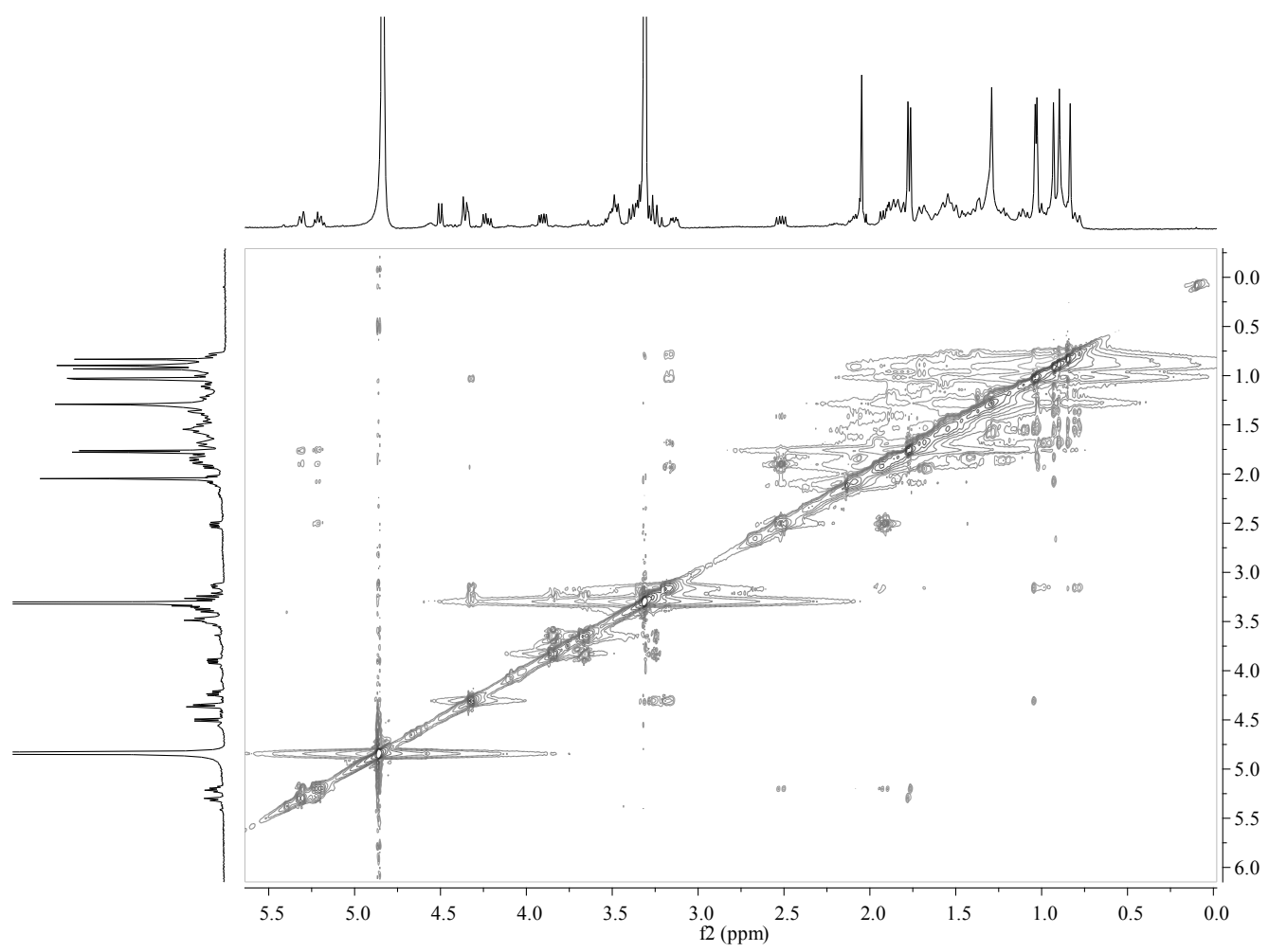

言 
Figure S29. HRESIMS of compound 17

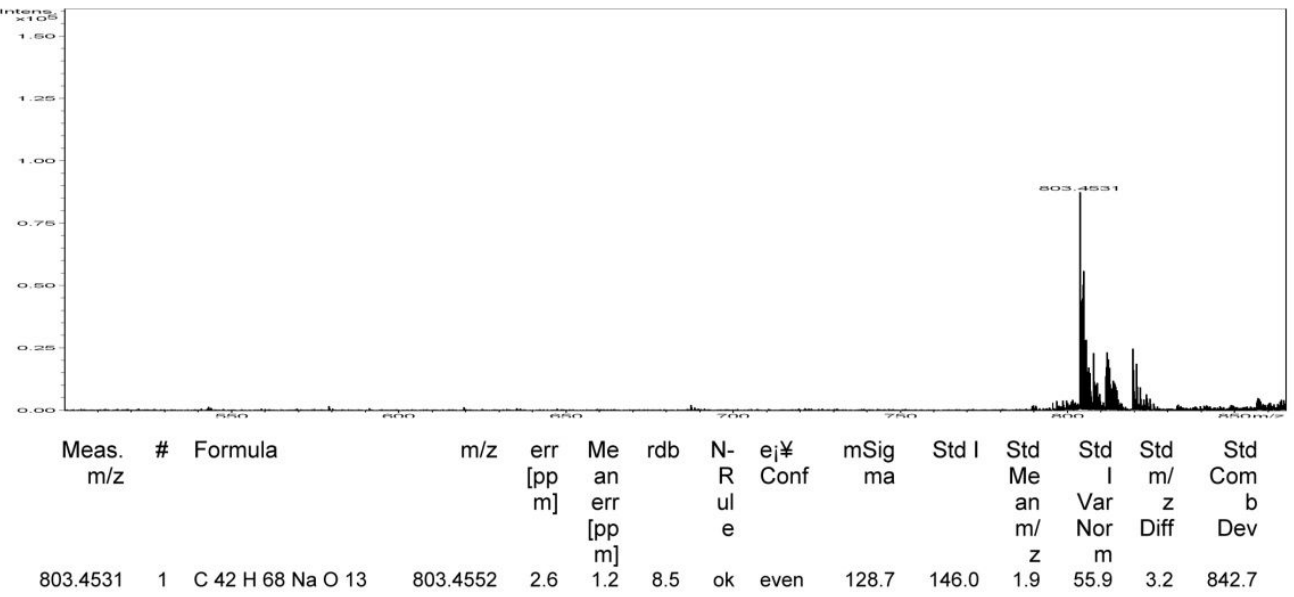

Figure S30. IR spectrum of compound 17

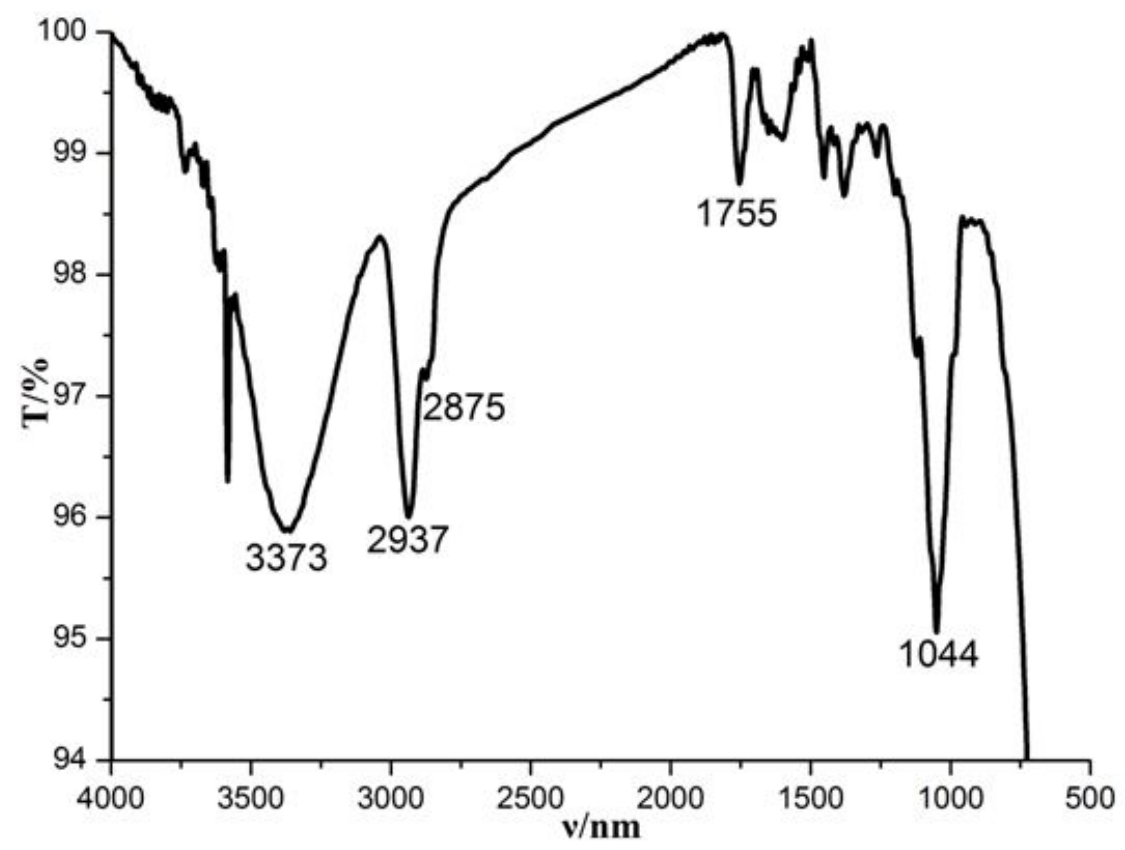


Figure S31. ${ }^{1} \mathrm{H}$ NMR (400 MHz, MeOH- $\left.d_{4}\right)$ spectrum of compound 17

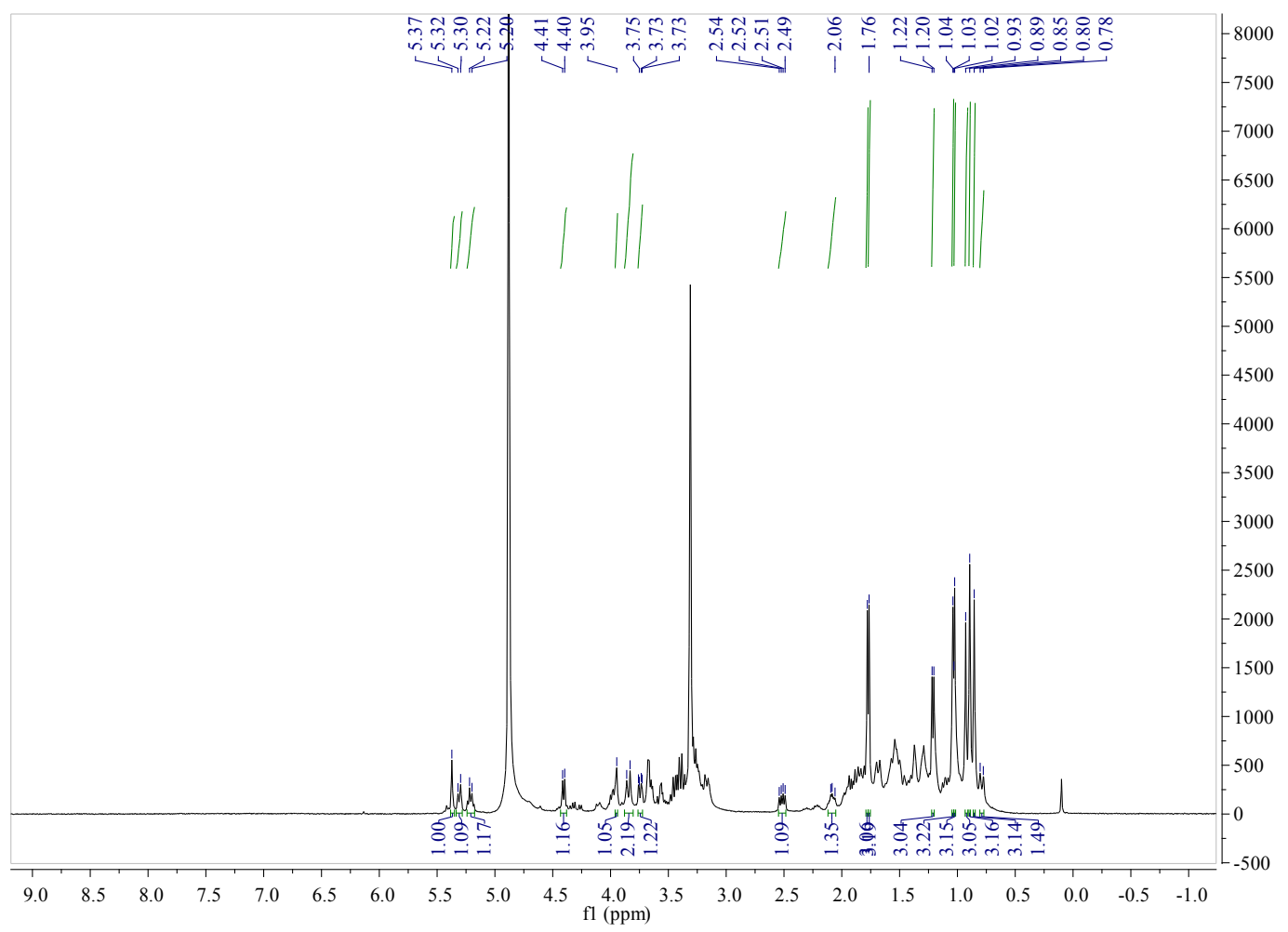

Figure S32. ${ }^{13} \mathrm{C}$ NMR $\left(100 \mathrm{MHz}, \mathrm{MeOH}-d_{4}\right)$ spectrum of compound 17

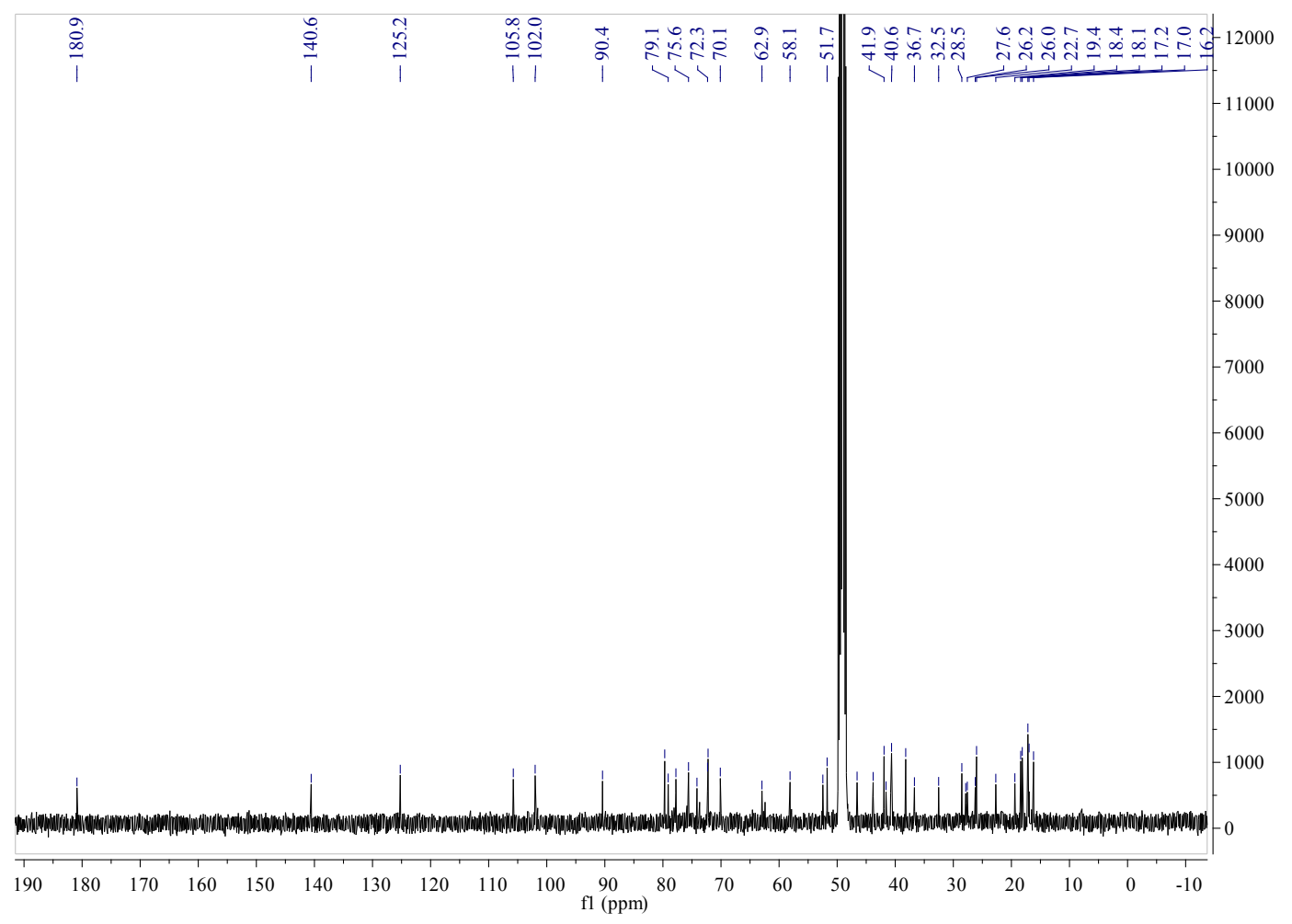


Figure S33. HSQC spectrum of compound 17 in $\mathrm{MeOH}-d_{4}$

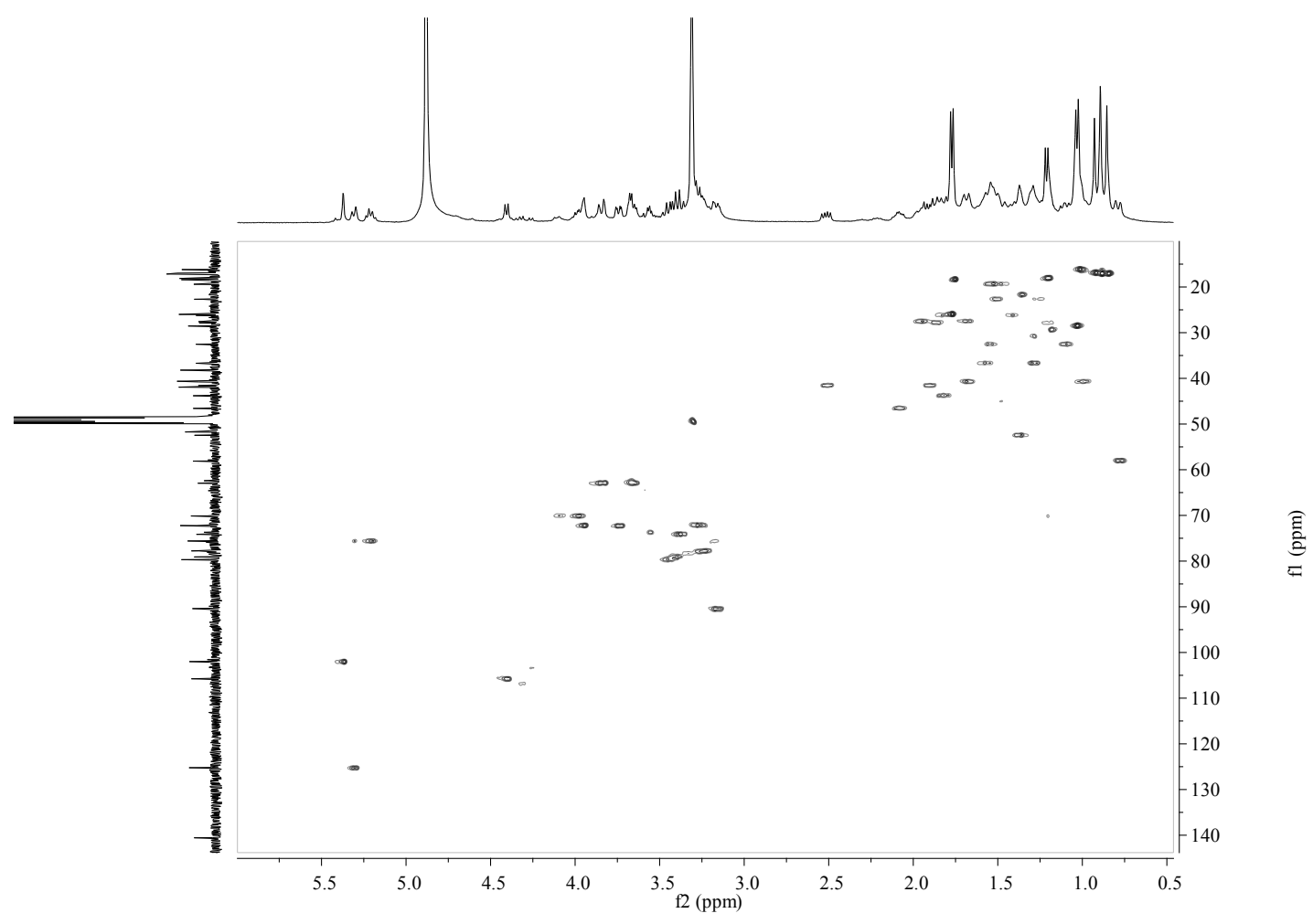

Figure S34. HMBC spectrum of compound 17 in $\mathrm{MeOH}-d_{4}$

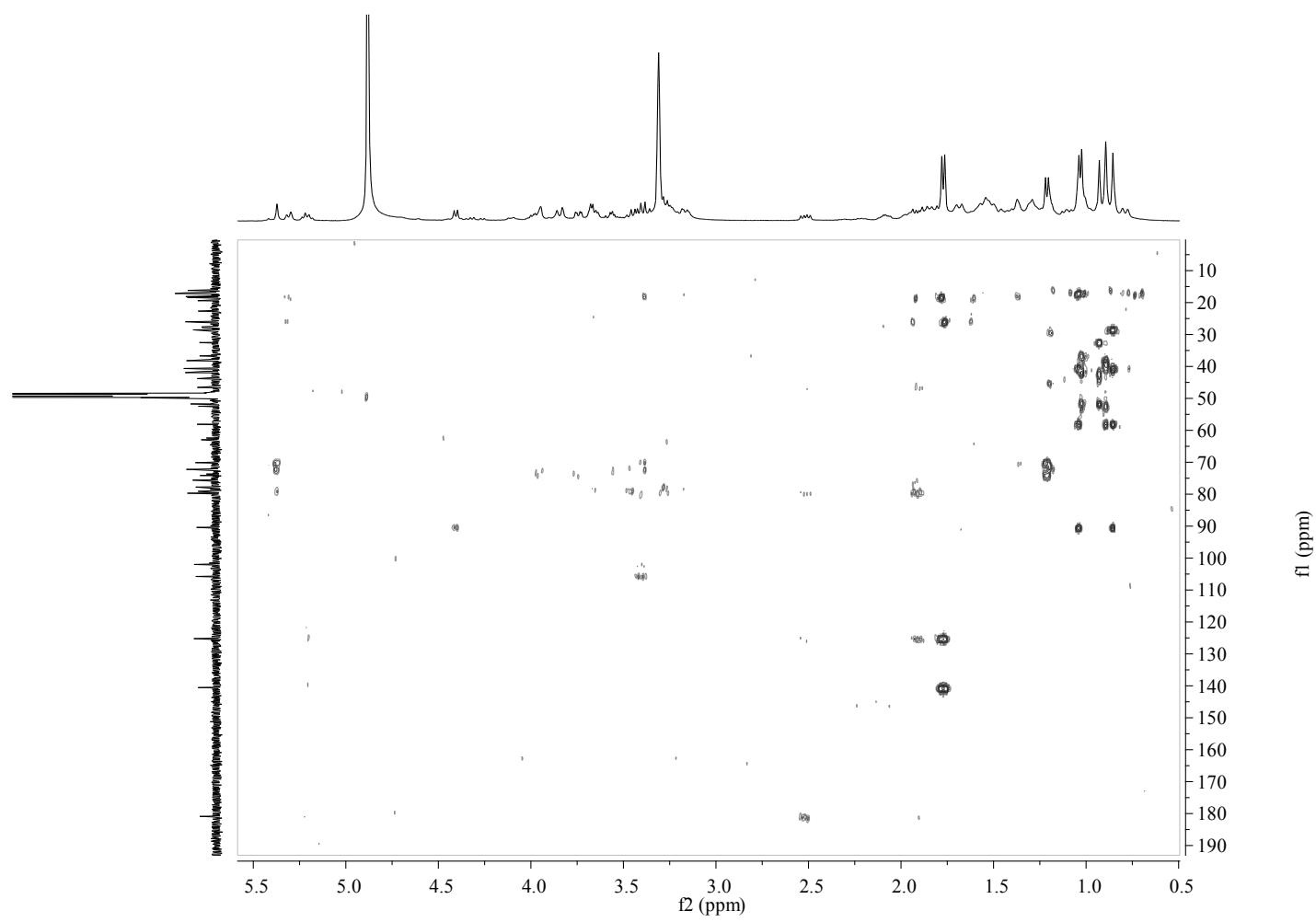


Figure S35. NOESY spectrum of compound 17 in MeOH- $d_{4}$

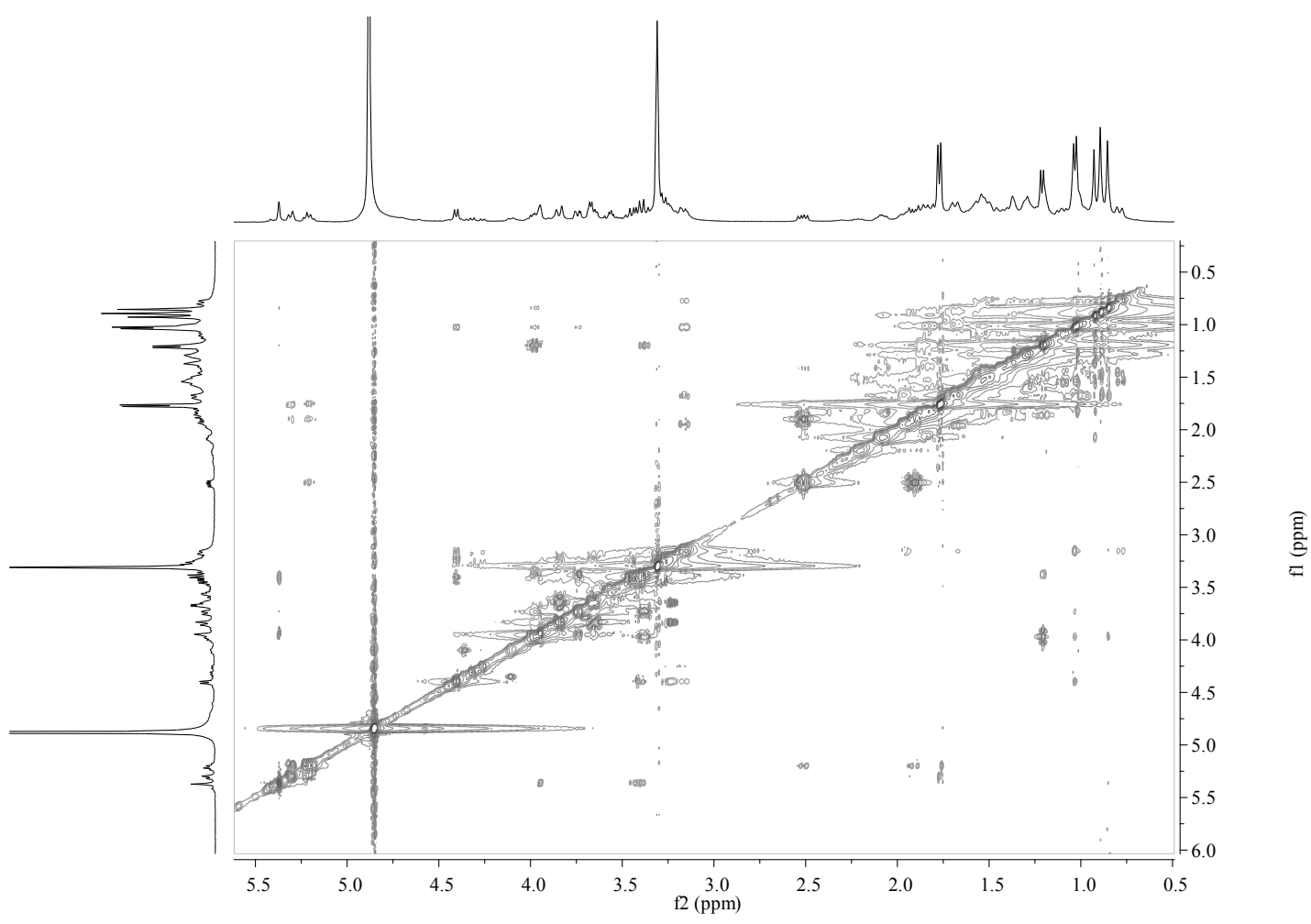

Figure S36. HRESIMS of compound 18

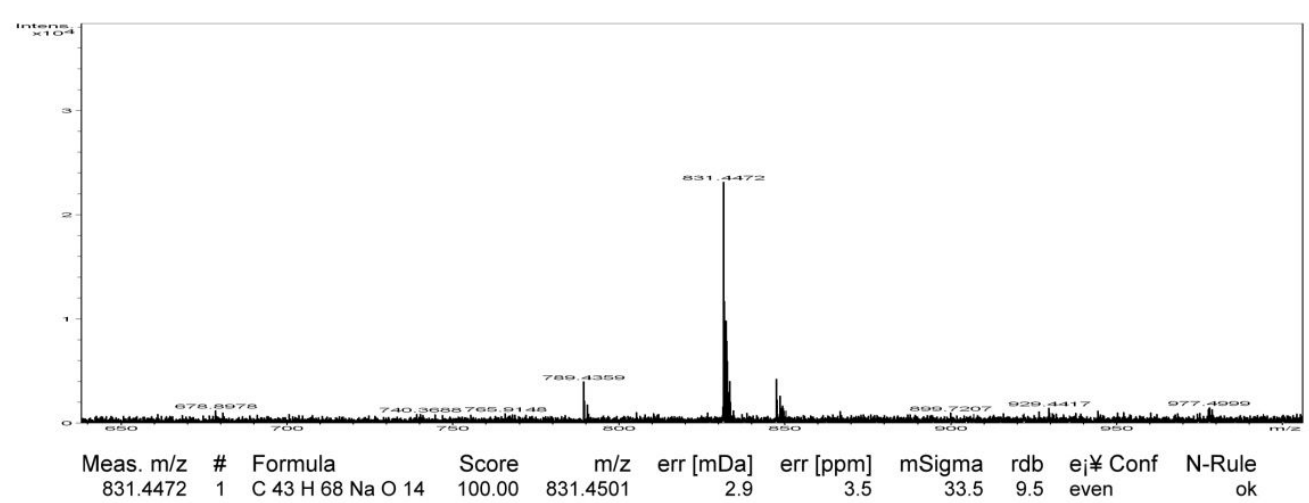


Figure S37. IR spectrum of compound 18

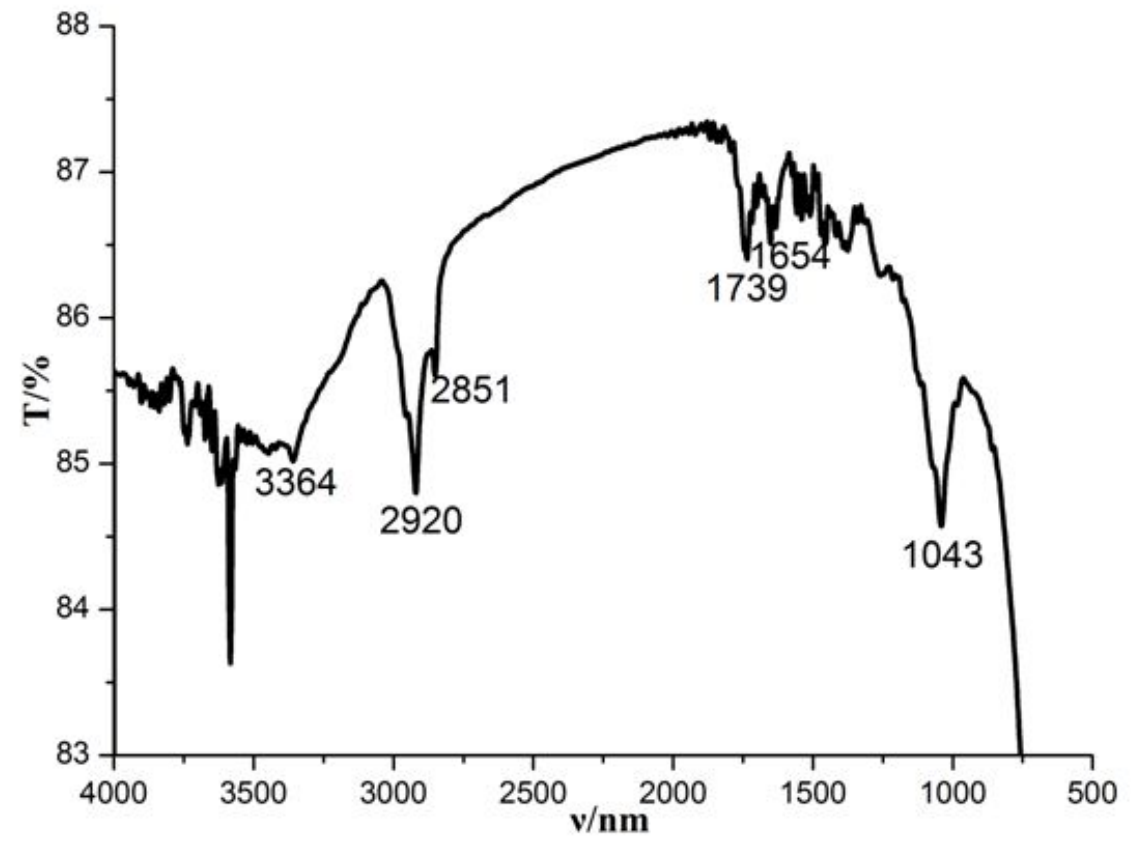

Figure S38. ${ }^{1} \mathrm{H}$ NMR (400 MHz, MeOH- $d_{4}$ ) spectrum of compound 18

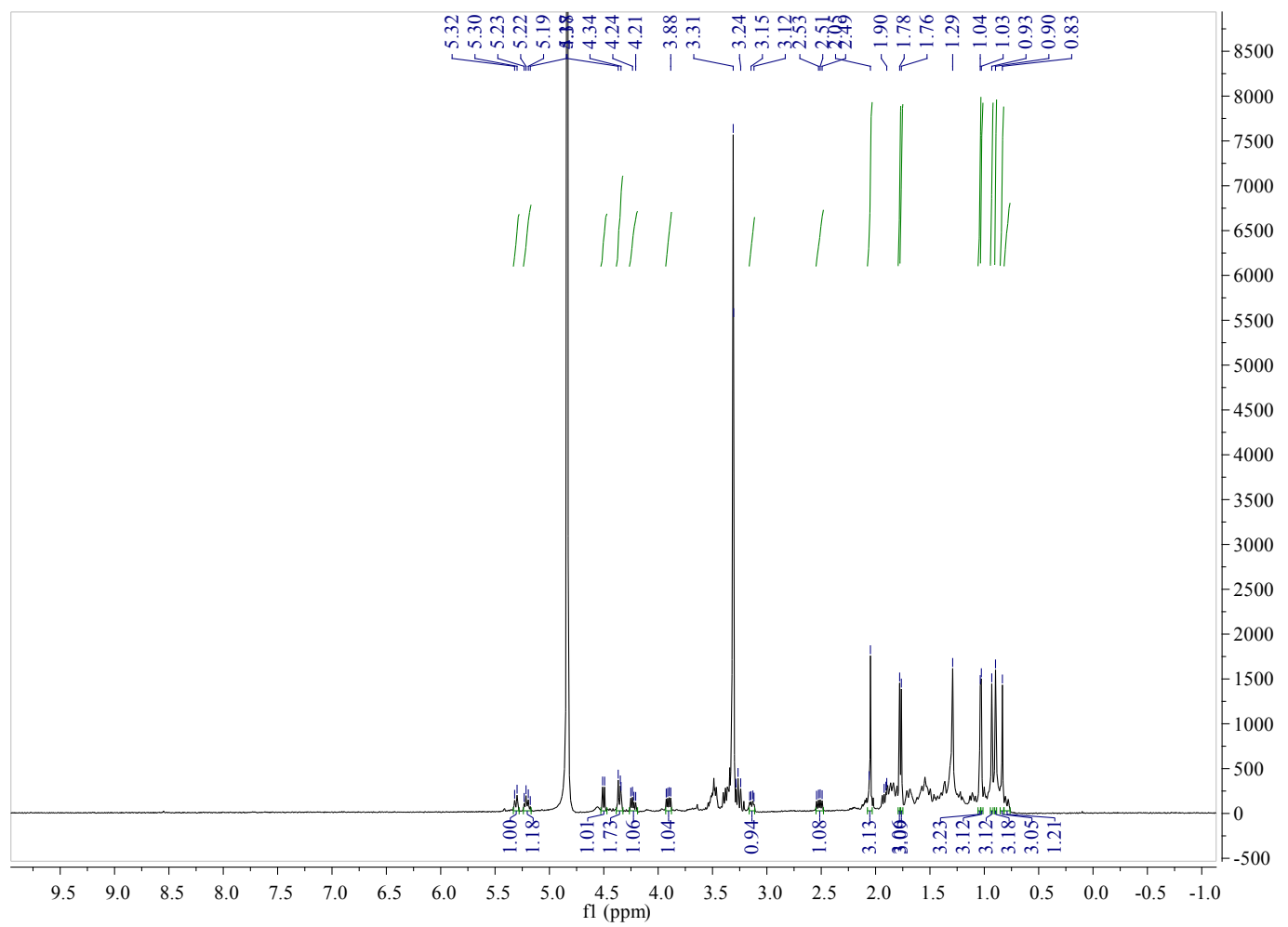


Figure S39. ${ }^{13} \mathrm{C}$ NMR $\left(100 \mathrm{MHz}, \mathrm{MeOH}-d_{4}\right)$ spectrum of compound 18

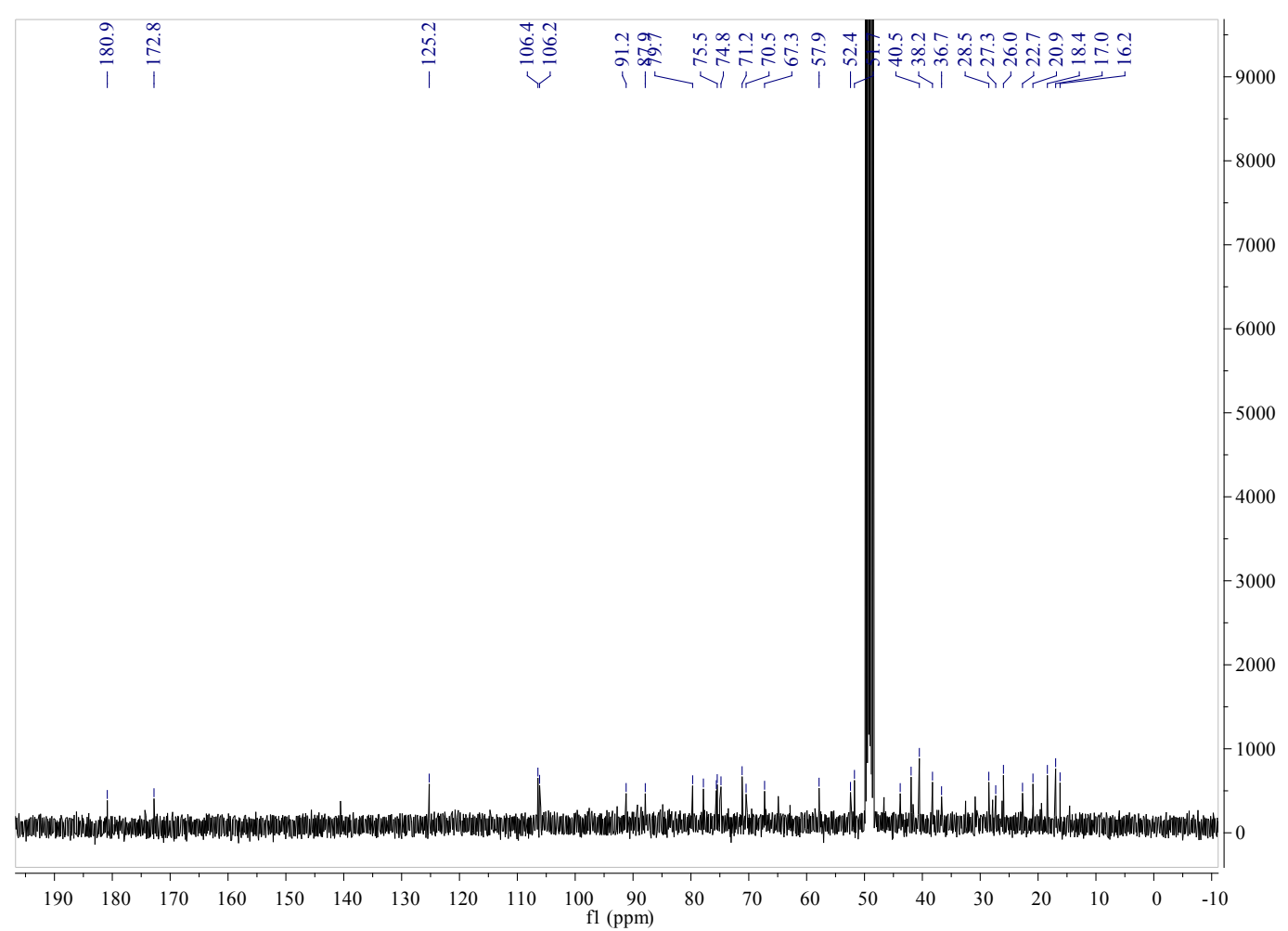

Figure S40. HSQC spectrum of compound 18 in $\mathrm{MeOH}-d_{4}$

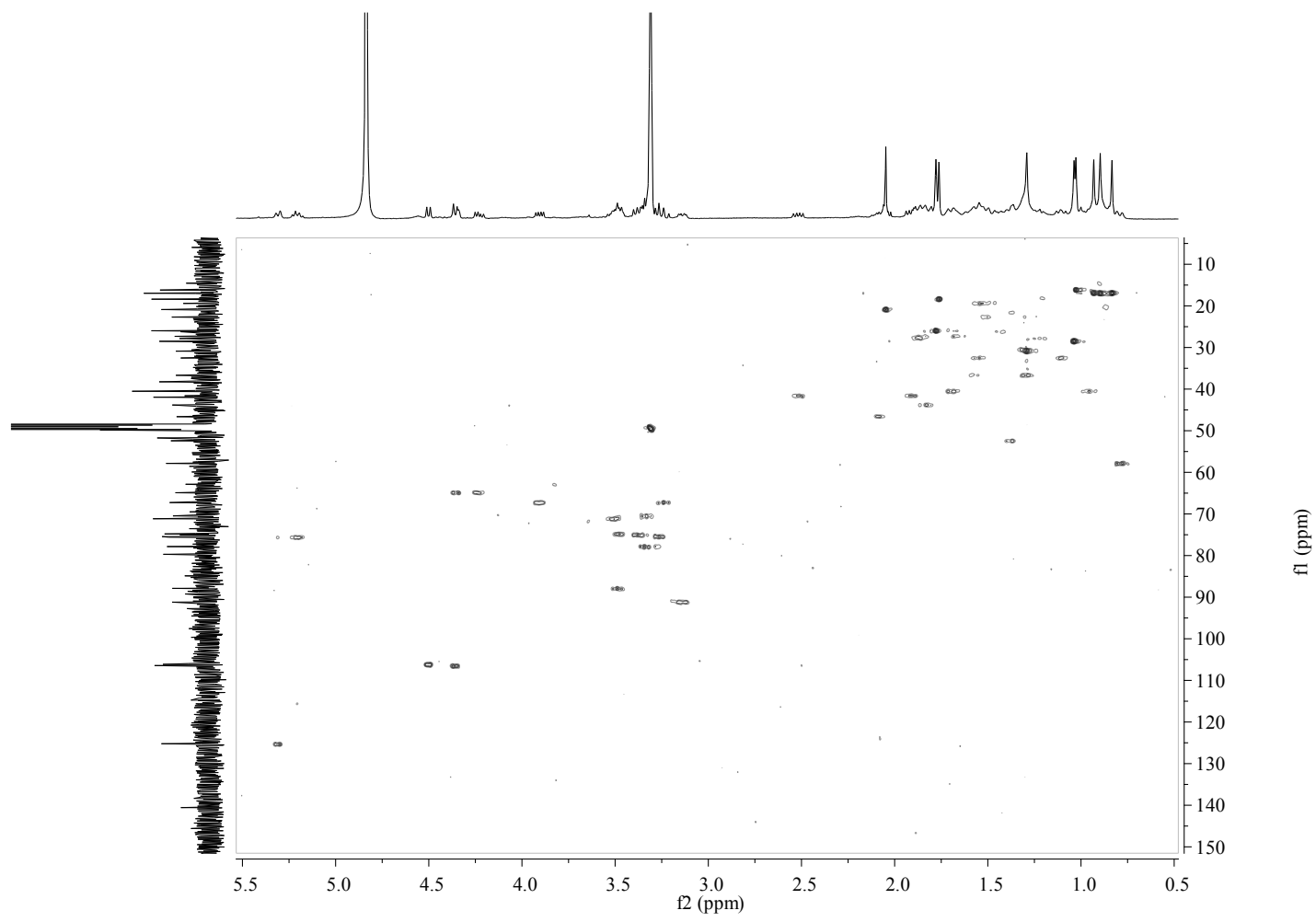


Figure S41. HMBC spectrum of compound 18 in $\mathrm{MeOH}-d_{4}$

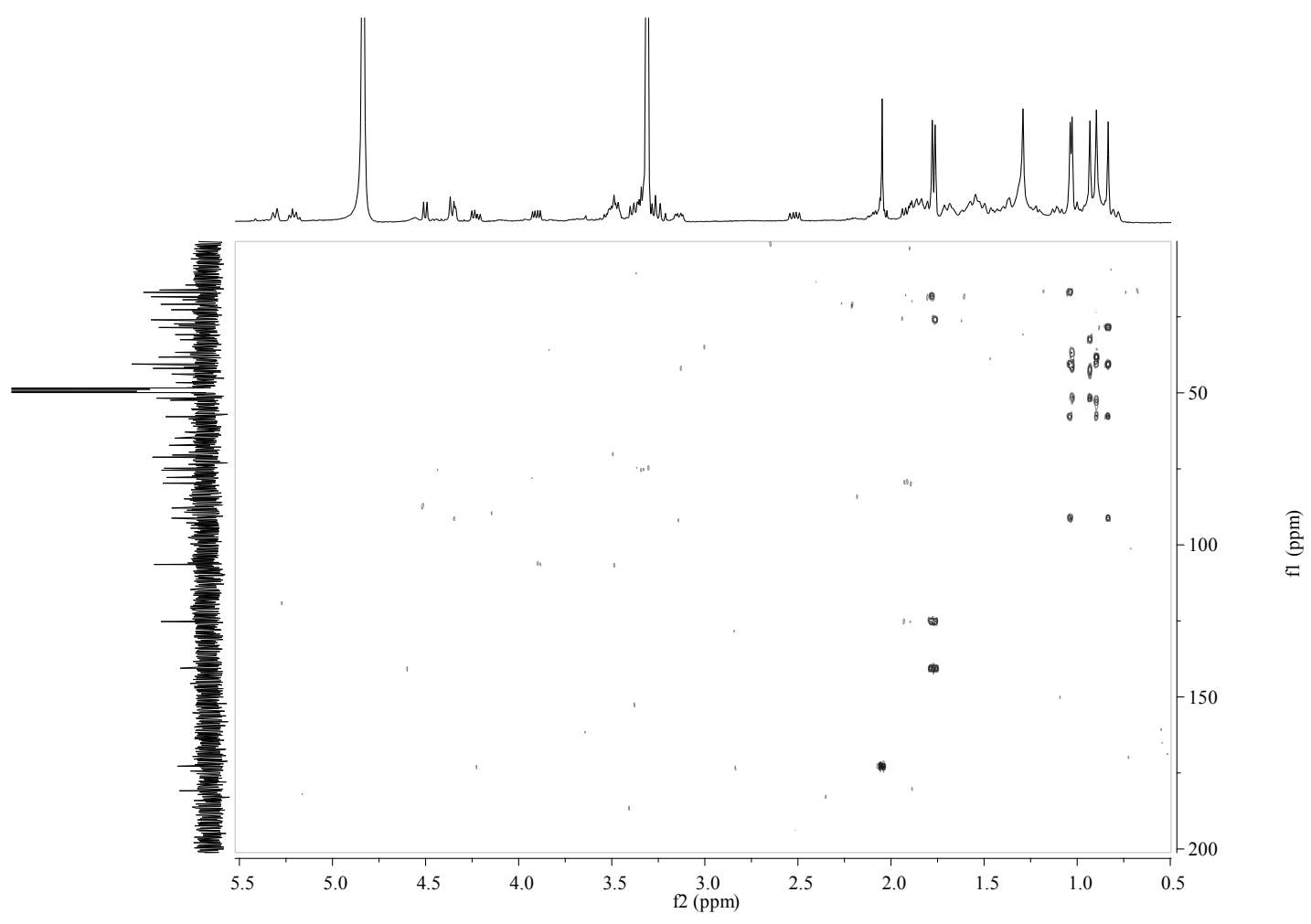

Figure S42. NOESY spectrum of compound 18 in MeOH- $d_{4}$

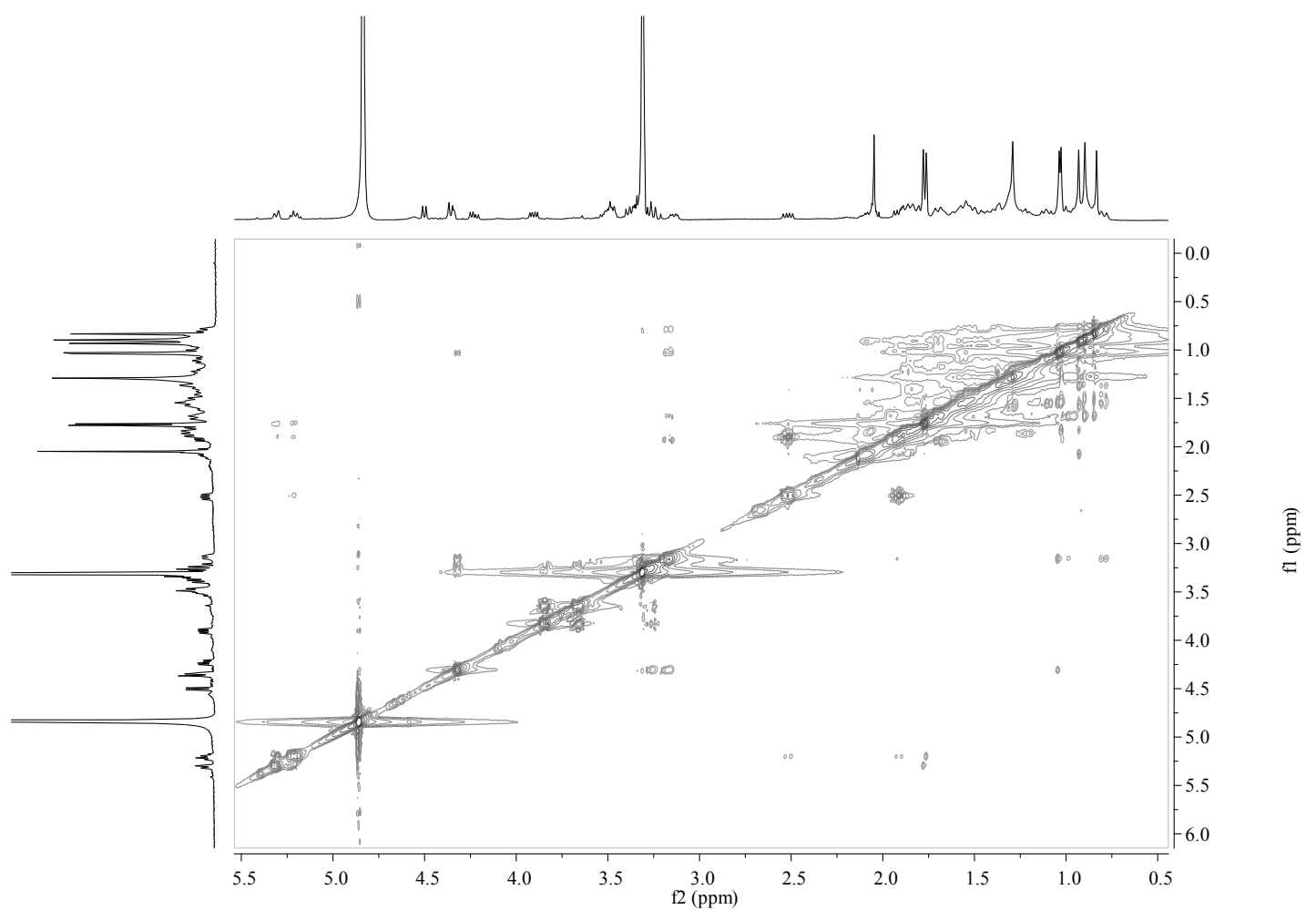


Figure S43. ${ }^{1} \mathrm{H}$ NMR (400 MHz, DMSO- $\left.d_{6}\right)$ spectrum of compound 3

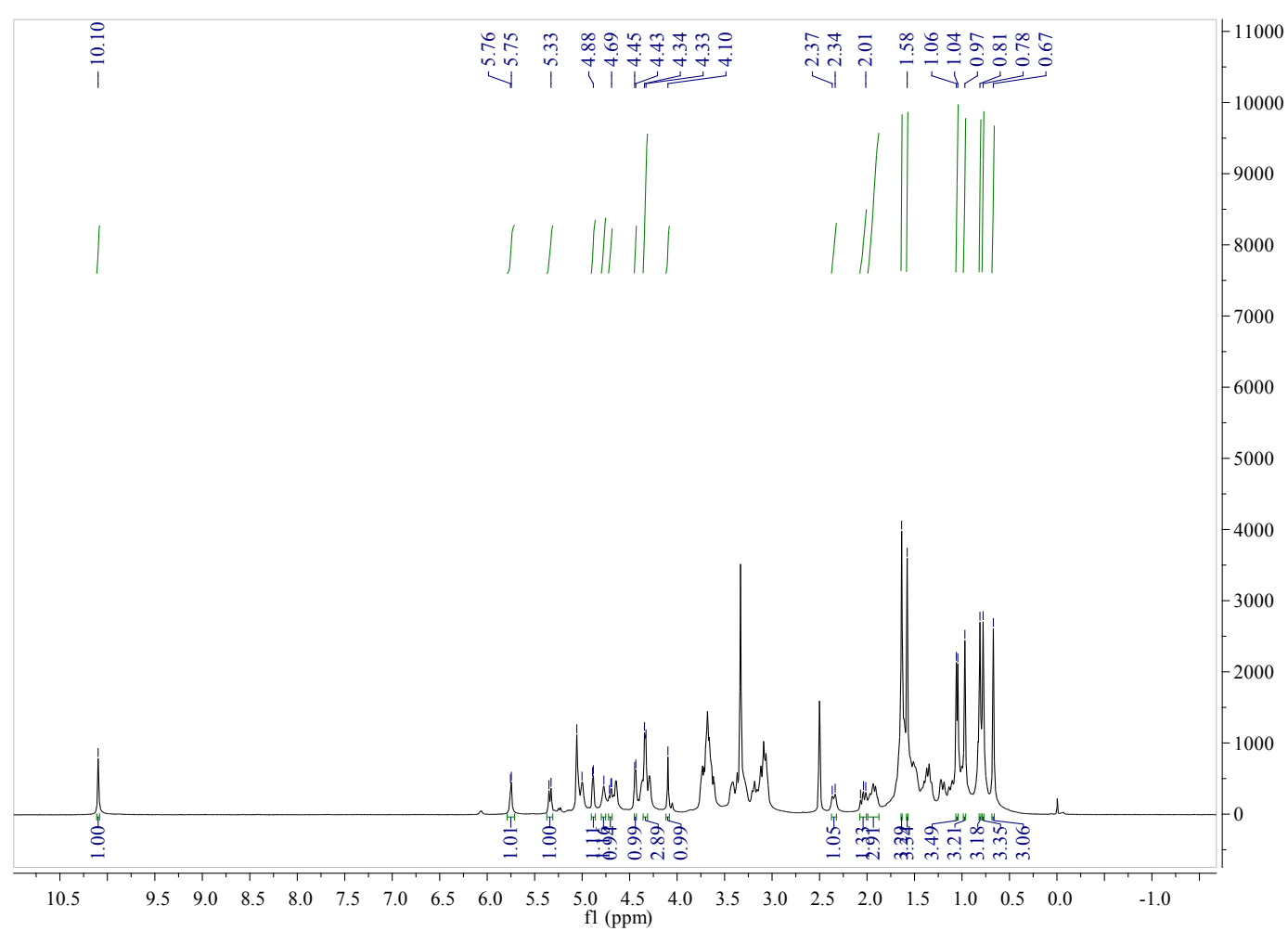

Figure S44. ${ }^{13} \mathrm{C}$ NMR (100 MHz, DMSO- $\left.d_{6}\right)$ spectrum of compound 3

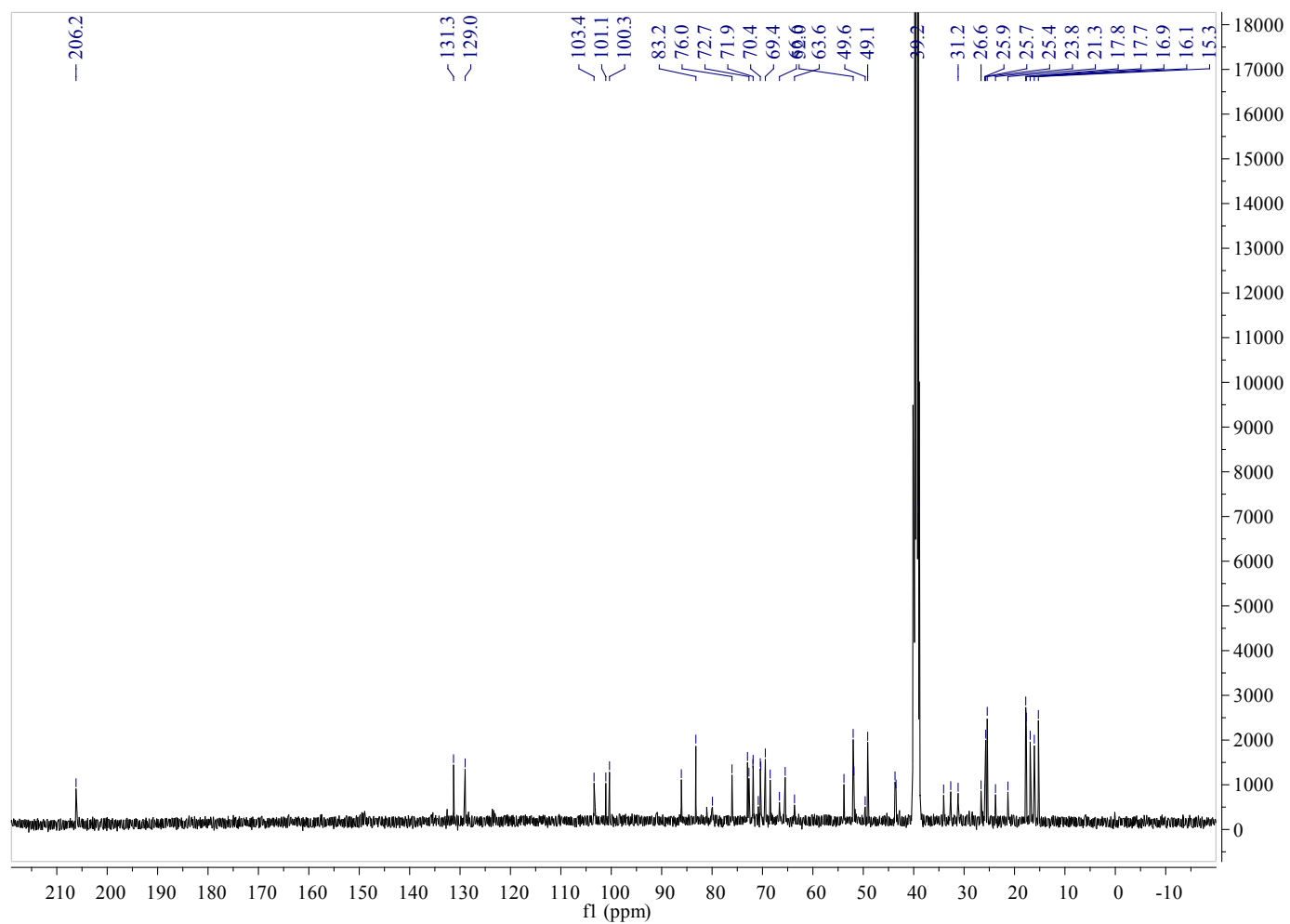


Figure S45. HSQC spectrum of compound 3 in DMSO- $d_{6}$

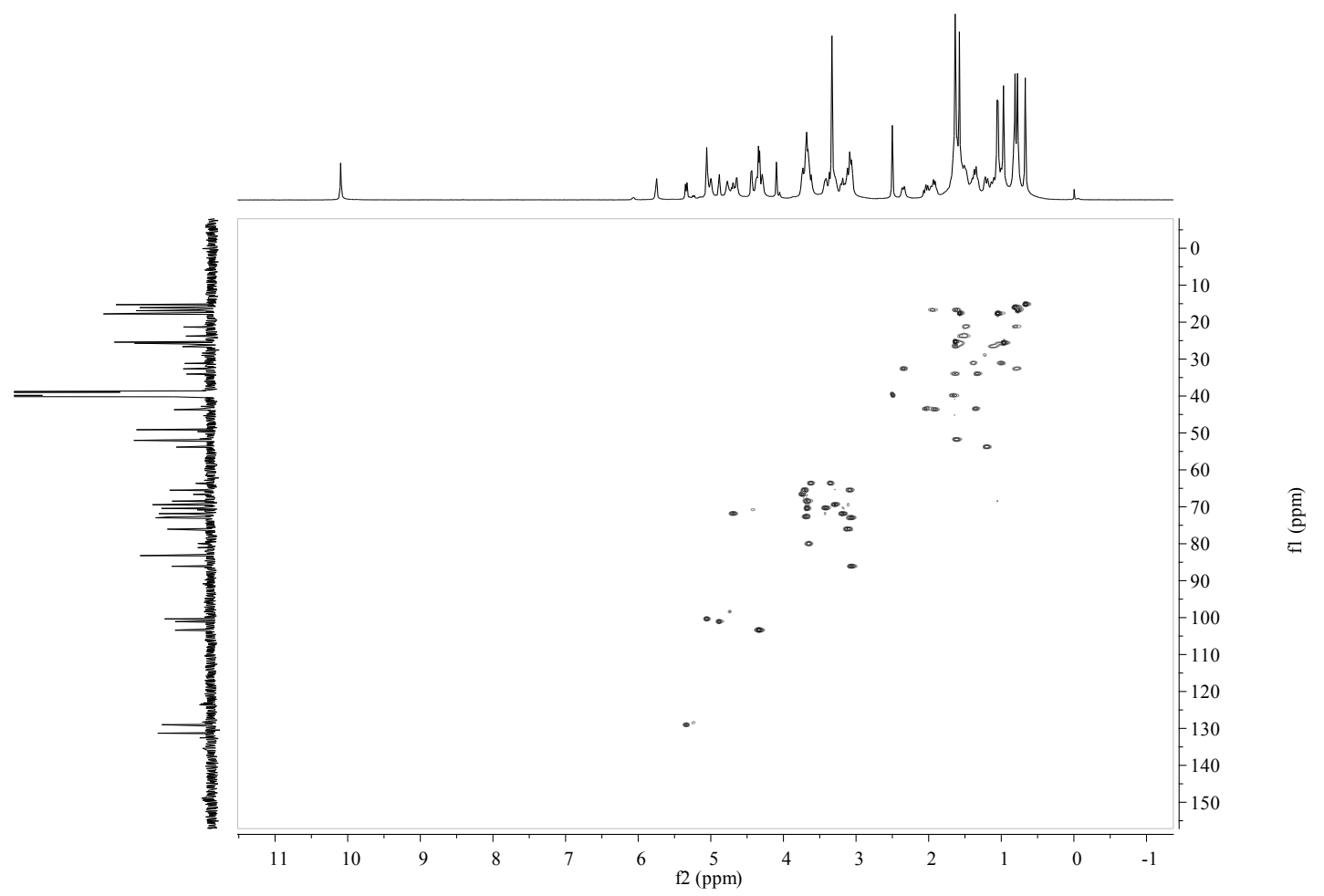

Figure S46. HMBC spectrum of compound 3 in DMSO- $d_{6}$ 


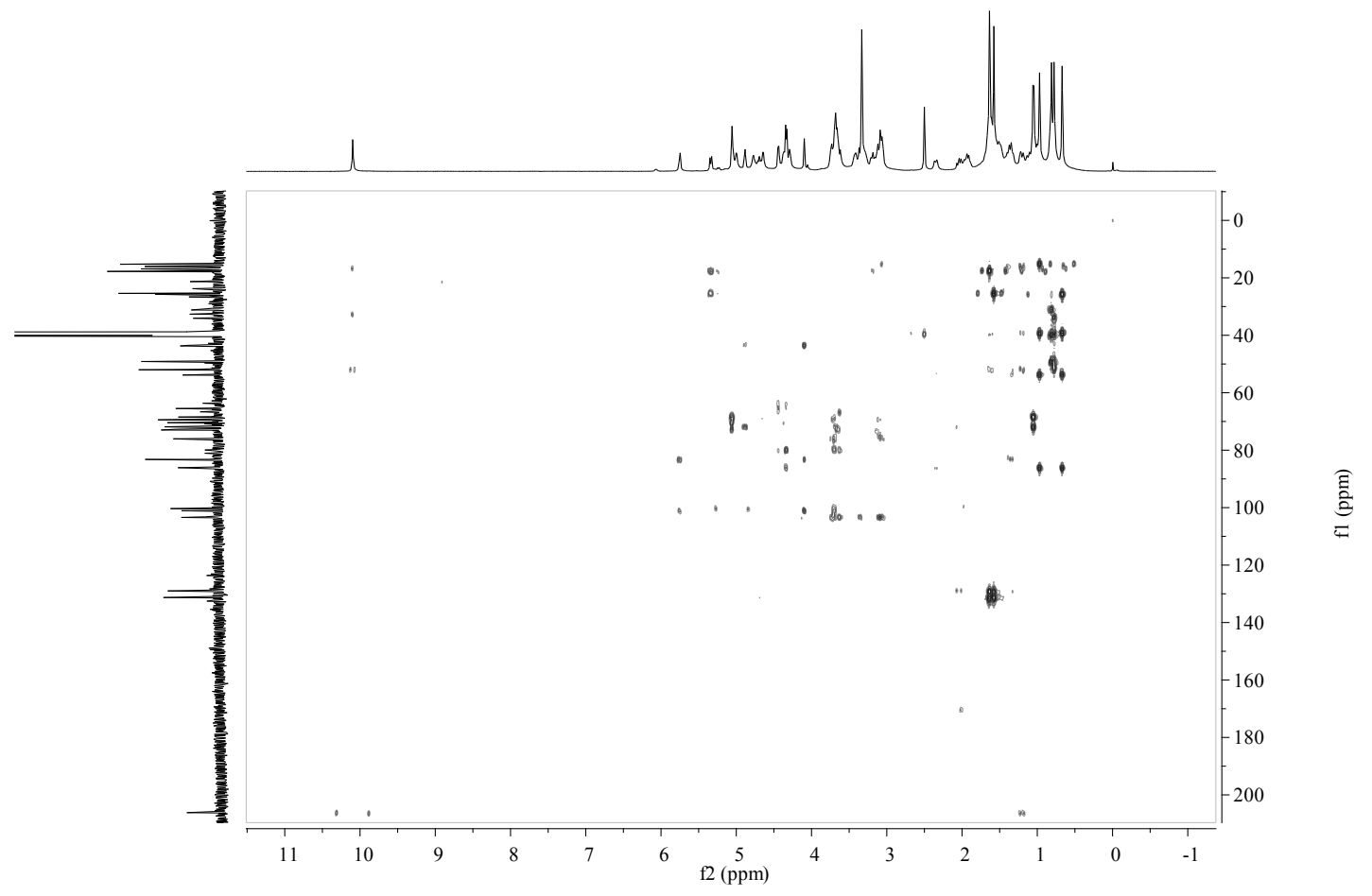

Figure S47. NOESY spectrum of compound 3 in DMSO- $d_{6}$

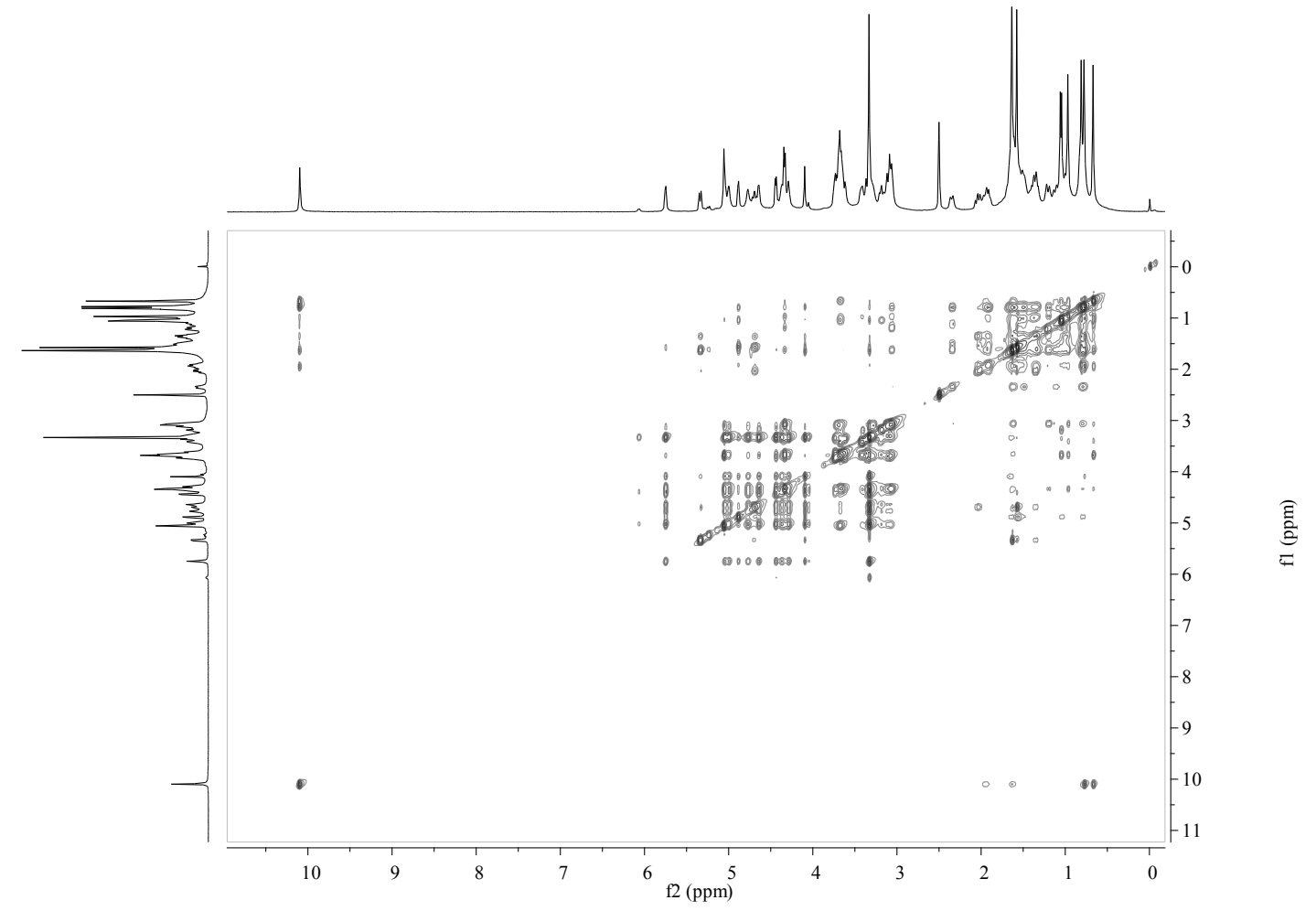


Figure S48. ${ }^{1} \mathrm{H}$ NMR $\left(400 \mathrm{MHz}, \mathrm{CDCl}_{3}\right)$ spectrum of compound a

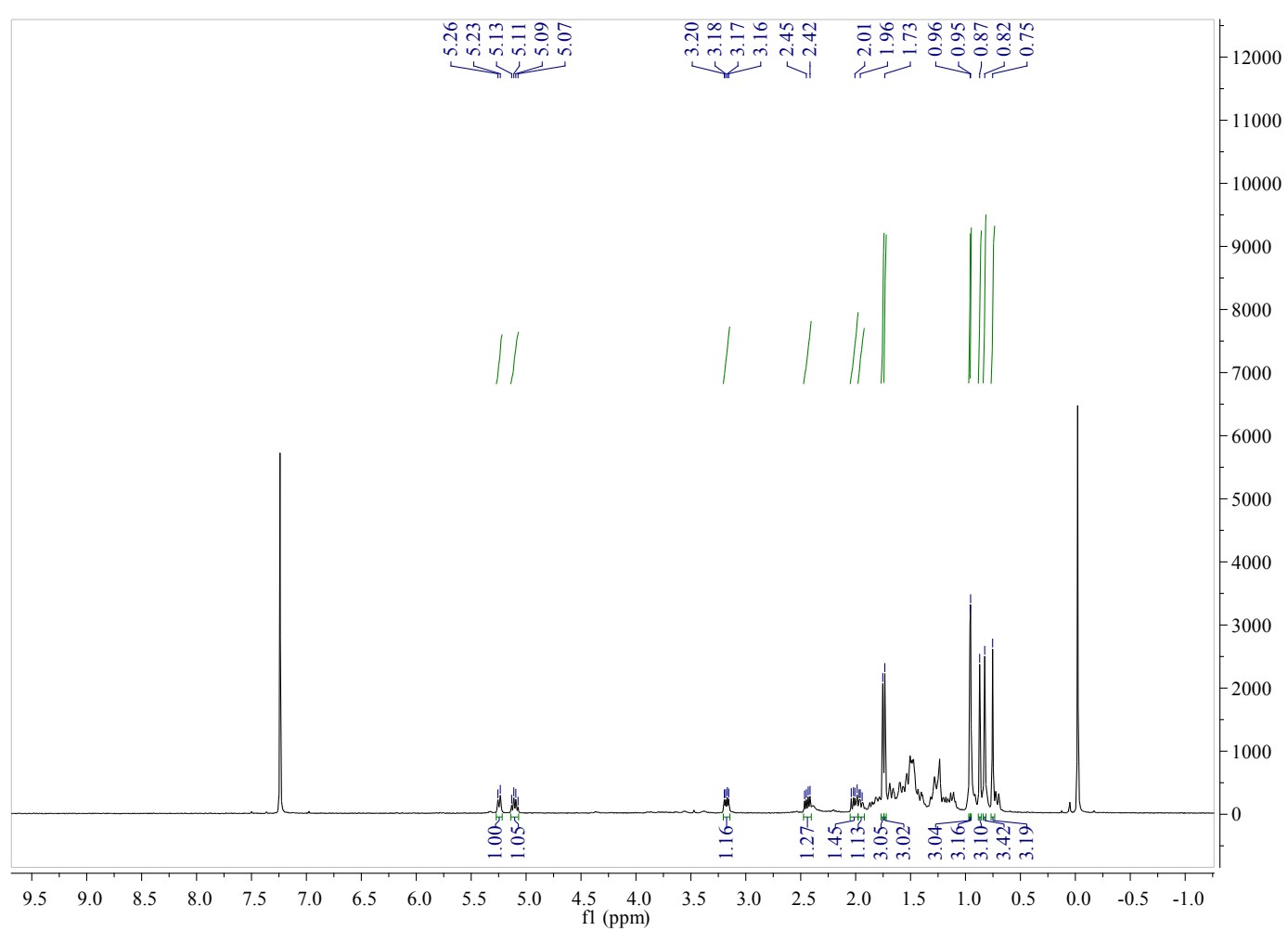

Figure S49. ${ }^{13} \mathrm{C} \mathrm{NMR}\left(100 \mathrm{MHz}, \mathrm{CDCl}_{3}\right)$ spectrum of compound a

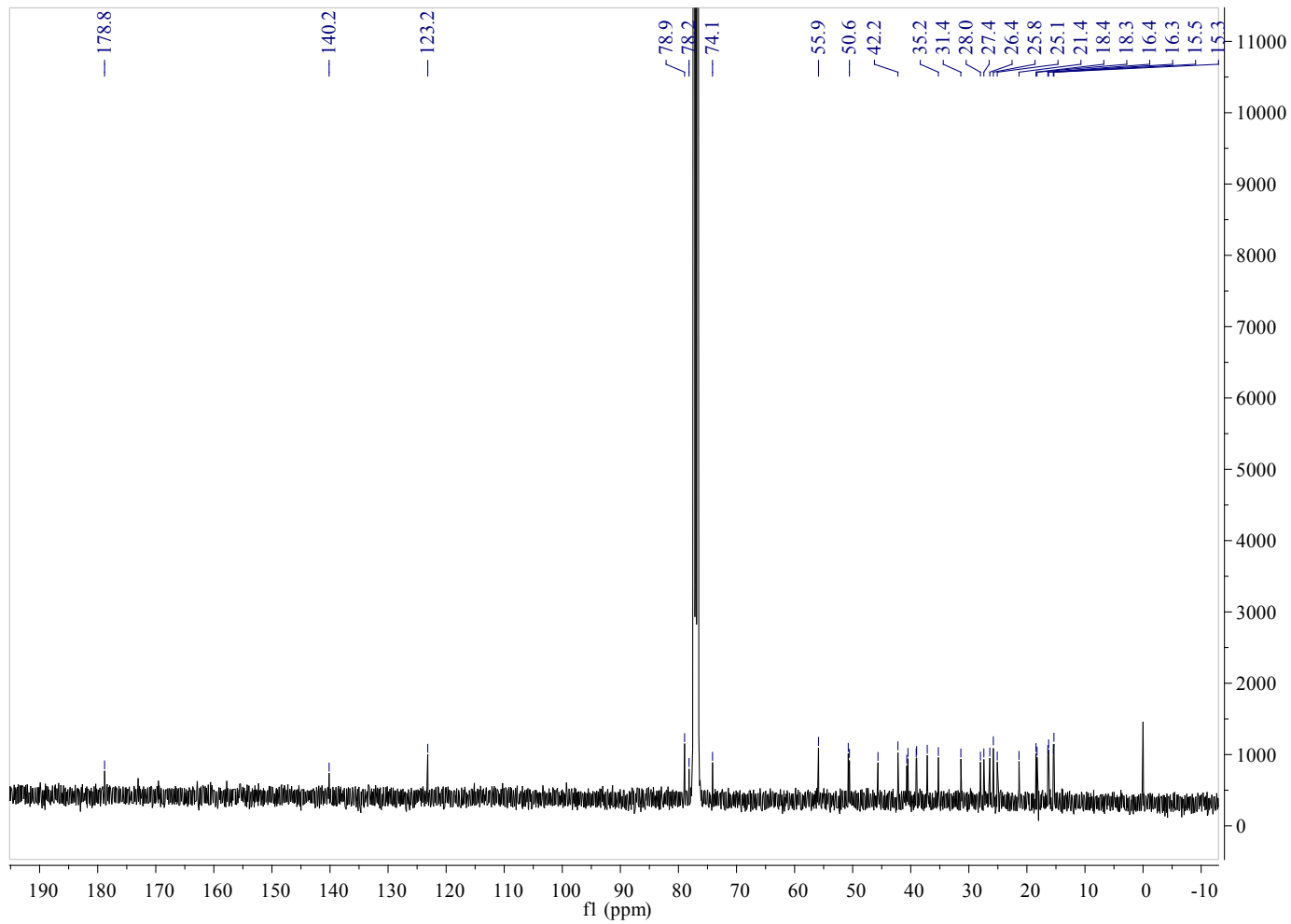


Figure S50. ${ }^{1} \mathrm{H}$ NMR $\left(400 \mathrm{MHz}, \mathrm{DMSO}-d_{6}\right)$ spectrum of compound a

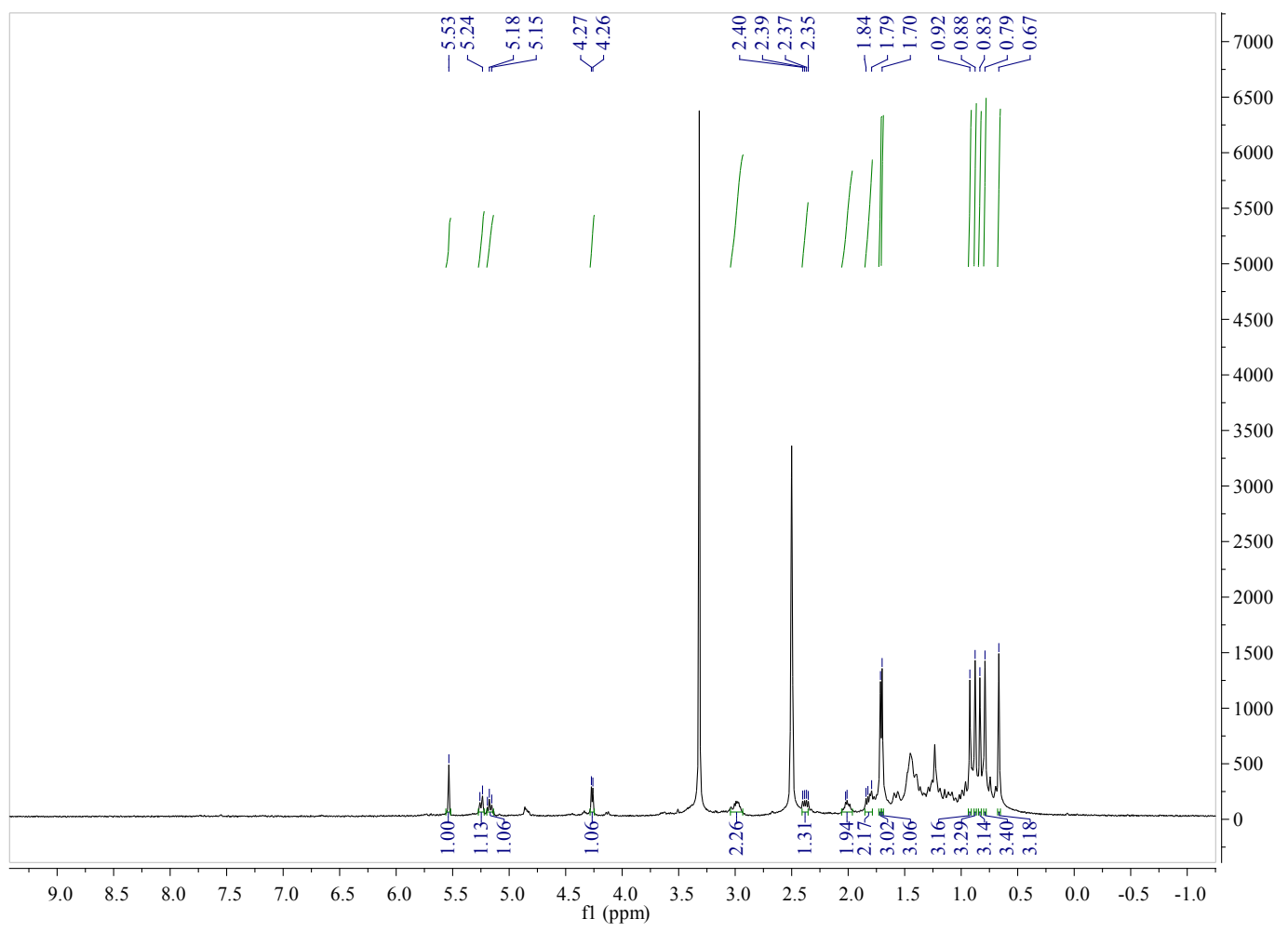

Figure S51. ${ }^{13} \mathrm{C}$ NMR $\left(100 \mathrm{MHz}, \mathrm{DMSO}-d_{6}\right)$ spectrum of compound a

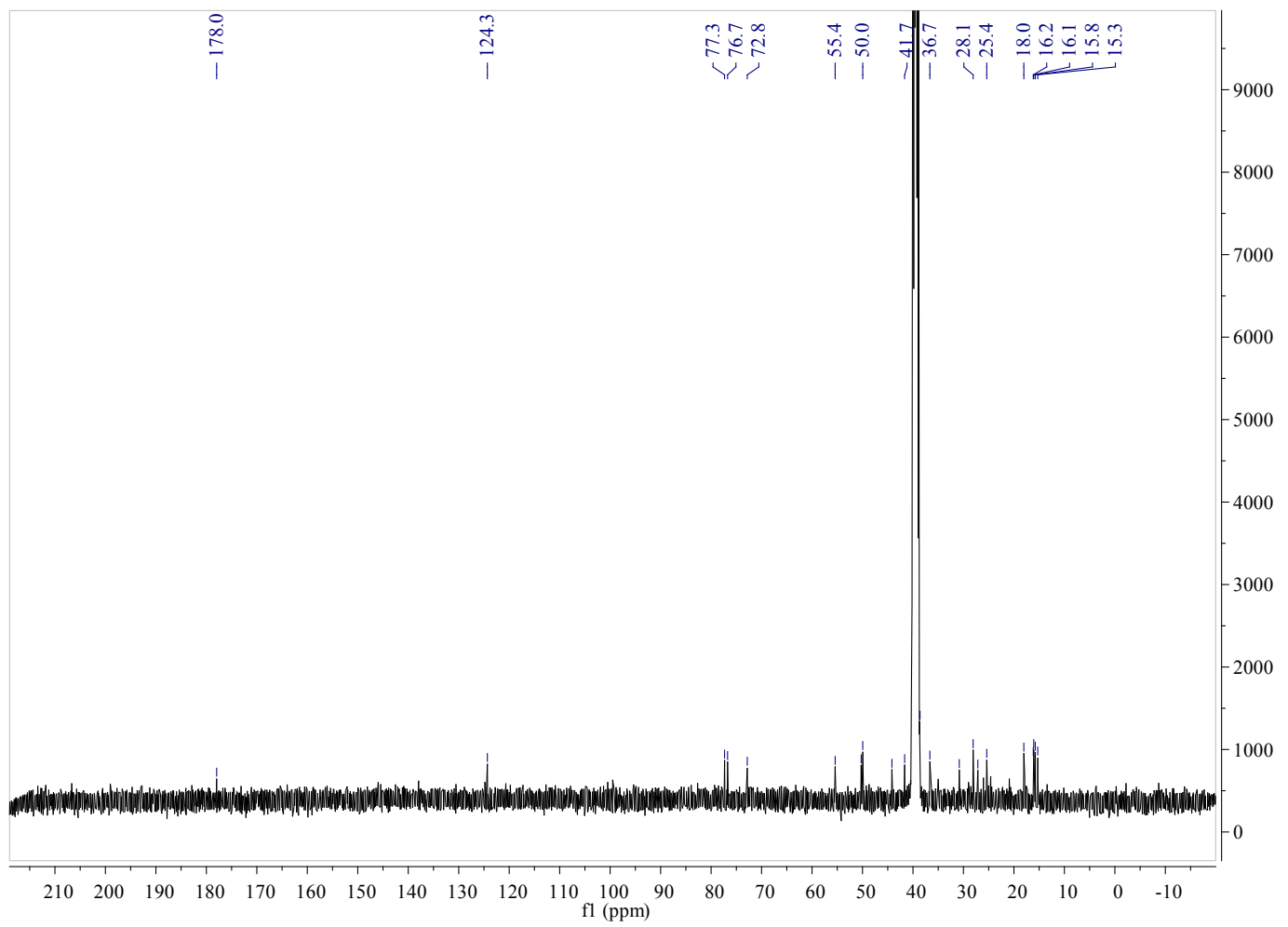


Figure S52. HSQC spectrum of compound a in DMSO- $d_{6}$

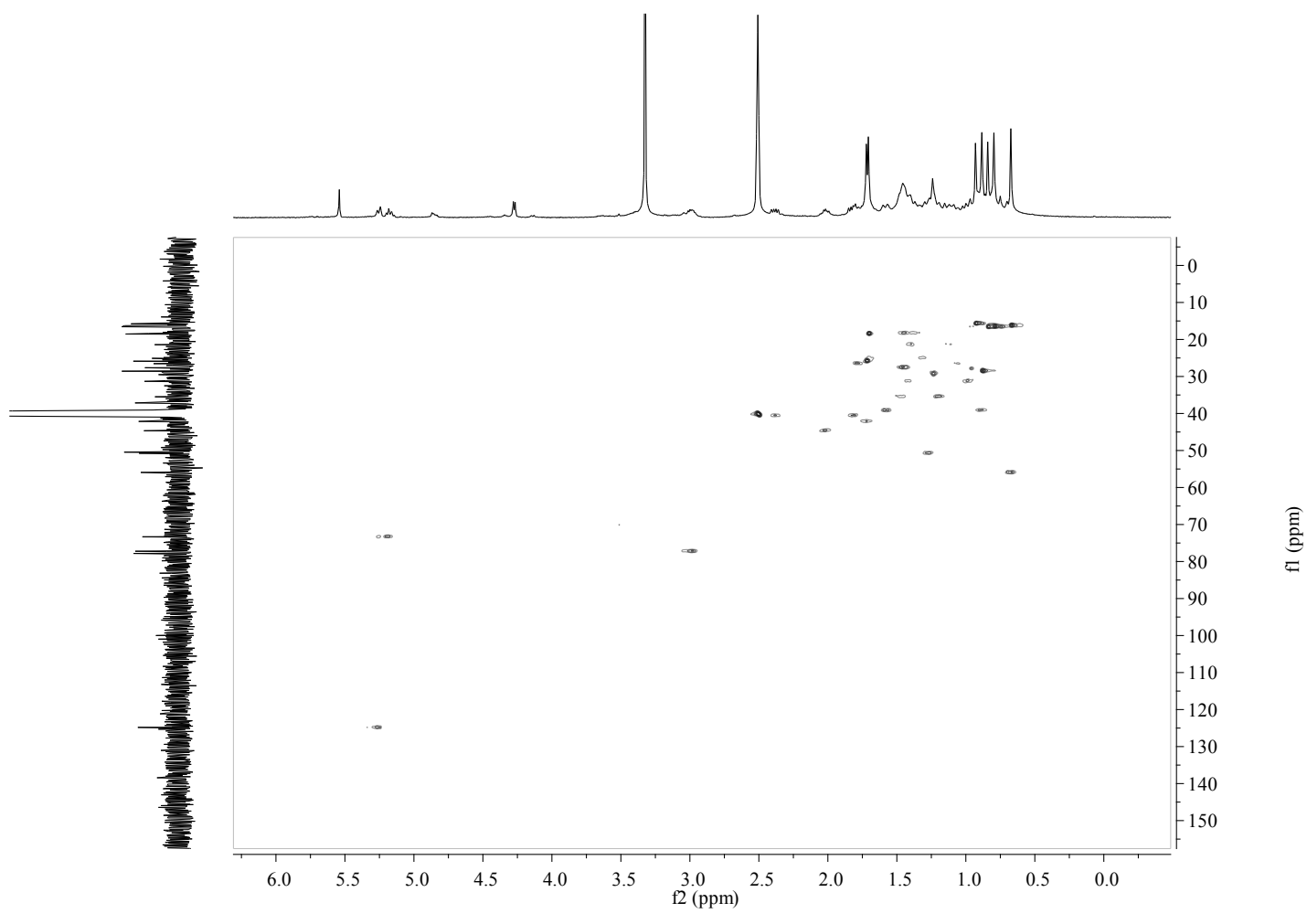

Figure S53. REOSY spectrum of compound a in DMSO- $d_{6}$

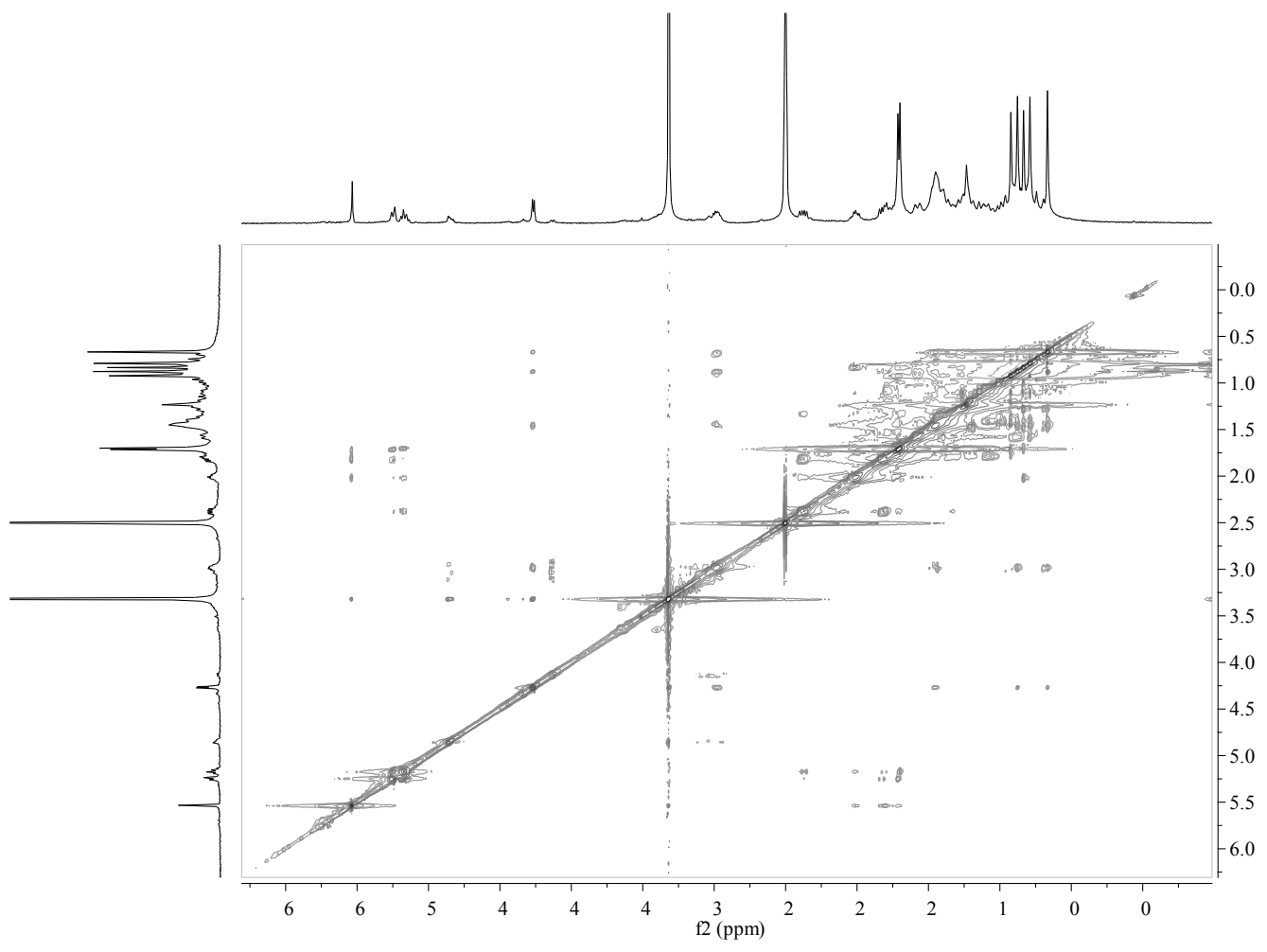

言 
Figure S54. ${ }^{1} \mathrm{H}$ NMR $\left(400 \mathrm{MHz}, \mathrm{CDCl}_{3}\right)$ spectrum of compound $\mathbf{b}$

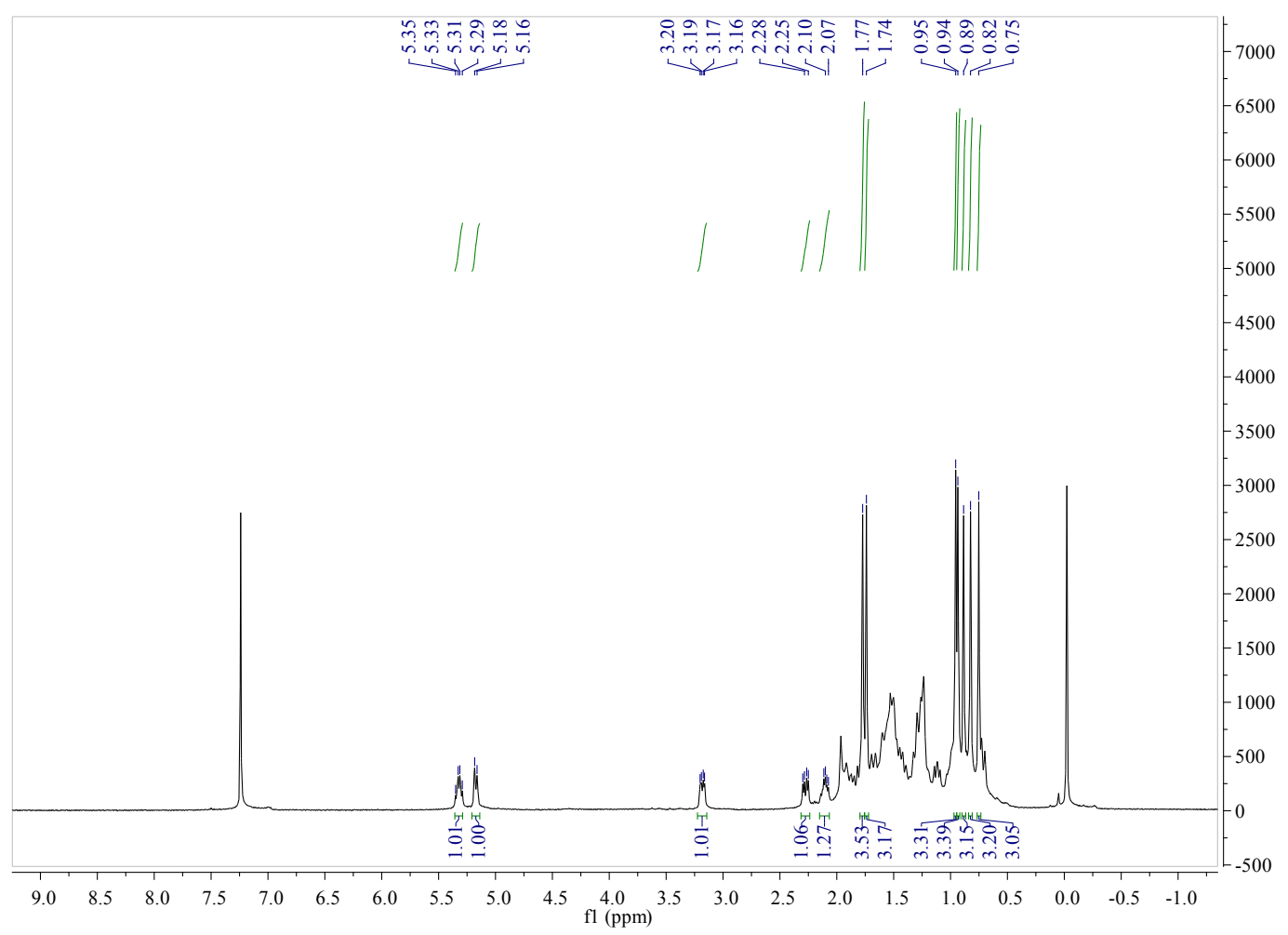

Figure S55. ${ }^{13} \mathrm{C} \mathrm{NMR}\left(100 \mathrm{MHz}, \mathrm{CDCl}_{3}\right)$ spectrum of compound $\mathbf{b}$

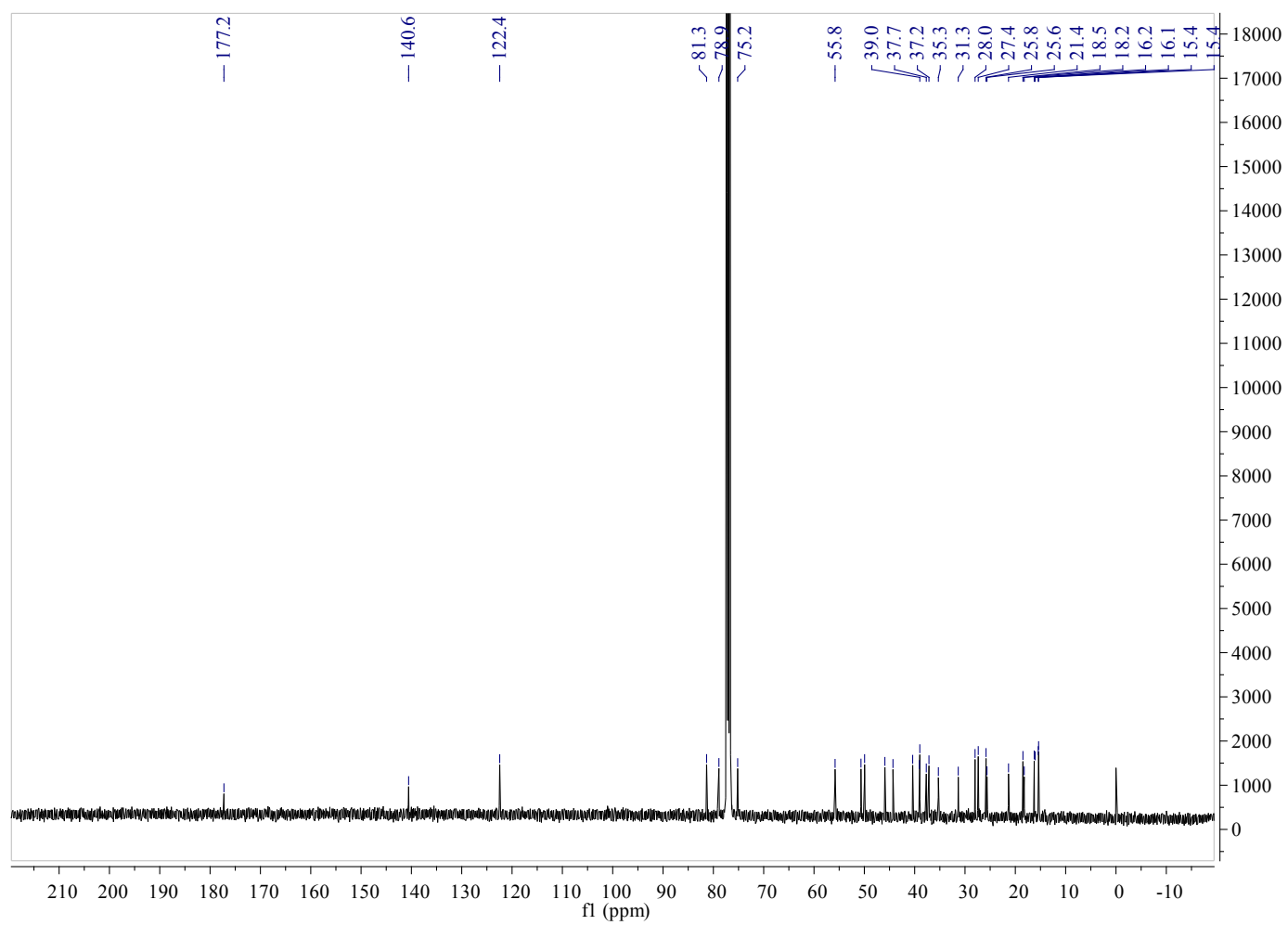


Figure S56. ${ }^{1} \mathrm{H}$ NMR $\left(400 \mathrm{MHz}, \mathrm{DMSO}-d_{6}\right)$ spectrum of compound $\mathbf{b}$

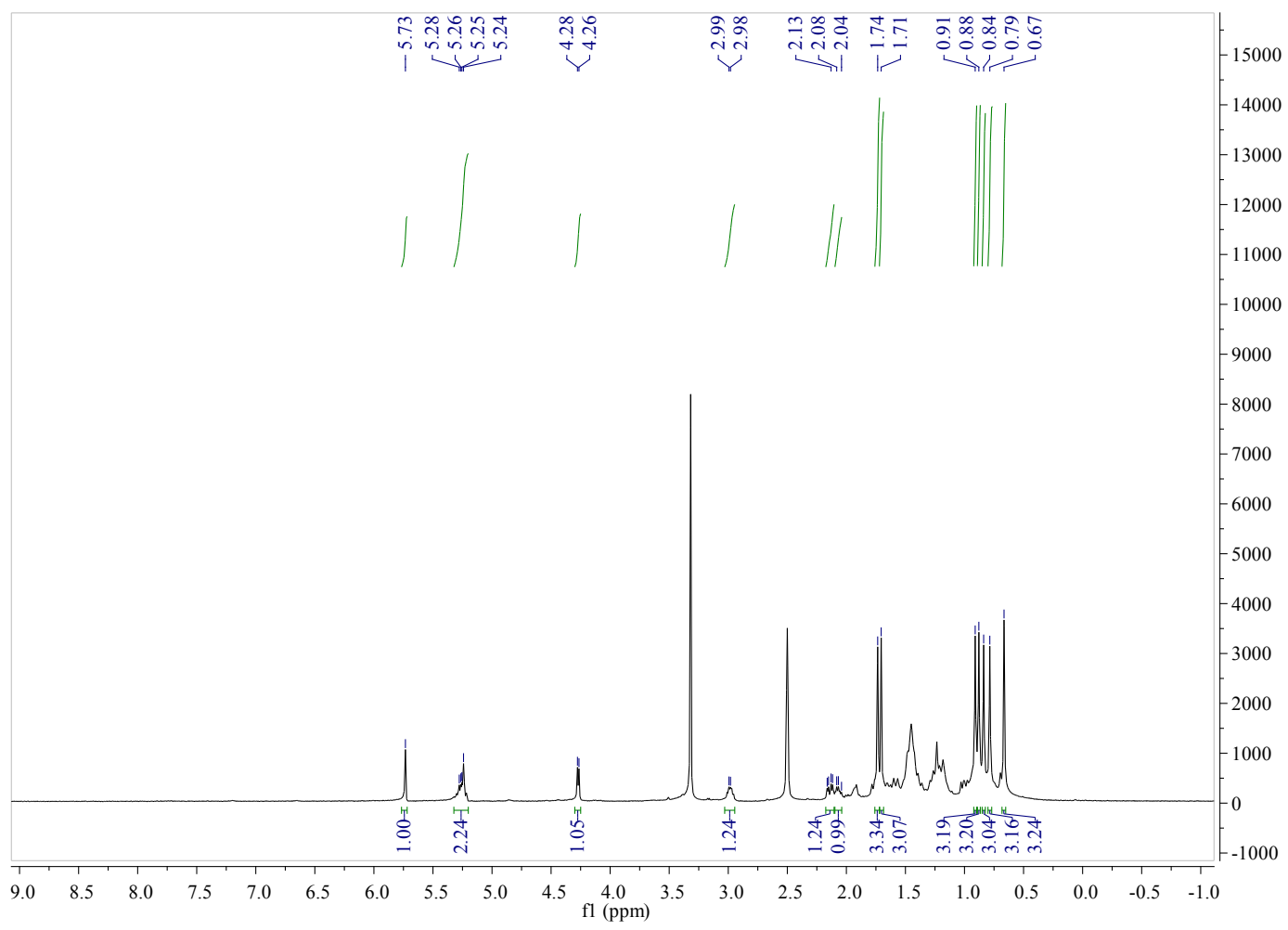

Figure S57. ${ }^{13} \mathrm{C}$ NMR (100 MHz, DMSO- $\left.d_{6}\right)$ spectrum of compound $\mathbf{b}$

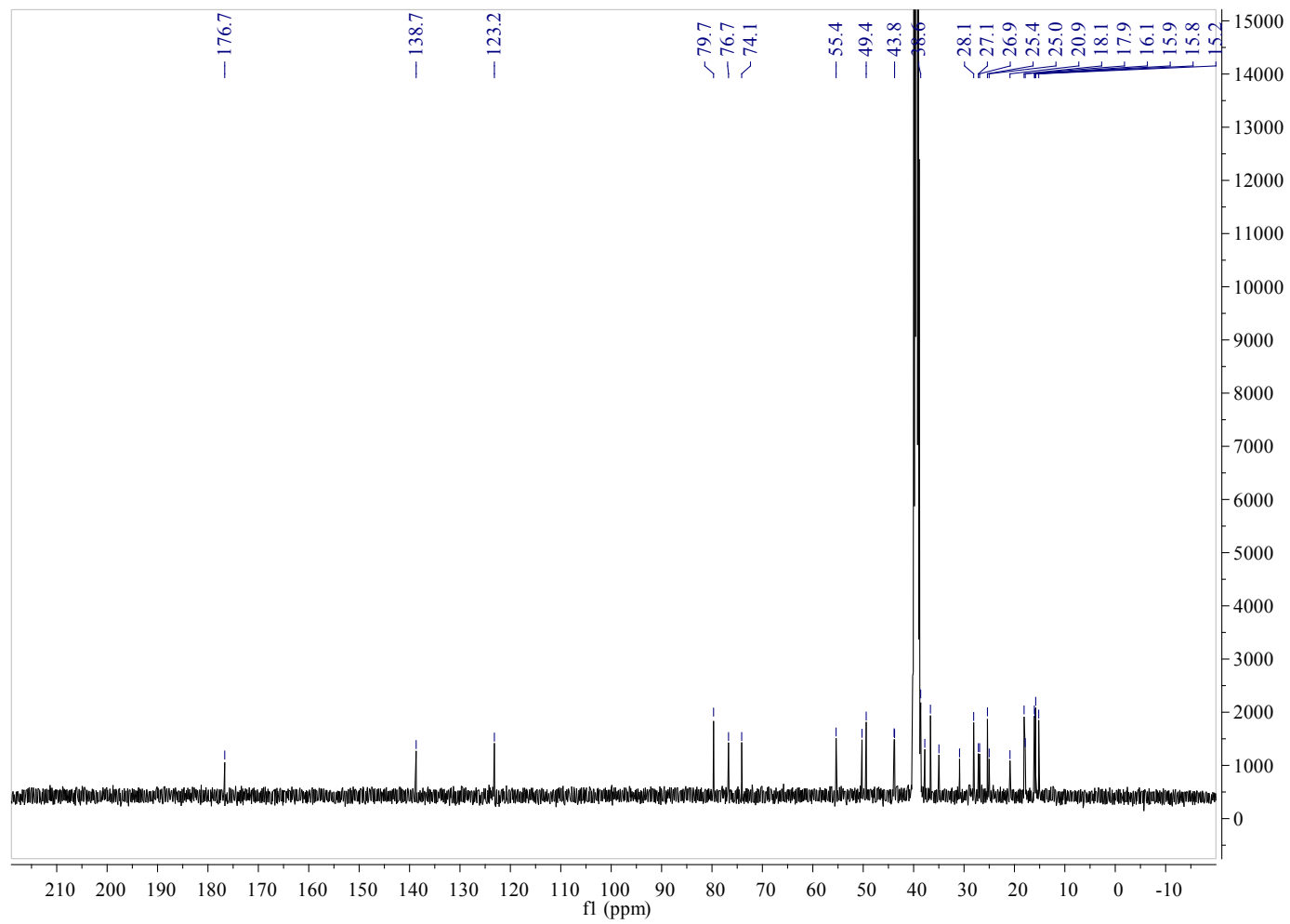


Figure S58. HSQC spectrum of compound $\mathbf{b}$ in DMSO- $d_{6}$

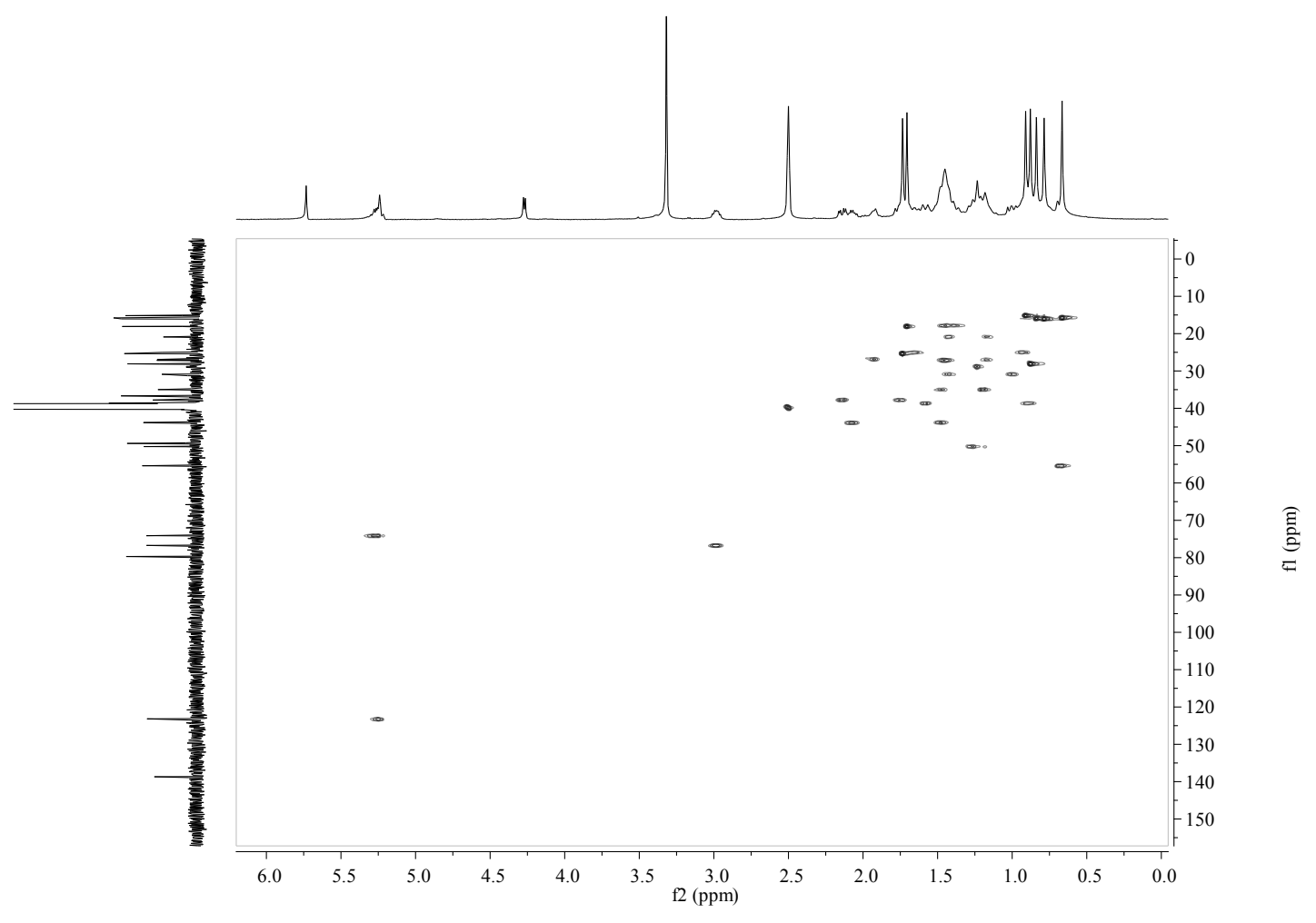

Figure S59. REOSY spectrum of compound $\mathbf{b}$ in DMSO- $d_{6}$

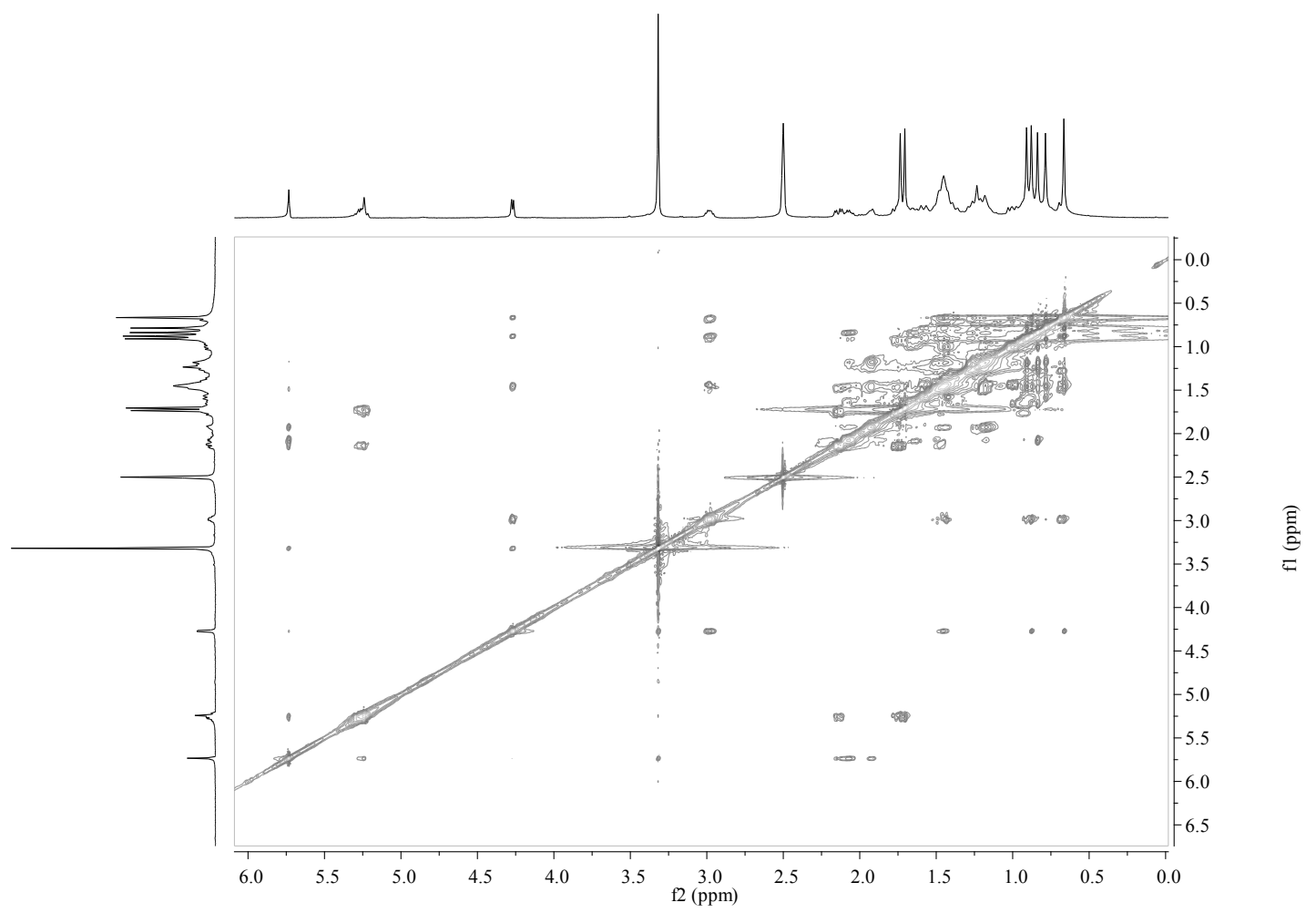


Extraction and Isolation. The aerial parts of G. pentaphyllum $(2.0 \mathrm{~kg})$ were dried and extracted successively with $70 \%$ aqueous ethanol solution $(3 \times 1 \mathrm{~L}$, three days for each time) at room temperature. A concentrated crude residue (30.0 g) was subjected to D101 macroporous resin eluting with $\mathrm{MeOH}-\mathrm{H}_{2} \mathrm{O}$ gradient $(0: 100,30$ : 70, 60: 40, 90: 10, 100: 0, v/v) to give six fractions A-F according to TLC analyses. PC12 cells viability indicated anti-hypoxia activity in the D fraction. Therefore, fraction $\mathrm{D}$ was further separated by $\mathrm{C}_{18}$ reverse phase silica gel column eluting with $\mathrm{MeOH}-\mathrm{H}_{2} \mathrm{O}$ gradient (50:50 to 100:0, v/v) to six fractions F1-F6. F1 was chromatographed over a silica gel eluting with with EtOAC-MeOH (20:1 to 1:1, v/v) to yield compounds $\mathbf{8}(36.9 \mathrm{mg})$ and $\mathbf{1 1}(9.5 \mathrm{mg})$. F2 was separated over preparative HPLC $\left(\mathrm{MeOH} / \mathrm{H}_{2} \mathrm{O}=70 / 30\right.$; flow rate: $\left.10 \mathrm{~mL} / \mathrm{min}\right)$ to get the compound $1(60.0 \mathrm{mg}$; $\left.t_{\mathrm{R}}=25 \mathrm{~min}\right)$. Fraction F3 was separated by silica gel eluting with EtOAC-MeOH (10:1 to $1: 1, \mathrm{v} / \mathrm{v})$ to yield further subfraction F3a and F3b. F3a fraction was purified by pre-HPLC $\left(\mathrm{MeOH} / \mathrm{H}_{2} \mathrm{O}=70 / 30\right.$; flow rate: $\left.10 \mathrm{~mL} / \mathrm{min}\right)$ to afford the compounds 2 $\left(6.5 \mathrm{mg} ; t_{\mathrm{R}}=25 \mathrm{~min}\right), 3\left(33.7 \mathrm{mg} ; t_{\mathrm{R}}=34 \mathrm{~min}\right)$ and $4\left(11.3 \mathrm{mg} ; t_{\mathrm{R}}=62 \mathrm{~min}\right)$. The F3b fraction was separated by pre-HPLC $\left(\mathrm{MeOH} / \mathrm{H}_{2} \mathrm{O}=70 / 30\right.$; flow rate: $\left.10 \mathrm{~mL} / \mathrm{min}\right)$ to get saponin $10\left(14.2 \mathrm{mg} ; t_{\mathrm{R}}=8 \mathrm{~min}\right)$. F4 was subjected to silica gel using $\mathrm{CHCl}_{3}-\mathrm{MeOH}(10: 1$ to $1: 1, \mathrm{v} / \mathrm{v})$ gradient to obtain three further subfractions $\mathrm{F} 4 \mathrm{a}-\mathrm{F} 4 \mathrm{c}$. The F4a fraction was separated by pre-HPLC $\left(\mathrm{MeOH} / \mathrm{H}_{2} \mathrm{O}=80 / 20\right.$; flow rate: 10 $\mathrm{mL} / \mathrm{min})$ to get the new saponin $18\left(2.0 \mathrm{mg} ; t_{\mathrm{R}}=39 \mathrm{~min}\right)$. The compound $\mathbf{5}(11.0 \mathrm{mg}$; $\left.t_{\mathrm{R}}=40 \mathrm{~min}\right)$ and the compound $6\left(13.0 \mathrm{mg} ; t_{\mathrm{R}}=45 \mathrm{~min}\right)$ were afforded by pre-HPLC $\left(\mathrm{MeOH} / \mathrm{H}_{2} \mathrm{O}=77 / 23\right.$; flow rate: $10 \mathrm{~mL} / \mathrm{min}$ ) from $\mathrm{F} 4 \mathrm{~b}$ fraction. The $\mathrm{F} 4 \mathrm{c}$ fraction was 
purified on pre-HPLC $\left(\mathrm{MeOH} / \mathrm{H}_{2} \mathrm{O}=75 / 25\right.$; flow rate: $\left.10 \mathrm{~mL} / \mathrm{min}\right)$ to get compounds $7\left(57.3 \mathrm{mg} ; t_{\mathrm{R}}=40 \mathrm{~min}\right)$ and $9\left(17.0 \mathrm{mg} ; t_{\mathrm{R}}=48 \mathrm{~min}\right)$. F6 was chromatographed over a silica gel eluting with $\mathrm{CHCl}_{3}-\mathrm{MeOH}(20: 1$ to $1: 1, \mathrm{v} / \mathrm{v})$ to yield three subfractions F6a-F6c. The F6a fraction was subjected to silica gel eluting with $\mathrm{CHCl}_{3}-\mathrm{MeOH}$ gradient (20:1 to 2:1, v/v) to get two subfractions F6a1 and F6a2. The compound 15 $\left(9.5 \mathrm{mg} ; t_{\mathrm{R}}=20 \mathrm{~min}\right)$ was obtained by pre-HPLC $\left(\mathrm{MeOH} / \mathrm{H}_{2} \mathrm{O}=73 / 27\right.$; flow rate: 10 $\mathrm{mL} / \mathrm{min})$ from F6a1. The compound $12\left(8.4 \mathrm{mg} ; t_{\mathrm{R}}=28 \mathrm{~min}\right)$ was obtained by pre-HPLC $\left(\mathrm{MeOH} / \mathrm{H}_{2} \mathrm{O}=78 / 22\right.$; flow rate: $\left.10 \mathrm{~mL} / \mathrm{min}\right)$ from $\mathrm{F} 6 \mathrm{a} 2$. F6b was separated by silica gel using $\mathrm{CHCl}_{3}-\mathrm{MeOH}$ gradient (40:1 to $1: 1$, v/v) to get $\mathrm{F} 6 \mathrm{~b} 1$, this subfraction was purified by pre-HPLC $\left(\mathrm{MeOH} / \mathrm{H}_{2} \mathrm{O}=75 / 25\right.$; flow rate: $\left.10 \mathrm{~mL} / \mathrm{min}\right)$ to afford two new compounds $17\left(3.9 \mathrm{mg} ; t_{\mathrm{R}}=28 \mathrm{~min}\right)$ and $16\left(10.2 \mathrm{mg} ; t_{\mathrm{R}}=21 \mathrm{~min}\right)$. The F6c fraction was subjected to silica gel eluting with $\mathrm{CHCl}_{3}-\mathrm{MeOH}$ gradient (30:1 to $2: 1, \mathrm{v} / \mathrm{v})$ to get the new saponin $14(11.9 \mathrm{mg})$ and the subfraction F6c1. The fraction F6cl was separated by pre-HPLC $\left(\mathrm{MeOH} / \mathrm{H}_{2} \mathrm{O}=95 / 5\right.$; flow rate: $\left.10 \mathrm{~mL} / \mathrm{min}\right)$ to obtain the new saponin $13\left(1.7 \mathrm{mg} ; t_{\mathrm{R}}=10 \mathrm{~min}\right)$. 
Acid hydrolysis of saponins 13-18. The gypenosides 13-18 (1.0 mg) were hydrolyzed by reacting with $1 \mathrm{M} \mathrm{HCl}\left(\mathrm{H}_{2} \mathrm{O} /\right.$ ethylene oxide, $\left.1: 1,2.0 \mathrm{~mL}\right)$ at $70{ }^{\circ} \mathrm{C}$ for 6 h. The dried mixtures were partitioned with EtOAc and $\mathrm{H}_{2} \mathrm{O}$. The dried residues obtained from $\mathrm{H}_{2} \mathrm{O}$ layer were dissolved in pyridine $(1.0 \mathrm{~mL})$, and added with $2.0 \mathrm{mg}$ of L-cysteine methyl ester hydrochloride. The reactions were stirred at $60{ }^{\circ} \mathrm{C}$ for $2 \mathrm{~h}$, and then mixed with $0.2 \mathrm{~mL}$ of trimethylsilylimidazole, the resultant reaction mixtures were continued to maintain at $60{ }^{\circ} \mathrm{C}$ for other $2 \mathrm{~h}$. The residues partitioned with $\mathrm{H}_{2} \mathrm{O}$ and $n$-hexane.The $n$-hexane parts were analyzed through GC (detector: FID; injection temperature, $250{ }^{\circ} \mathrm{C}$; detector temperature: $280{ }^{\circ} \mathrm{C}$; column temperature: 100 ${ }^{\circ} \mathrm{C}$ to $280{ }^{\circ} \mathrm{C}\left(10^{\circ} \mathrm{C} / \mathrm{min}\right)$, capillary column: $\mathrm{DB}-5,30 \mathrm{~m} \times 0.25 \mathrm{~mm} \times 0.25 \mu \mathrm{m}$; carrier gas: $\mathrm{N}_{2}$ ). The absolute configurations of sugar units were determined (D-xylopyranose, 17.60 min; L-arabinopyranose, $17.72 \mathrm{~min}$; L-rhamnopyranose, 18.32 min; D-glucose, $19.50 \mathrm{~min}$ ) by comparing the retention time of the derivatives of authentic sugar components and trimethylsilyl-L-cysteine derivatives of the samples. 
Cell culture. PC12 cells were cultured in RPM 1640 medium (Hyclone, Utah, USA) supplemented with 10\% fetal bovine serum (Hyclone, Utah, USA), $100 \mathrm{U} / \mathrm{mL}$ penicillin and $100 \mu \mathrm{g} / \mathrm{mL}$ streptomycin (Gibco, Life Technologies, Grand Island, NY) at $37^{\circ} \mathrm{C}$ in an humidified atmosphere containing $5 \% \mathrm{CO}_{2}$. Culture medium was changed every other day. For cells hypoxia treatment, the cells were placed in a hypoxic incubator with $0.1 \% \mathrm{O}_{2} / 5 \% \mathrm{CO}_{2} / 92 \% \mathrm{~N}_{2}$ at $37^{\circ} \mathrm{C}$. 
Morris water maze test. The water maze apparatus was a circular pool (diameter $=120 \mathrm{~cm}$, height $=40 \mathrm{~cm}$ ) filled with water (temperature approximately $22-24^{\circ} \mathrm{C}$ ). A hidden styrofoam platform was placed $1 \mathrm{~cm}$ below the water surface. Four visual cues were placed on the curtain (above the pool edge) that surrounded the maze. The pool was divided into four quadrants. Behavior was monitored and recorded by a digital camera interfaced to a computer installed with the ANY-maze video imaging software. During the five days of the acquisition training period, the mice were placed in the water facing the midpoint section of each quadrant. The mice were allowed to swim freely until they found and climbed onto the platform. If a mouse failed to locate the platform within $60 \mathrm{~s}$, it was placed on the platform for $10 \mathrm{~s}$. Each mouse was subjected to 4 trials per day, and the starting position was changed each day. For the spatial probe test, the platform was removed, and the mouse was placed into the water; the number of the mouse cross the previous location of the platform and the distance in the target quadrant within $60 \mathrm{~s}$ were recorded. 
Western Blot. Frozen hippocampi were disaggregated in ice-cold RIPA buffer containing protein inhibitors. The dissolved proteins were collected after centrifugation at $10,000 \times \mathrm{g}$ for $10 \mathrm{~min}$ at $4^{\circ} \mathrm{C}$, and the supernatant was then collected. The protein concentration was determined using a Pierce BCA Protein Assay kit (Thermo Scientific). A quantity of $50 \mu \mathrm{g}$ of total protein was loaded onto a $10-15 \%$ SDS-PAGE, electrophoretically transferred to polyvinylidene difluoride membrane (PVDF) membranes (Millipore, Bedford, MA, USA). Membranes were blocked with $5 \%$ non-fat milk for $2 \mathrm{~h}$ at room temperature and then probed at $4^{\circ} \mathrm{C}$ overnight with primary antibodies. The primary antibodies: anti-p-ERK (\#9101), anti-ERK (\#9102), anti-p-AKT (\#4060), anti-AKT (\#4685), and anti- $\beta$-actin (\#4970) were all purchased from Cell Signaling Technology (Beverly, MA, USA) and were prepared in 5\% BSA at a dilution of 1: 1000. Then the membranes were incubated with HRP-conjugated secondary antibodies (Sigma-Aldrich) at a 1: 5000 dilution for another $2 \mathrm{~h}$ at room temperature. The membranes were developed using an enhanced chemiluminescence detection system (Pierce, Rockford, IL). For densitometry of the protein bands, the optical densities (OD) of the protein bands were quantified using Quantity One software (Bio-Rad). The relative band densities were calculated as the ratio of the protein band OD relative to the $\beta$-actin (internal loading control) band OD from the same sample. The ratios for the untreated control samples were set to 1 . 